University of Windsor

Scholarship at UWindsor

\title{
Evaluating the Microbial Community and Gene Regulation Involved in Crystallization Kinetics of ZnS Formation in Reduced Environments
}

Nick William Falk

University of Windsor

Follow this and additional works at: https://scholar.uwindsor.ca/etd

\section{Recommended Citation}

Falk, Nick William, "Evaluating the Microbial Community and Gene Regulation Involved in Crystallization Kinetics of ZnS Formation in Reduced Environments" (2017). Electronic Theses and Dissertations. 5979. https://scholar.uwindsor.ca/etd/5979

This online database contains the full-text of PhD dissertations and Masters' theses of University of Windsor students from 1954 forward. These documents are made available for personal study and research purposes only, in accordance with the Canadian Copyright Act and the Creative Commons license-CC BY-NC-ND (Attribution, Non-Commercial, No Derivative Works). Under this license, works must always be attributed to the copyright holder (original author), cannot be used for any commercial purposes, and may not be altered. Any other use would require the permission of the copyright holder. Students may inquire about withdrawing their dissertation and/or thesis from this database. For additional inquiries, please contact the repository administrator via email (scholarship@uwindsor.ca) or by telephone at 519-253-3000ext. 3208. 


\title{
Evaluating the Microbial Community and Gene Regulation Involved in Crystallization Kinetics of $\mathrm{ZnS}$ Formation in Reduced Environments
}

\author{
By
}

Nicholas W. Falk

\begin{abstract}
A Thesis
Submitted to the Faculty of Graduate Studies

through the Great Lakes Institute for Environmental Research in

Partial Fulfillment of the Requirements for the Degree of Master of Science at the University of Windsor
\end{abstract}

Windsor, Ontario, Canada

2017

(C) 2017 Nicholas Falk 
Evaluating the Microbial Community and Gene Regulation Involved in Crystallization Kinetics of $\mathrm{ZnS}$ Formation in Reduced Environments

\author{
By
}

Nicholas W. Falk

APPROVED BY:

I. Samson
Earth and Environmental Sciences

J. Gagnon

Great Lakes Institute for Environmental Research

S. R. Chaganti

Great Lakes Institute for Environmental Research

C. Weisener, Advisor

Great Lakes Institute for Environmental Research

February $6^{\text {th }}, 2017$ 


\section{DECLARATION OF CO-AUTHORSHIP}

I hereby declare that this thesis incorporates material that is result of joint research, as follows:

This thesis also incorporates the outcome of joint research undertaken under the supervision of professors Christopher Weisener and Subba Rao Chaganti. The collaboration is covered in Chapter 2 and 3 of the thesis. In all cases, the key ideas, primary contributions, experimental designs, data analysis and interpretation, were performed by the author, and the contribution of co-authors was primarily through the provision of comments and direction/scope of the thesis and manuscript. I am aware of the University of Windsor Senate Policy on Authorship and I certify that I have properly acknowledged the contribution of other researchers to my thesis, and have obtained written permission from each of the co-author(s) to include the above material(s) in my thesis. I certify that, with the above qualification, this thesis, and the research to which it refers, is the product of my own work. I declare that, to the best of my knowledge, my thesis does not infringe upon anyone's copyright nor violate any proprietary rights and that any ideas, techniques, quotations, or any other material from the work of other people included in my thesis, published or otherwise, are fully acknowledged in accordance with the standard referencing practices. Furthermore, to the extent that I have included copyrighted material that surpasses the bounds of fair dealing within the meaning of the Canada Copyright Act, I certify that I have obtained a written permission from the copyright owner(s) to include such material(s) in my thesis.

I declare that this is a true copy of my thesis, including any final revisions, as approved by my thesis committee and the Graduate Studies office, and that this thesis has not been submitted for a higher degree to any other University or Institution. 


\begin{abstract}
In anaerobic environments, sulfate-reducing bacteria (SRB) may precipitate sparinglysoluble, fine-grained sulfides as by-products of dissimilatory sulfate reduction. This biomechanism lends importance to environmental remediation research for its ability to immobilize harmful metals from contaminated environments. This research focuses on the effectiveness of this mechanism within a novel bioreactor treatment method employed at the Stockton coal mine in New Zealand. The bioreactor consists of a matrix of organics and ground mussel shells that intercept and neutralize acidic mine drainage (AMD) runoff while also serving as a substrate to sustain SRB that enhance removal of harmful dissolved metals. Material collected from the bioreactor will be used to provide SRB enrichments in the lab to investigate their ability to precipitate biogenic zinc-sulfides (ZnS). This study uses a combination of solution chemistry and scanning electron microscopy (SEM) to understand the crystallization kinetics and morphological/bacterial relationships during ZnS formation. This, in tandem with RNA-based community analysis and investigations into relevant functional genes/metabolic pathways via metatranscriptomics will enhance understanding of the key microbial influences in situ. The objective of this work is to investigate the microbial causal relationships related to early nucleation of biogenic ZnS within a chemical, solid phase, and omics framework.
\end{abstract}




\section{DEDICATION}

This work is dedicated to all my family, friends, teammates, and colleagues whose support I could not have gone without. 


\section{ACKNOWLEDGEMENTS}

First and foremost, I would like to thank my advisor Dr. Chris Weisener for his guidance in shaping my research project and for being an all-around great mentor. I would also like to thank my co-supervisor Dr. Subba Rao Chaganti for all his help in microbial data analysis and interpretation, and recognize Dr. Iain Samson and Dr. Joel Gagnon for their support and serving as members of my committee and as excellent lecturers during my undergrad. Thank you to Sharon Lackie for aiding and supervising in SEM work, J.C. Barette for help with ICP-OES analysis, and Russ Hepburn in the genomics facility, and additional gratitude to all three for being friendly and always open for conversation. Thank you to Vera Barker, Sharon Horne, Melissa Price, and Margaret Mayer for aiding in and organizing GA duties. A big thank you to Christina Semeniuk and Christine Weisener for help with all graduate student paperwork and keeping me on track, and to Mary Lou Scratch for solving countless tasks related to just about everything and anything at GLIER. Thank you to Travis Casagrande, Andreas Korinek, and Marcia Reid, at the CCEM at McMaster University and to Carrie Hamilton and staff at the Biotron Experimental Climate Change Research Centre, Western University, for help in data acquisition. Thank you to all past and present members of the Weisener Lab, Tom Reid, Zach DiLoreto, Danielle VanMensel, Sabari Prakasan, Ryan Boudens, Sara Butler, and Adam Skoyles, whom I could not have survived my project without, and to undergraduate assistants Jumin Lee, Aline Joilbois, Brittany Ives, and Joelle Pecz for aiding with laboratory experiments. Thank you to the staff and students at GLIER, all Windsor Lancer track and field and cross country athletes and coaches, and to my amazing family, Wendy, Kevin, Andrew, and everyone else for their love and support! 


\section{TABLE OF CONTENTS}

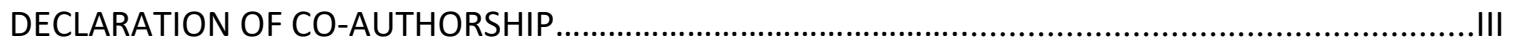

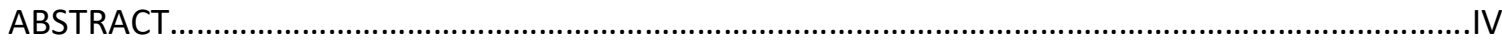

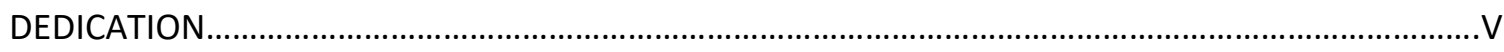

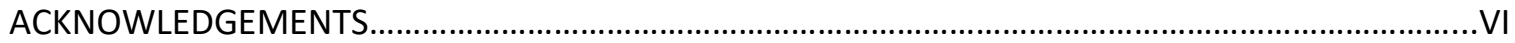

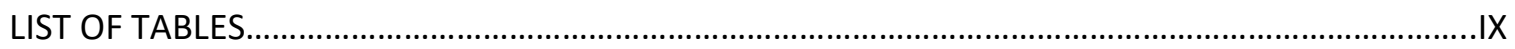

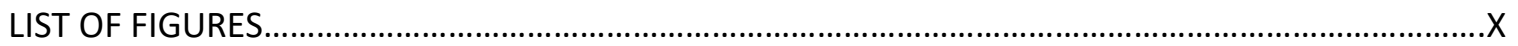

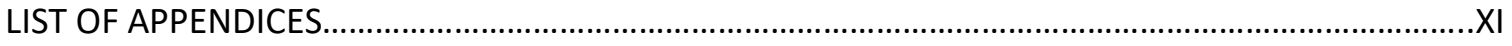

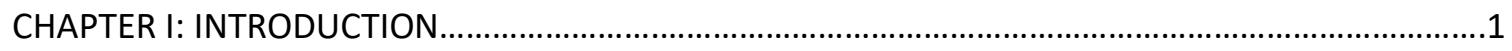

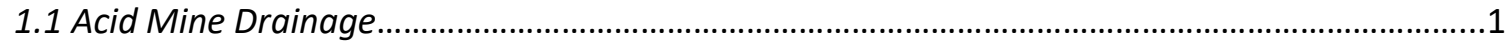

1.2 Acid Mine Drainage Research and Treatment ..........................................................................2

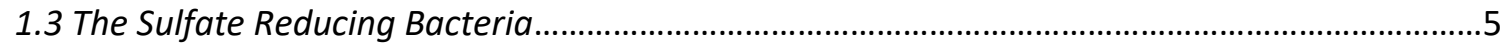

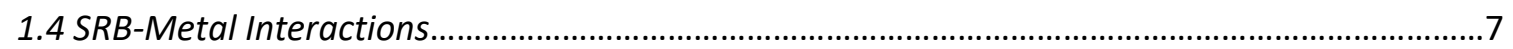

1.5 Omic Approaches in AMD Studies.........................................................................................1

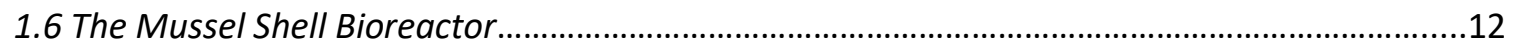

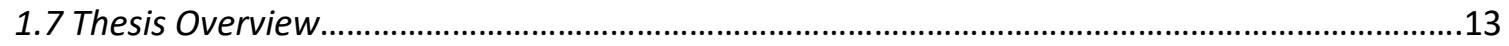

1.7.1 Objectives and Hypotheses......................................................................................13

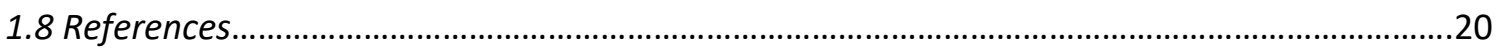

CHAPTER II: PHYSICO-CHEMICAL INVESTIGATIONS DURING BACTERIALLY-MEDIATED ZNS

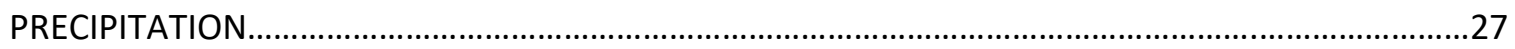

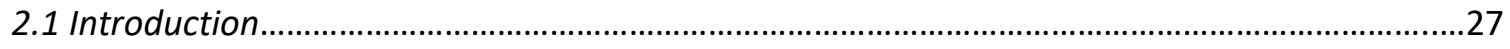

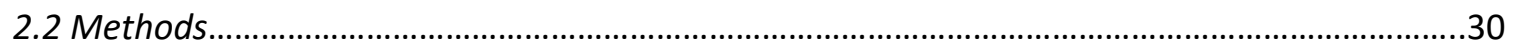

2.2.1 Site Characterization and Sample Collection...............................................................30

2.2.2 Bacterial Community Enrichment Conditions............................................................

2.2.3 ZnS Precipitation Experiments...................................................................................32

2.2.4 Analytic Methods.........................................................................................................

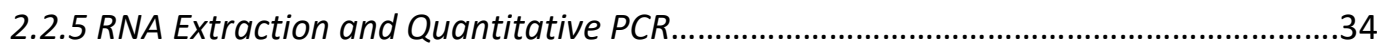

2.2.6 Microscopy



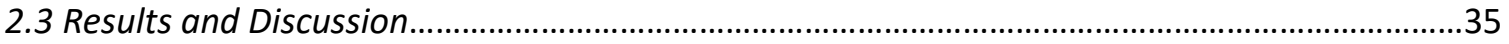




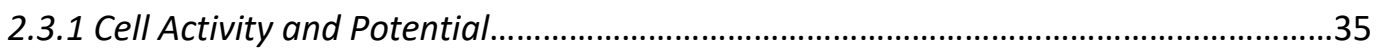

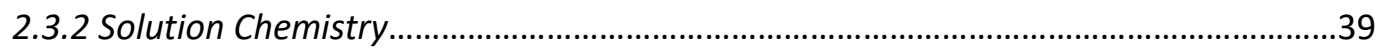

2.3.3 Scanning Electron Microscopy and Solid Phases Investigations.................................45

2.3.4 Conclusions ...............................................................................................................

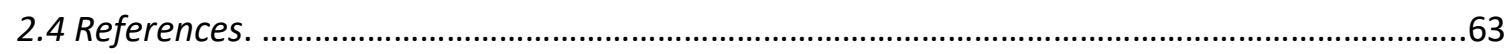

CHAPTER III: BACTERIAL COMMUNITY CHARACTERIZATION AND FUNCTIONAL ANALYSIS CONTRIBUTING TO ZNS FORMATION ASSESSED THROUGH AMPLICON SEQUENCING AND

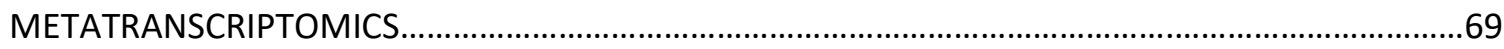

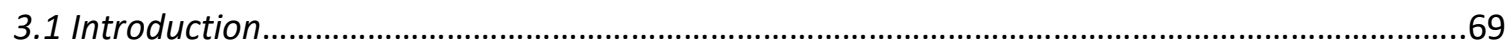

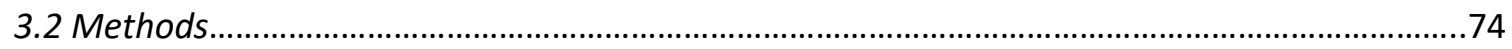

3.2.1 RNA Extraction and Community Analysis of 16S rRNA.............................................74

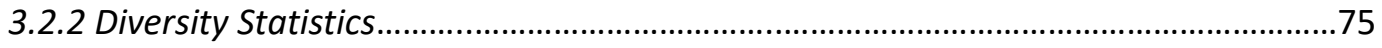

3.2.3 Metatranscriptomic Analysis.....................................................................................

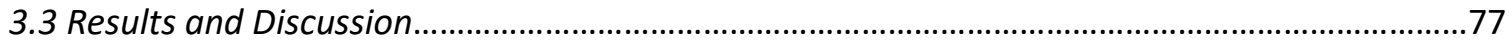

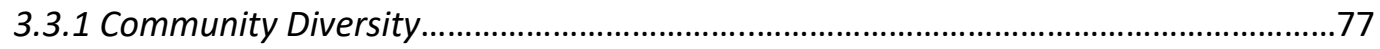

3.3.2 Microbial Taxonomy .................................................................................................

3.3.3 Functional mRNA Results from Metatranscriptomics...............................................80

3.3.4 Taxonomic and functional mRNA Interpretation and Analysis..................................82

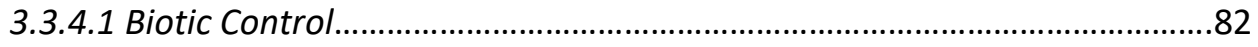

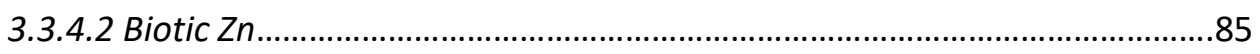

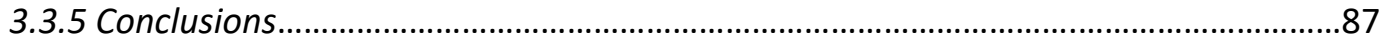

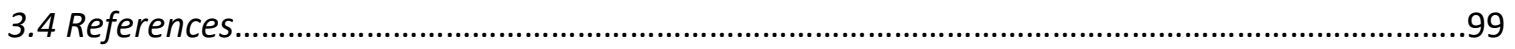



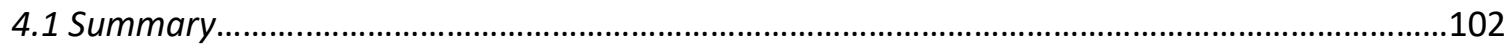

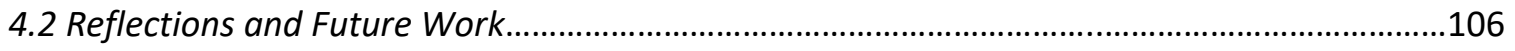

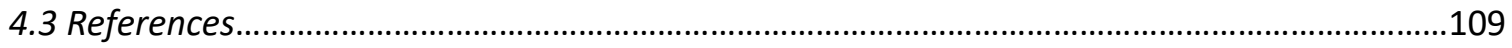

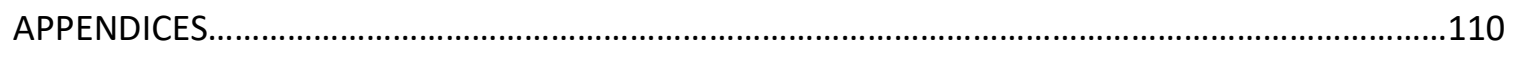

Appendix A

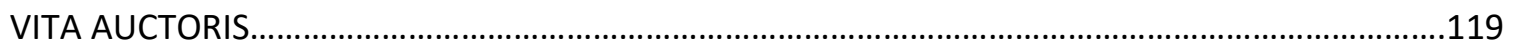




\section{LIST OF TABLES}

Table 1.1: Relevant genera of sulfur-utilizing bacteria recognized in bioreactors treating acid mine drainage (AMD)

Table 1.2: log Ksp values of carbonate, hydroxide, and sulfide species of metals associated with

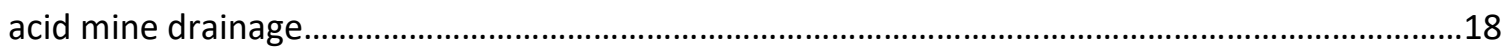

Table 2.1: Zinc $(\mathrm{Zn})$ and Thallium $(\mathrm{TI})$ concentrations used in experimental treatments...............53

Table 2.2: $\mathrm{Zn}$ and TI Solution chemistry values for all 6 treatments..............................................54

Table 2.3: Initial and final Sulfate $\left(\mathrm{SO}_{4}{ }^{2-}\right)$ and Hydrogen Sulfide $\left(\mathrm{H}_{2} \mathrm{~S}\right)$ concentrations for all 6

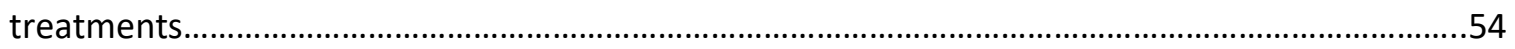

Table 2.4: Mass balance estimations of $\mathrm{Zn}$ removed from $\mathrm{Zn}$-amended treatments by reaction

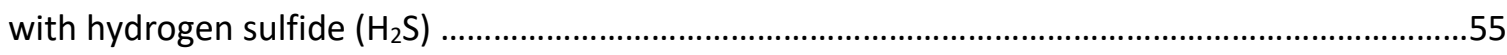

Table 3.1: Significance values acquired through Tukey's pairwise comparisons for differences in

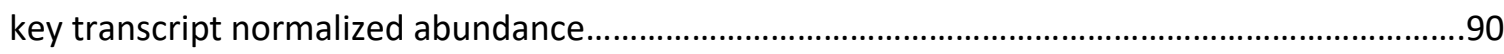




\section{LIST OF FIGURES}

Figure 1.1: Figure 1.1: Sulfide Speciation Dependence on $\mathrm{pH}$ .18

Figure 1.2: Overhead view of the Mussel Shell Bioreactor (MSB) at the Stockton Coal Mine of the South Island of New Zealand. .19

Figure 2.1: Cell counts over time for the Biotic Control, Biotic $\mathrm{Zn}$, and Biotic $\mathrm{ZnTI}_{25}$ treatments..56

Figure 2.2: Cell counts over time for the Biotic Control and Biotic $\mathrm{Zn}$ against corresponding inverted $\mathrm{Ct}$ values from qPCR. .56

Figure 2.3: Hydrogen Sulfide $\left(\mathrm{H}_{2} \mathrm{~S}\right)$ and metal concentrations over time. .57

Figure 2.4: Hydrogen Sulfide $\left(\mathrm{H}_{2} \mathrm{~S}\right)$ and Sulfate $\left(\mathrm{SO}_{4}{ }^{2-}\right)$ concentrations over time. .58

Figure 2.5: Enzyme and enzyme groups detected by metatranscriptomics analysis in two primary prokaryotic sulfate activating pathways. .59

Figure 2.6: SEM images of ZnS precipitates at time 450 hours. .60

Figure 2.7: SEM images of raw Mussel Shell Bioreactor material taken from the Whirlwind reactor at the Stockton Coal Mine, New Zealand. 61

Figure 2.8: SEM images of FIB-exposed ZnS. .62

Figure 3.1: Shannon $\mathrm{H}$ and Chao1 diversity index values for Biotic Control and Biotic Zn treatments

Figure 3.2: Filtered Operational Taxonomic Unit (OTU) relative abundance data at the phylum level.

Figure 3.3: Filtered Operational Taxonomic Unit (OTU) relative abundance data at the family level.

Figure 3.4: Relative abundance of families within the Clostridiales and genera of sulfate reducing bacteria (SRB) in the Biotic Control at 24 and 96 hours................................................................95

Figure 3.5: Key microbial lactate and acetate oxidation pathways..................................................96

Figure 3.6: Acetyl-CoA pathway for acetate utilization by sulfate reducing bacteria.....................97

Figure 3.7: Key enzyme transcripts of energy metabolism pathways in the Biotic Control at 24 and 96 hours and Biotic $\mathrm{Zn}$ at 24 hours . .98 


\section{LIST OF APPENDICES}

Figure S1: ANOVA Output, Tukey's Pairwise Comparisons, and Input data for zinc concentration change across $\mathrm{Zn}$-amended treatments

Figure S2: ANOVA Output, Tukey's Pairwise Comparisons, and Input data for Sulfate concentration change across all treatments.

Figure S3: ANOVA Output, Tukey's Pairwise Comparisons, and Input data for maximum hydrogen sulfide concentrations across all treatments......

Figure S4: ANOVA Output, Tukey's Pairwise Comparisons, and Input data for final hydrogen

sulfide concentrations across all treatments.

Table S1: Shannon $H$ and Chao1 Index values for Biotic Control and Biotic $\mathrm{Zn}$ treatments for 24,

48,72 , and 96 hours.

Table S2. Read numbers before and after filtering of 16S rRNA amplicon sequenced samples for Biotic Control and Biotic Zn treatment...

Table S3: Sequence data pre and post quality control for metatranscriptomic data. Vales provided by MG-RAST (Metagenomics Analysis Server)

Table S4: Normalized relative abundance values (\%) from duplicates for key transcripts across samples

Table S5: OTU assignments and relative abundance of dominant phyla in the Biotic Control and Biotic $\mathrm{Zn}$ treatments for $24,48,72$, and 96 hours.

Table S6: OTU assignments and relative abundance values of dominant families in the Biotic Control and Biotic Zn for 24, 48, 72, and 96 hours. 


\section{Chapter I: Introduction}

\subsection{Acid Mine Drainage}

Acid Rock Drainage (ARD) is a form of weathering and is in some respect pollution when it is associated with mining operations and inadequate tailing storage facilities. Both underground and surface mining operations require the excavation of large quantities of earth material to obtain the desired resource. Substantial amounts of tailings and/or spoils from these processes are usually maintained at the site before they can be re-processed or used to refill excavations. These materials often contain abundant sulfidic minerals, primarily pyrite $\left(\mathrm{FeS}_{2}\right)$, that when liberated from the sub-surface begin to weather upon exposure to water and oxygen (Equation 1.1) (Johnson et al. 2005).

$\mathrm{FeS}_{2}+3.5 \mathrm{O}_{2}+\mathrm{H}_{2} \mathrm{O} \leftrightarrow \mathrm{Fe}^{2+}+2 \mathrm{SO}_{4}^{2-}+2 \mathrm{H}^{+}$

Ferrous iron $\left(\mathrm{Fe}^{2+}\right)$ is further oxidized in these environments to ferric iron $\left(\mathrm{Fe}^{3+}\right)$ (Equation 1.2) which serves as an oxidizing agent for additional pyrite (Equation 1.3).

$\mathrm{Fe}^{2+}+0.25 \mathrm{O}_{2}+\mathrm{H}^{+} \leftrightarrow \mathrm{Fe}^{3+}+0.5 \mathrm{H}_{2} \mathrm{O}$

$\mathrm{FeS}_{2}+14 \mathrm{Fe}^{3+}+8 \mathrm{H}_{2} \mathrm{O} \leftrightarrow 15 \mathrm{Fe}^{2+}+2 \mathrm{SO}_{4}^{2-}+16 \mathrm{H}^{+}$

Present iron-oxidizing bacteria can exasperate the problem by catalyzing the conversion of $\mathrm{Fe}^{2+}$ to $\mathrm{Fe}^{3+}$, increasing the rate of pyrite oxidation (Blowes et al., 2003; Nordstrom et al., 1997; Schrenk et al., 1998; Silverman et al., 1964). The result of this weathering reaction chain is a net increase in acidity attributed to the generation of $\mathrm{H}^{+}$ions (effluent usually characterized by a $\mathrm{pH}$ of 2-3), which can cause the dissolution of other potentially toxic metals present along the ARD pathway, including $\mathrm{Ag}, \mathrm{As}, \mathrm{Be}, \mathrm{Cd}, \mathrm{Cr}, \mathrm{Cu}, \mathrm{Hg}, \mathrm{Ni}, \mathrm{Pb}, \mathrm{Sb}, \mathrm{Se}, \mathrm{Tl}$, and $\mathrm{Zn}$ (Akcil et al., 2006, Sparks et al., 2005). The inherent geology of an area may result in the production of acid drainage naturally, 
such as in the weathering of iron sulfide-bearing rocks by rainfall and/or running water. In this case, local acidification may be termed Acid Rock Drainage. However, Acid Mine Drainage (AMD) pollution is more commonly associated with active or abandoned mining operations. This discharge can disrupt local ecosystems through decreases in $\mathrm{pH}$, altering of substrate availability, and increased metal loading (Salomans 1995) as metals may improperly substitute into vital functional pathways or disrupt cycling of biologically significant elements, causing stress to terrestrial and aquatic organisms (Flemming et al., 1989). Furthermore, metal concentrations, even at the trace level, from AMD can compromise drinking water sources if not contained properly (Cravotta et al., 2008; Lefticariu et al., 2015). The production of effluent is also a financial burden on mining operators and stakeholders. AMD is a widespread environmental issue. In 1989, it was estimated that approximately $19,300 \mathrm{~km}$ of streams and rivers, and ca. 72,000 ha of lakes and reservoirs worldwide had been seriously damaged by mine effluents (Johnson et al., 2005), with Tremblay and Hogan estimating the liability cost of AMD-associated remediation to be in the realm of US\$100 billion (Tremblay et al., 2001). In Canada, an estimated 750 million tonnes of waste rock and 12,500 ha of tailings have the potential to form AMD (Mulligan et al., 2001). Research conducted on the South Bay Mine and Mill of Northwest Ontario, for example, estimated the effluent of $15 \mathrm{t} / \mathrm{y}$ of zinc and other metals in AMD into the nearby lake; a result of 10 years of mining activity (Kalin 2001). In the Eastern United States, a 1995 EPA report stated that an estimated $20,000 \mathrm{~km}$ of rivers and streams are polluted by AMD, of which about $90 \%$ is due to underground abandoned coal mine sites (Ziemkiewicz et al., 2003). It is further estimated that there are approximately 200,000 sites in the United States that do, or have the potential to, produce acid mine drainage via sulfide ore dissolution (Hochella et al., 1999).

\subsection{Acid Mine Drainage Research and Treatment}


Early AMD research focused on its formation and detrimental effects and was often organism or site-specific (Barnes et al., 1968; Chapman et al., 1983; Koryak et al., 1972; Roback et al., 1969; Wassel et al., 1983). Much research has been directed at the microbial communities of AMD sites, as groups of acidophilic iron-oxidizing bacteria, as stated previously, are responsible for a large portion, if not the majority of the AMD produced at any given site (Baker et al., 2003). AMD sites also exhibit relatively low microbial diversity, making them good test subjects for metagenomic surveys that seek to unravel the complexities associated with the in situ functioning of bacterial communities. As iron redox chemistry is the main driver of microbial metabolism in AMD environments, research has concentrated on iron oxidizers such as Acidithiobacillus ferrooxidans (formerly Thiobacillus ferrooxidans) and Thiobacillus thiooxidans within the Gammaproteobacteria and Leptospirillum ferrooxidans within the Nitrospirae (Denef et al., 2010). Various groups within the phyla Actinobacteria, Acidobacteria, Firmicutes, and within the class divisions of the Proteobacteria $(\alpha, \beta, \gamma$, and $\delta$ ) have also been identified that exhibit iron and/or sulfur oxidation/reduction potential (Baker et al., 2003; Bond et al., 2000; Tan et al., 2007). However, with increased resolution in metagenomic and metatranscriptomic techniques, more relevant iron-oxidizing species are being characterized, including those of the Ferrovum genus (Hallberg 2010; Hua et al., 2014).

Publications based on AMD treatment options were not popularized until the early 1990 's. Dunbabin and colleagues suggested the use of constructed wetlands to sequester metals from industrial waste water and mine seepage. Hedin and colleagues researched the treatment of low pH AMD using limestone as a neutralizing agent, with Benner and Blowes publishing abundant research on permeable reactive barriers (PRBs) for neutralization and metal removal, to name a few (Blowes et al., 1995, 2000; Benner et al., 1997, 1999; Dunbabin et al., 1992; Hedin et al., 1994). Other research focused on the influence of microorganisms on the remediation of 
$A M D$, such as the biogenic formation of low solubility metal precipitates to remove metals from waste streams (Urritia et al., 1994; Evangelou et al., 1995). Generally, the two main objectives in treating AMD include neutralizing the acidity of the effluent and removing potentially harmful metals from solution. Taking these strategies into account, research and literature today have divided treatments into two main categories; active treatment and passive treatment.

Active treatment is a direct approach where the pollution is remediated using chemical agents and/or engineered barriers. Chemical and physical processes in active treatment may include reverse osmosis, evaporation, and ion exchange, or the regular addition of biocides or neutralising agents such as lime (calcium oxide), slaked lime, calcium carbonate, sodium carbonate, sodium hydroxide, or magnesium oxide and hydroxide to effluent and effluent pathways. Active treatment may also include the use of limestone drains, limestone-bedded channels, or water covers to prevent oxidation. These latter approaches buffer the acidity of the AMD up to an acceptable level, usually circum-neutral $\mathrm{pH}$ of $6.5-7.5$, while also promoting the precipitation of metal-hydroxides, metal-carbonates, and other insoluble metal-complexes (da Silveira et al., 2009; Johnson et al., 2005). These induced chemical reactions have been shown to successfully remove metals from solution and increase $\mathrm{pH}$ levels. However, they are considered more labour-intensive and expensive due to regular maintenance and monitoring.

Alternatively, passive treatment options seek to take advantage of natural materials to buffer acidity and precipitate metals, including the use of constructed or regenerated wetlands, artificial bio-reactors, or compost bioreactors/wetlands (Gazea et al., 1996). These systems are designed to intercept $A M D$ and treat it through the microbial-catalyzed reactions that occur within them. They may be further categorized as in situ or ex situ systems. In situ methods are generally less labour-intensive, and have a greater lifespan able to treat more effluent over longer time periods (ex. anaerobic wetlands, permeable reactive barriers), whereas ex situ methods use 
technologies that allow for regulation of the chemical parameters that exist within them (ex. sulfidogenic bioreactors) (Sánchez-Andrea et al., 2014). Furthermore, ex-situ systems are more applied to achieve metal recovery and are often limited by costs of the substrate used as electron donors (Weijma et al., 2001). There is no "one size fits all" approach to implementing a passive treatment system, however the common components include an organic carbon source, a neutralizing substance, a solid but porous substrate for microbial viability, and a substrate to sustain species of sulfate-reducing bacteria (DiLoreto et al., 2016; Vasquez et al., 2016; Weber et al., 2015). Costa and Chockalingam have studied the effects of various different substrates for passive systems, such as using rice husks, or various matrices such as cereal straw or sand. It was concluded in these works that a neutralising material is necessary for incorporation into reactors, and that some porous substrates perform better than others (rise husk > cereal straw) (Chockalingam et al., 2006; Costa et al., 2008). The presence of sulfate-metabolizing bacterial species is also vital. Sulfate-reducing bacteria are an important component of passive systems due to their ability to reverse the reactions of AMD with respect to metal mobility, and abundant research has implemented these species in the application of passive systems (Luptakova et al., 2005, 2007, 2012; Neculita et al., 2007). Thus, despite the detriment some bacterial species have on AMD environments via the promotion of sulfide dissolution, the application of others may be beneficial.

\subsection{The Sulfate-Reducing Bacteria}

Microbes play an important role in passive treatment applications by degrading harmful compounds and/or altering the speciation of metals. Bacteria, specifically, are omnipresent in the environment, with estimates of prokaryote numbers on earth in the range of $10^{29}$ to $10^{31}$ (Kallmeyer et al., 2012; Whitman et al., 1998). This ubiquity poses a tremendous influence over the biogeochemical cycling of matter and energy by bacteria. These single-celled organisms 
exploit the available energy from light and/or redox reactions to drive their cellular metabolism and reproduce, transforming organic and inorganic compounds in the process. Within the cycling of sulfur, the sulfate-reducing bacteria (SRB) define a diverse taxonomical group of chemotrophic bacteria that can utilize sulfate $\left(\mathrm{SO}_{4}^{2-}\right)$ to initiate electron-transport phosphorylation, generating sulfite $\left(\mathrm{SO}_{3}^{2-}\right)$ as a terminal electron acceptor during cellular metabolism, reducing it to sulfide species $\left(\mathrm{S}^{-}\right)$. This dissimilatory sulfate reduction requires an electron donor, which is commonly hydrogen (Equation 1.4) or a reduced carbon substrate such as acetate (Equation 1.5), lactate, butyrate, and/or propionate which is consequently oxidized (Druschel et al., 2002; Hansen 1994; Muyzer et al., 2008).

$\mathrm{SO}_{4}^{2-}+4 \mathrm{H}_{2}+\mathrm{H}^{+} \leftrightarrow \mathrm{HS}^{-}+4 \mathrm{H}_{2} \mathrm{O}$

$\mathrm{SO}_{4}^{2-}+\mathrm{C}_{2} \mathrm{H}_{3} \mathrm{O}_{2}^{-}$(Acetate) $\leftrightarrow \mathrm{HS}^{-}+2 \mathrm{HCO}_{3}^{-}$(Eq. 1.5)

Although these compounds are favoured in terms of SRB metabolism, species have been shown to thrive off a variety of other substrates including sugars, amino acids, aromatic hydrocarbons, methanol, and carbon monoxide, to name a few (Hansen 1994; Morasch et al., 2004; Sass et al., 2002; Stams et al., 1985). SRB thrive mainly in anaerobic environments or microenvironments where reducing conditions persist, as a redox potential (Eh) of at least $-100 \mathrm{mV}$ is generally required for sulfate reduction (Postgate., 1979). However, research has shown SRB to be able to survive in aerobic environments as well (Mogensen et al. 2005; Sigalevich et al., 2000). SRBs have been detected in the shallow and deep subsurface, fresh and marine water sediments, hydrothermal vents, oil fields and hydrocarbon seeps, and wastewater treatment plants (Muyzer et al., 2008). Thus, SRB can live within a wide range of environmental tolerances, though favour some environments or parameters (such as an abundance of sulfate) over others for sustained growth and reproduction. 
In terms of taxonomy, sulfate-reducing bacteria have been classified within 4 different bacterial phyla based on the hypervariable region of the $16 \mathrm{~S}$ ribosomal RNA (rRNA) gene; the Proteobacteria, Firmicutes, Nitrospirae, and the Thermodesulfobacteria, as well as two lineages within the Archaea (Castro el al., 2000; Muyzer at al., 2008). Many SRB reside in the class Deltaproteobacteria (within the Proteobacteria) and are more involved with dissimilatory sulfur cycling, including species within the genus Desulfovibrio, and in the families Desulfobulbaceae and Desulfobacteraceae. This is followed by the class Clostridia (within the Firmicutes) which are more so diverse organic degraders, including Desulfotomaculum spp. Desulfotomaculum spp. are also classified based on their ability to form endospores, and thus can persist in chemically or physically hostile environments (Widdel et al., 2006). Sánchez-Andrea and colleagues reviewed the relevant groups of SRB that have been identified in reactors for the treatment of AMD. These genera are outlined in Table 1.1 along with a list of the known substrates used as electron donors. They include species of Desulfobulbus, Desulfobacterium, Desulfohorhadbus, Desulfobacca, Desulfomonile, Desulfovibrio, and Desulferella within the class Deltaproteobacteria and Desulfosporosinus, Desulfitobacterium, and Desulfotomaculum within the class Clostridia, based on 16S rRNA sequence (Sánchez-Andrea et al., 2014).

\subsection{SRB-Metal Interactions}

Coupled with the reduction of sulfur, SRB have been shown to directly and indirectly transform a variety of metals. Metalloids, including selenium and arsenic, may be reduced via specific or non-specific enzymes. These include cytochromes and hydrogenases which can also reduce $\mathrm{Fe}, \mathrm{Cr}, \mathrm{U}, \mathrm{Mn}$, and $\mathrm{Pd}$ (Barton et al., 2015). These metals may be reduced from oxidized states to an elemental state where they commonly precipitate as nanoparticles within the periplasm and/or cytoplasm of cells. This mechanism is of interest in remediation research as an avenue for reducing toxic metal loads in solution or the retrieval and extraction of more valuable 
metals. For example, gold in the oxidized state $A u(I I I)$ may be reduced to elemental $A u(0)$ by Desulfovibrio desulfuricans resulting in nanoparticle precipitation within the extracellular space (Creamer et al., 2006). Within the context of AMD research, sulfate-reducing bacteria have demonstrated the ability to facilitate the removal of potentially toxic metals from solution through the binding of metals with a portion of the reduced sulfur that is the by-product of their sulfate metabolism (Foucher et al., 2001; Huisman et al., 2006; Tuttle et al., 1969). This includes chalcophilic transition metals such as $\mathrm{Cu}, \mathrm{Zn}, \mathrm{Cd}, \mathrm{Ag}, \mathrm{Hg}, \mathrm{As}$, and $\mathrm{Pb}$. Dissolved metals are kinetically favoured to react with the hydrogen sulfide diffused from the cells to form sparingly soluble fine-grained metal-sulfides in these environments according to the generalized Equation 1.6, where $\mathrm{M}^{2+}$ represents a dissolved metal and MS represents the metal-sulfide.

$\mathrm{M}^{2+}+\mathrm{HS}^{-} \leftrightarrow \mathrm{MS}+\mathrm{H}^{+} \quad$ (Eq. 1.6)

Such is the case in the formation of zinc-sulfide, for example (Equation 1.7).

$\mathrm{Zn}^{2+}+\mathrm{HS}^{-} \leftrightarrow \mathrm{ZnS}+\mathrm{H}^{+} \quad$ (Eq. 1.7)

These reactions may also occur with $\mathrm{S}^{2-}$ as the sulfide species, in which case $\mathrm{H}^{+}$would not be generated. This indirect biomineralization mechanism makes these species an attractive component of passive treatments for chalcophilic metals due to the low solubility of metal sulfides in relation to hydroxides and carbonates (Table 1.2). Furthermore, AMD-affected environments generate high sulfate concentrations, making them a suitable (although undesirable) natural analog for the proliferation of sulfate-utilizing prokaryotes. As stated previously, SRB are applied in passive systems in tandem with organic substrates which they utilize as electron donors, and neutralizing agents, which create a suitable environment for sulfate reduction. Sulfide speciation is highly controlled by $\mathrm{pH}$ (Figure 1.1) thus it is essential to buffer local pH to facilitate metal sulfide formation and precipitation. Low $\mathrm{pH}$ values $(<4)$, may decrease the rate of $\mathrm{H}_{2} \mathrm{~S}$ dissolution, and 
thus the rate of reaction of metals with $\mathrm{HS}^{-}$or $\mathrm{S}^{-}$, as well as increasing the solubility of metal sulfides (Lewis et al., 2010).

Of the metals of concern, zinc $(\mathrm{Zn})$ has attracted much attention in the avenues of AMD research. Although less harmful in its metallic form, $\mathrm{Zn}$ can be toxic in relatively low concentrations upon reaction with acids and/or oxygen and is prevalent in AMD waste, and whereas trivalent metal species including $\mathrm{Al}^{3+}$ or $\mathrm{Fe}^{3+}$ may undergo reduced mobility due to hydroxide precipitation with an increase in $\mathrm{pH}$, divalent $\mathrm{Zn}$ may remain in solution under the same chemical circumstances (Radhika et al., 2006). Furthermore, $\mathrm{Zn}$ can be a relatively safer representative of more toxic metals, making it an ideal candidate for biogenic sulfide studies (Azabou et al., 2007). Past research has focused on the formation of nanometer to micrometerscale, zinc sulfide minerals because of $\mathrm{HS}^{-}$liberation from SRB in regions of high sulfate and zinc concentrations. Zbinden and colleagues observed zinc sulfide biogenesis in the tubes of pompeii worms living at deep-sea hydrothermal vents, where mineralization occurred in association with filamentous bacteria. The mechanism behind ZnS formation was speculated to be a result of either bacterial sulfate reduction or chemical processes, as zinc sulfide precipitation may occur abiotcially at high temperatures (Zbinden et al., 2001). Mineral structure was determined to be analogous to that of the zinc sulfide polymorphs wurtzite and sphalerite (Zbinden et al., 2003). Alternatively, natural biofilms collected from the flooded Piquette mine of Wisconsin (approximately $8-10^{\circ} \mathrm{C}$ ) where spp. within the family Desulfobacteriaceae were detected, have been shown to contain abundant bacterially-derived spherical ZnS mineral precipitates. The water was modest with respect to zinc concentration (< $5 \mathrm{ppm} \mathrm{Zn),} \mathrm{however} \mathrm{carbonate} \mathrm{host} \mathrm{geology}$ provided a favourable circumneutral $\mathrm{pH}$ environment for sulfide mineralization. This phenomenon suggests that SRB under these natural environmental conditions can remove metals from solution as well as serving as important players in the formation of low-temperature ZnS ore 
deposits (Druschel et al., 2002; Labrenz et al., 2000). Moreau et al. showed that biogenic zinc sulfides from the same site precipitate initially as nanocrystalline sphalerite and wurtzite that concentrate into 1-5 micron-scale spheroids (Moreau et al., 2008). These spheroids were suspected to grow via intermittent aggregation of the ZnS nanoparticles, as indicated by disordered stacking sequences, potentially during episodic sulfate reduction. It has been hypothesized by these authors and others that both organics and cell wall constituents play a role in mineral precipitation, however, it is unknown to what extent these materials serve as growth templates (Gondikas et al., 2012; Moreau et al., 2008; Yoon et al., 2012). Laboratory studies using both mixed cultures and pure strains of SRB have found similar results to the natural biofilms. In batch experiments performed by Castillo and colleagues, zinc concentrations fell from $260 \mathrm{mg} \mathrm{L}^{-1}$ to below detection limits in the presence of a mixed inoculum of SRB from metal-laden mining districts of the Iberian Pyrite Belt (IPB), Portugal, corresponding with the formation of ZnS precipitates of sphalerite and wurtzite. It was determined that the use of SRB could reduce the mobility of all metals in AMD-affected landscapes, even in the presence of sulfate and zinc concentrations up to 2000 and $260 \mathrm{mg} \mathrm{L}^{-1}$, respectively (Castillo et al., 2012). The spore-forming SRB Desulfotomaculum nigrificans has also been exhibited to ameliorate $\mathrm{Zn}$ at $210 \mathrm{mg} \mathrm{L}^{-1}$, a concentration once considered to be fatal, via bioprecipitation and biosorption, providing insight into the importance of metal-tolerant species (Radhika et al., 2006). A similar lab study found mixed SRB cultures enriched from wastewater treatment sludge were capable of removing over 95\% of dissolved zinc from concentrations up to $150 \mathrm{mg} \mathrm{L}^{-1}$ (Azabou et al., 2007). Peltier et al. assessed the stability and reactivity of zinc sulfides formed by SRB of the Desulfovibrio $s p$. A decrease in aqueous zinc concentration was observed in batch experiments and biogenic zincsulfides were more resistant to re-oxidation than chemically produced species (Peltier et al., 2011). 


\subsection{Omic Approaches in AMD Studies}

Observations from natural environments, as well as research from mixed cultures and/or pure strains of SRB enriched from AMD regions have demonstrated the effectiveness of biotic sulfide generation in metal-removal pathways, especially at low temperatures where sulfide generation may be thermodynamically constrained. However, rarely in nature do individual microbial groups function alone; rather there exists a complex network of substrate sharing and/or competition between different bacterial guilds, often partitioned by distinct chemical or redox zones. SRB will coexist with multiple species, contending for carbon substrates with methanogens and homoacetogens, and often relying on the degradation products of amino acids, sugars, and long-chain fatty acids by fermentative bacteria (Muyzer et al., 2008; Ozuolmez et al., 2015). Few studies have explored the interactions of SRB with other species and associated metalsulfide precipitation (Alexandrino et al., 2014; Zhang et al., 2016), thus a research gap exists in this context. If the goal of passive treatment systems for AMD is to develop a pseudo-natural environment suitable for prolonged SRB activity and concurrent metal immobilization, then the bacterial community must be better quantified and understood. Phylogenetic approaches utilizing specific genes to infer taxonomy, such as the bacterial 16S rRNA gene, are a valuable part of unravelling microbial diversity (Baker et al., 2003; Baldwin et al., 2015; DiLoreto et al., 2016; Tan et al., 2007) however, combining these techniques with shotgun sequencing approaches resulting in meta data sets (metagenomics or metatranscriptomics for total DNA or RNA, respectively) provides a more powerful, holistic analysis of the in-situ functioning of a bacterial community. It is therefore beneficial for geochemists to expand their techniques into the "omics toolbox" to investigate these interactions and improve and develop reliable treatment technologies. Such endeavours have recently been undertaken in AMD-affected landscapes (Bertin et al., 2011; Chen et al., 2016; Hua et al., 2014) yet seldom have they been applied to remediation technologies for 
AMD, despite many reviews stating the potential of such research (Dick et al., 2015; Fraser et al., 2015; Garris et al., 2016; Moran et al., 2009; Moran et al., 2013; Simon et al., 2011). This is not surprising, as sequencing platforms, bioinformatics pipelines, and constructed libraries are only now being optimized for large microbial meta data sets. These innovations are changing the way microbial ecologist examine how bacteria influence their environment; from a focus on taxonomy (who is there) to an emphasis on function (what are they doing).

\subsection{The Mussel Shell Bioreactor}

As stated previously, passive treatment systems for acid mine drainage require a source of organic carbon, a neutralizing substance, and a solid substrate for bacterial adhesion and sustenance. Ease of construction can be increased if the materials selected are sourced locally and are readily available. An innovative passive bioreactor treating AMD at the Stockton Coal Mine of New Zealand fits all these criteria. The Stockton mine resides in the Brunner Coal Measure (BCM) on the South Island of New Zealand, where sulfidic coal has a high Fe leaching and acidgenerating potential due to the hydrolysis and oxidation of pyrite $\left(\mathrm{FeS}_{2}\right)$. Al liberation is prominent, with release from micaceous and feldspathic-rich rocks, as well as liberation of $\mathrm{Cu}, \mathrm{Ni}$, $\mathrm{Zn}, \mathrm{Cd}, \mathrm{As}, \mathrm{Pb}$, and Mn (Black et al., 2005; McCauley et al., 2010). The reactive mixture treating metal-laden effluent is ground mussel shell material composed primarily of green-lipped mussels, otherwise waste from the seafood industry, and is termed a Mussel Shell Bioreactor (MSB) (DiLoreto et al., 2016). The material has a high calcium carbonate $\left(\mathrm{CaCO}_{3}\right)$ content for neutralization of acidic mine effluent as well as a high organic content (5-12 wt\%) for bacterial metabolism, including sulfate reduction (Crombie et al., 2011; Trumm et al., 2010). The bioreactor (Figure 1.2), which consist of 3 cells, intercepts drainage from the Whirlwind seep at the Stockton site. The first cell allows for the settling of sediment, before effluent is drained into the second reactive cell, consisting of a trapezoidal pit filled with mussel shell waste product, where acid 
neutralization and metal removal takes place before outflow to a third settling pond. Assessment of the MSB performance demonstrates removal efficiencies of up to $~ 99 \%$ of dissolved $\mathrm{Al}$ and $\mathrm{Fe}$, and $>90 \% \mathrm{Ni}, \mathrm{Tl}$, and $\mathrm{Zn}$, while increasing drainage $\mathrm{pH}$ from 3.4 to 8.3 (DiLoreto et al., 2016). Over time, a geochemical gradient developed with depth in the bioreactor, with an oxidizing zone of Al and $\mathrm{Fe}$ oxyhydroxide precipitates overlying increasingly reducing layers characterized by amorphous Al hydroxides and sulfides. Microbial-induced sulfide generation is theorized to contribute to metal removal in the anoxic layers of the MSB, as prior 16s rRNA amplicon analysis based on extracted DNA sequences detected the presence of a sulfate-reducing community in this zone of the mussel shell bioreactor (DiLoreto et al., 2016). Eh and pH values for pore water from reduced layers (<-55 $\mathrm{mV}$ and $7.1-8.3$, respectively) also eluded to bacterial sulfate reduction, as bicarbonate $\left(\mathrm{HCO}_{3}^{-}\right)$is a common by-product of fatty acid oxidation leading to local acidity decrease (Equation 1.5).

\subsection{Thesis Overview}

\subsubsection{Objectives and Hypotheses}

Knowledge of the positive contributions of SRB to passive treatment systems for AMD have been thoroughly compiled over the past decade of research. However, as sequencing and software technologies allow for higher throughput, more detail can be revealed about the interactions between bacterial groups that permit favourable reactions for remediation. This new information can then be combined with traditional chemical approaches to track the fate of metals and other parameters of interest. This thesis will address the limited and disparate information on multi-bacterial species and function in a passive AMD treatment system, with emphasis on the establishment of sulfate-reducing genera and concurrent metal-removal by sulfide biogenesis. The bacterial inoculum used in this study was derived from the Mussel Shell bioreactor of the Stockton Coal Mine of New Zealand; a currently functioning passive treatment 
technology. Selective enrichments from the chemically reduced layer (e.g. zone of anoxia) of the bioreactor were used to seed batch experiments to measure the chemical dynamics and microbial function operating in the MSB. In these experiments the presence and absence of zinc and Thallium were measured, specifically. Both these metals are common elements in AMD effluent and are a concern at the Stockton site, thus are appropriate for chemical tracking. Data collected will be divided into two chapters in this dissertation.

The first data chapter of this thesis will focus primarily on physico-chemical and solid phase measurements and observations and will test the following three predictions:

1) Over time, microbial treatments will exhibit a decrease in dissolved sulfate concentration and concurrent production of hydrogen sulfide due to the metabolism of sulfate-reducing bacterial species within the community. This will coincide with zinc-sulfide mineral precipitation in $\mathrm{Zn}$-amended treatments, resulting in net metal removal of $\mathrm{Zn}$ as the primary chalcophilic metal, and Thallium as a trace element.

2) Bacterial activity will be lessened in metal-supplemented treatments compared to designated controls due to toxicity effects on the bacterial community.

3) Sulfide precipitates within batch experiments will be lower in abundance compared to raw bioreactor material. It is predicted that present organics from the raw bioreactor material will provide greater surface area and physical templates for metal nucleation and eventual mineral precipitation.

These predictions are summarized as the following respective null hypothesis statements:

1) Changes in sulfate, sulfide, and metal concentrations will not be significantly different between abiotic and biotic treatments. 
2) Bacterial activity will not be significantly different between treatments amended with metals and non-amended treatments.

3) Any zinc sulfide mineral precipitation in batch experiments will be similar in quantity, structure, and composition to minerals observed in raw bioreactor material

To test these hypotheses, the experiment will consist of periodic sampling of experimental batches over 37 days ( 888 hours) while monitoring relevant chemical parameters (Eh, $\mathrm{pH}$ ) and track the behaviour of key chemical species during cell growth and acclimatization, including aqueous $\mathrm{Zn}$ and $\mathrm{Tl}$, and the active redox pair sulfate $\left(\mathrm{SO}_{4}^{2-}\right)$ and sulfide $\left(\mathrm{HS}^{-}\right)$which will serve as a proxy for biological sulfate reduction (Equations 1.4, 1.5). Chemical analysis will be performed in tandem with electron microscopy to characterize and confirm potential metal sulfide precipitation as a consequence of microbial sulfur metabolism in both experimental batches and raw bioreactor material.

The second data chapter will focus on taxonomy and gene functioning of the bacterial community and will test the following predictions:

1) Sulfate-reducing genera will comprise a significant portion of the active bacterial community.

2) The potential for translation of key sulfate-reducing enzymes derived from dissimilatory sulfate reduction genes will be detected in tandem with increased sulfide production and concurrent zinc sulfide precipitation.

These predictions are summarized as the following respective null hypothesis statements:

1) Sulfate-reducing genera will not comprise a significantly different proportion of the bacterial community than any other genus. 
2) Dissimilatory sulfate reduction genes transcripts will not change significantly throughout the duration of the experiment.

To test these hypotheses, community RNA will be extracted periodically during the experiment and used for targeted amplicon sequencing of the $16 \mathrm{~S}$ subunit of bacterial rRNA, providing snapshots of the metabolically active groups present during early substrate use/competition and community establishment. The approach of using rRNA for community analysis is novel compared to the traditional use of DNA, as it can provide a finer-tuned investigation of the functionallyrelevant species. The advantages, as well as the biases of an RNA-bases taxonomic approach will be discussed in the context of the experiment, and extrapolated to the successful implementation and refining of passive treatment technologies. In addition to community characterization, extracted RNA will be analyzed through metatranscriptomics; the shotgun sequencing of total functional messenger RNA (mRNA) present. This approach will provide insight into the gene pathways that have been transcribed and activated within the bacterial population.

In conclusion, this dissertation aims to combine genomic information with chemical and microscopy data under the overarching goal of capturing the events, both physical and biological, leading to metal immobilization by a community enriched from a passive treatment technology treating Acid Mine Drainage. 
Table 1.1: Relevant genera of sulfur-utilizing bacteria recognized in bioreactors treating acid mine drainage (AMD). In column three, " $\mathrm{C}$ " or "I" represents the ability to completely or incompletely oxidize carbon substrates to acetate, respectively.

\begin{tabular}{|c|c|c|c|c|}
\hline $\begin{array}{l}\text { Deltaproteobacteria } \\
\text { (Genera) }\end{array}$ & Electron donors & $\begin{array}{l}\text { Complete (C) } \\
\text { or Incomplete } \\
\text { (I) }\end{array}$ & Reference(s) & Notes \\
\hline Desulfobulbus & $\begin{array}{l}\text { Hydrogen, Acetate, } \\
\text { Propionate, Lactate, } \\
\text { ethanol, mono and } \\
\text { disaccharides }\end{array}$ & 1 & $\begin{array}{l}\text { Muyzer 2008; Castro 2000; } \\
\text { Sass 2002; Hansen } 1994\end{array}$ & \\
\hline Desulfobacterium & $\begin{array}{l}\text { Hydrogen, Phenol, } \\
\text { Acetate, Butyrate, } \\
\text { Ethanol, Acetone, } \\
\text { Propionate, Aniline, } \\
\text { Amino Acids }\end{array}$ & C & $\begin{array}{l}\text { Jansen 1995; Castro 2000, } \\
\text { Rees } 1997\end{array}$ & \\
\hline Desulforhadbus & Acetate & & Elferink 1995 & \\
\hline Desulfobacca & Acetate & C & Elferink 1999 & \\
\hline Desulfomonile & $\begin{array}{l}\text { Hydrogen, Acetate, } \\
\text { lactate, pyruvate, } \\
\text { benzoates, formate }\end{array}$ & C & Sun 2001, DeWeerd 1990 & \\
\hline Desulfovibrio & $\begin{array}{l}\text { Hydrogen, ethanol, } \\
\text { diols, formate, lactate, } \\
\text { pyruvate, malate and } \\
\text { succinate, choline, } \\
\text { benzaldehydes, }\end{array}$ & 1 & $\begin{array}{l}\text { Muyzer 2008, Castro 2000, } \\
\text { Hansen } 1994\end{array}$ & $\begin{array}{l}\text { Model organisms for } \\
\text { research, genome only } \\
40 \% \text { size of E. coli, } \\
\text { probably the majority of } \\
\text { spp. of SRB classified }\end{array}$ \\
\hline Desulfurella & $\begin{array}{l}\text { Lactate, hydrogen, } \\
\text { acetate, fumarate, } \\
\text { malate, pyruvate, } \\
\text { propionate }\end{array}$ & C & $\begin{array}{l}\text { Kaksonen 2004, } \\
\text { Miroshnichenko } 1998\end{array}$ & $\begin{array}{l}\text { Thermal environments, } \\
\text { not known to reduce } \\
\text { sulfate. }\end{array}$ \\
\hline \multicolumn{5}{|l|}{ Firmicutes (Genera) } \\
\hline Desulfosporosinus & $\begin{array}{l}\text { Lactate, fructose, } \\
\text { glycerol, H2, pyruvate, } \\
\text { butyrate, yeast } \\
\text { extract, }\end{array}$ & $\mathrm{I} / \mathrm{C}$ & $\begin{array}{l}\text { Sanchez Andrea 2014, Spring } \\
2006\end{array}$ & $\begin{array}{l}\text { Commonly in low } \mathrm{pH} \\
\text { reactors, spore-forming; } \\
\text { fermentation of lactate }\end{array}$ \\
\hline Desulfitobacterium & $\begin{array}{l}\text { Lactate, formate, } \\
\text { pyruvate, } \mathrm{H} 2 \text {, }\end{array}$ & $\mathrm{I} / \mathrm{C}$ & $\begin{array}{l}\text { Sanchez-Andrea 2014; Spring } \\
2006\end{array}$ & $\begin{array}{l}\text { Commonly in low } \mathrm{pH} \\
\text { reactors, spore-forming }\end{array}$ \\
\hline Desulfotomaculum & $\begin{array}{l}\text { Lactate, pyruvate, } \mathrm{H} 2 \text {, } \\
\text { ethanol, formate, } \\
\text { malate, succinate }\end{array}$ & $\mathrm{I} / \mathrm{C}$ & Muyzer 2008; Radhika, 2006 & $\begin{array}{l}\text { Incomplete oxidation of } \\
\text { substrate to acetate is } \\
\text { common (acetyl-coA } \\
\text { pathway) }\end{array}$ \\
\hline
\end{tabular}


Table 1.2: log Ksp values of carbonate, hydroxide, and sulfide species of metals associated with acid mine drainage

\begin{tabular}{|c|l|l|l|}
\hline Metal & Carbonate & Hydroxide & Sulfide \\
\hline $\mathrm{Cu}^{2+}$ & -9.8 & -19.7 & -35.9 \\
\hline $\mathrm{Fe}^{2+}$ & -10.5 & -15.1 & -18.8 \\
\hline $\mathrm{Fe}^{3+}$ & $\mathrm{NA}$ & -37.4 & $\mathrm{NA}$ \\
\hline $\mathrm{Mn}^{2+}$ & -10.7 & -12.7 & -13.3 \\
\hline $\mathrm{Ni}^{2+}$ & -8.2 & -14.7 & -18.5 \\
\hline $\mathrm{Pb}^{2+}$ & -13.1 & -14.9 & -27.5 \\
\hline $\mathrm{Zn}^{2+}$ & -10.8 & -16.9 & -24.5 \\
\hline
\end{tabular}

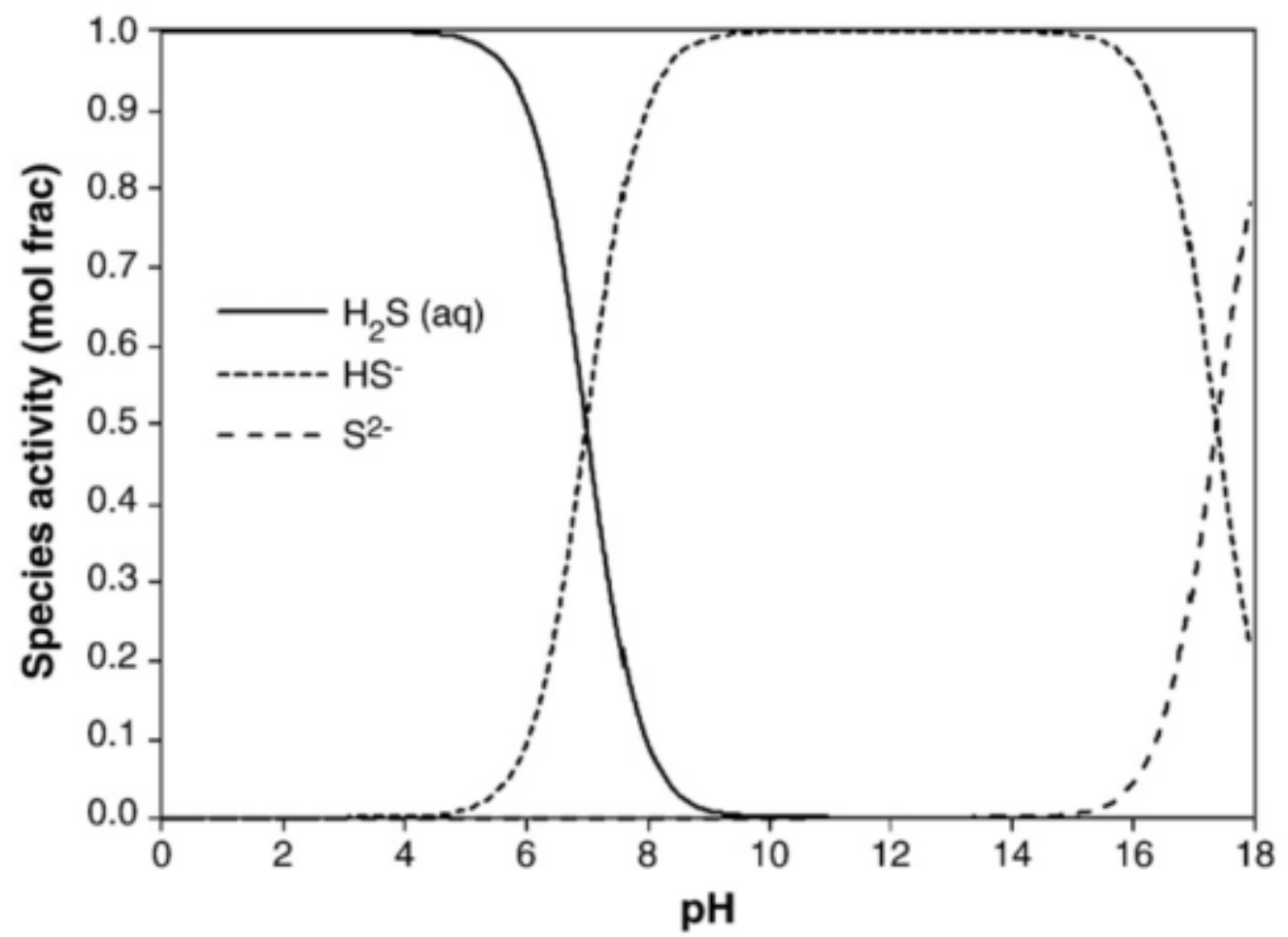

Figure 1.1: Sulfide Speciation Dependence on pH (Lewis et al., 2010). 




Figure 1.2: Overhead view of the Mussel Shell Bioreactor (MSB) at the Stockton Coal Mine of the South Island of New Zealand. A, B, and C, represent the $1^{\text {st }}$ sediment retention pond, the $2^{\text {nd }}$ reactor cell comprising the mussel shell material, and the $3^{\text {rd }}$ settling pond, respectively. D) cross section on the MSB in cell $B$, exhibiting the upper oxic layers overlying sequentially more chemically reduced layers with depth. 


\subsection{References}

Akcil, A., \& Koldas, S. (2006). Acid Mine Drainage (AMD): causes, treatment and case studies. Journal of Cleaner Production, 14(12), 1139-1145.

Alexandrino, M., Costa, R., Canário, A. V., \& Costa, M. C. (2014). Clostridia initiate heavy metal bioremoval in mixed sulfidogenic cultures. Environmental science \& technology, 48(6), 33783385.

Azabou S., Mechichi T. and Sayadi S. (2007) Zinc precipitation by heavy-metal tolerant sulfatereducing bacteria enriched on phosphogypsum as a sulfate source. Miner. Eng. 20, 173-178.

Baker B. J. and Banfield J. F. (2003). Microbial communities in acid mine drainage. FEMS Microbiol. Ecol. 44, 139-52.

Barnes, H. L., \& Romberger, S. B. (1968). Chemical aspects of acid mine drainage. Journal (Water Pollution Control Federation), 371-384.

Barton L. L., Tomei-torres F. A., Xu H. and Zocco T. (2015) Bacteria-Metal Interactions. 10.1007/978-3-319-18570-5.

Benner, S. G., Blowes, D. W., \& Ptacek, C. J. (1997). A full-scale porous reactive wall for prevention of acid mine drainage. Groundwater Monitoring \& Remediation, 17(4), 99-107.

Benner, S. G., Blowes, D. W., Gould, W. D., Herbert, R. B., \& Ptacek, C. J. (1999). Geochemistry of a permeable reactive barrier for metals and acid mine drainage. Environmental Science \& Technology, 33(16), 2793-2799.

Bertin, P. N., Heinrich-Salmeron, A., Pelletier, E., Goulhen-Chollet, F., Arsène-Ploetze, F., Gallien, S., ... \& Bonnefoy, V. (2011). Metabolic diversity among main microorganisms inside an arsenicrich ecosystem revealed by meta-and proteo-genomics. The ISME journal, 5(11), 1735-1747.

Black, A., Trumm, D., \& Lindsay, P. (2005). Impacts of coal mining on water quality and metal mobilisation: case studies from West Coast and Otago.Metal Contaminants in New Zealand, Sources, Treatments, and Effects on Ecology and Human Health. Published by Resolutionz Press, a trading arm of Resolutionz Consulting Limited, 62, 247-260.

Blowes, D. W., Ptacek, C. J., Bain, J. G., Waybrant, K. R., \& Robertson, W. D. (1995) Treatment of mine drainage water using in situ permeable reactive walls. Proc. Sudbury '95-Mining and the Environment May, 979-987.

Blowes, D. W., Ptacek, C. J., Benner, S. G., McRae, C. W., Bennett, T. A., \& Puls, R. W. (2000) Treatment of inorganic contaminants using permeable reactive barriers. Journal of Contaminant Hydrology, 45(1), 123-137.

Blowes, D. W., Ptacek, C. J., Jambor, J. L., \& Weisener, C. G. (2003). The geochemistry of acid mine drainage. Treatise on geochemistry, 9, 612.

Bond P. L., Druschel G. K. and Banfield J. F. (2000). Comparison of Acid Mine Drainage Microbial Communities in Physically and Geochemically Distinct Ecosystems Comparison of Acid Mine 
Drainage Microbial Communities in Physically and Geochemically Distinct. Appl. Environ. Microbiol. 66, 4962-4971.

Castro H., Williams N. and Ogram a (2000). Phylogeny of sulfate-reducing bacteria (1). FEMS Microbiol. Ecol. 31, 1-9.

Chapman, B. M., Jones, D. R., \& Jung, R. (1983). Processes controlling metal ion attenuation in acid mine drainage streams. Geochimica et Cosmochimica Acta, 47(11), 1957-1973.

Chen, L. X., Huang, L. N., Méndez-García, C., Kuang, J. L., Hua, Z. S., Liu, J., \& Shu, W. S. (2016). Microbial communities, processes and functions in acid mine drainage ecosystems. Current opinion in biotechnology, 38, 150-158.

Chockalingam, E., \& Subramanian, S. (2006). Studies on removal of metal ions and sulphate reduction using rice husk and Desulfotomaculum nigrificans with reference to remediation of acid mine drainage.Chemosphere, 62(5), 699-708.

Costa, M. C., Martins, M., Jesus, C., \& Duarte, J. C. (2008). Treatment of acid mine drainage by sulphate-reducing bacteria using low cost matrices. Water, air, and soil pollution, 189(1-4), 149162.

Cravotta, C. A. (2008). Dissolved metals and associated constituents in abandoned coal-mine discharges, Pennsylvania, USA. Part 1: constituent quantities and correlations. Applied Geochemistry, 23(2), 166-202.

Creamer, N. J., Baxter-Plant, V. S., Henderson, J., Potter, M., \& Macaskie, L. E. (2006). Palladium and gold removal and recovery from precious metal solutions and electronic scrap leachates by Desulfovibrio desulfuricans. Biotechnology letters, 28(18), 1475-1484.

Crombie, F. M., Weber, P. A., Lindsay, P., Thomas, D. G., Rutter, G. A., Shi, P., ... \& Pizey, M. H. (2011, June). Passive treatment of acid mine drainage using waste mussel shell, Stockton coal mine, New Zealand. In 7th Australian acid and metalliferous drainage workshop, Darwin, Australia.

da Silveira, A. N., Silva, R., \& Rubio, J. (2009). Treatment of acid mine drainage (AMD) in South Brazil: comparative active processes and water reuse. International Journal of Mineral Processing, 93(2), 103-109.

Denef V. J., Mueller R. S. and Banfield J. F. (2010). AMD biofilms: using model communities to study microbial evolution and ecological complexity in nature. ISME J. 4, 599-610.

DeWeerd, K. A., Mandelco, L., Tanner, R. S., Woese, C. R., \& Suflita, J. M. (1990). Desulfomonile tiedjei gen. nov. and sp. nov., a novel anaerobic, dehalogenating, sulfate-reducing bacterium. Archives of Microbiology,154(1), 23-30.

Dick G. J. and Lam P. (2015) Omic Approaches to Microbial Geochemistry. Elements 11, 403-408.

DiLoreto, Z. A., Weber, P. A., \& Weisener, C. G. (2016). Solid phase characterization and metal deportment in a mussel shell bioreactor for the treatment of AMD, Stockton Coal Mine, New Zealand. Applied Geochemistry, 67, 133-143. 
DiLoreto Z. A., Weber P. A., Olds W., Pope J., Trumm D., Chaganti S. R., Heath D. D. and Weisener C. G. (2016) Novel cost effective full scale mussel shell bioreactors for metal removal and acid neutralization. J. Environ. Manage.

Druschel G. K., Labrenz M., Thomsen-Ebert T., Fowle D. a. and Banfield J. F. (2002) Geochemical modeling of ZnS in biofilms: An example of ore depositional processes. Econ. Geol. 97, 13191329.

Dunbabin, J. S., \& Bowmer, K. H. (1992). Potential use of constructed wetlands for treatment of industrial wastewaters containing metals. Science of the Total Environment, 111(2), 151-168.

Elferink, S. W. H., Maas, R. N., Harmsen, H. J. M. \& Stams, A. J. M. (1995). Desulforhabdus amnigenus gen. nov. sp. nov., a sulfate reducer isolated from anaerobic granular sludge. Arch Microbioll 64, 119-124.

Elferink, S. J. O., Akkermans-van Vliet, W. M., Bogte, J. J., \& Stams, A. J. (1999). Desulfobacca acetoxidans gen. nov., sp. nov., a novel acetate-degrading sulfate reducer isolated from sulfidogenic granular sludge.International Journal of Systematic and Evolutionary Microbiology, 49(2), 345-350.

Evangelou, V. P., \& Zhang, Y. L. (1995). A review: pyrite oxidation mechanisms and acid mine drainage prevention. Critical Reviews in Environmental Science and Technology, 25(2), 141-199.

Flemming CA, \& Trevors JT. 1989. Copper toxicity and chemistry in the environment: a review, Water, Air, \& Soil Pollution, 44: 143-158

Fraser L. H., Garris H. W., Baldwin S. A. and Van Hamme J. D. (2015) Using genomics in mine reclamation. Mine Clos. 2015, 1-12.

Gazea, B., Adam, K., \& Kontopoulos, A. (1996). A review of passive systems for the treatment of acid mine drainage. Minerals engineering, 9(1), 23-42.

Garris H. W., Baldwin S. A., Van Hamme J. D., Gardner W. C. and Fraser L. H. (2016) Genomics to assist mine reclamation: A review. Restor. Ecol. 24, 165-173.

Gondikas A. P., Masion A., Auffan M., Lau B. L. T. and Hsu-Kim H. (2012) Early-stage precipitation kinetics of zinc sulfide nanoclusters forming in the presence of cysteine. Chem. Geol. 329, 10-17.

Hallberg, K. B. (2010). New perspectives in acid mine drainage microbiology. Hydrometallurgy, 104(3), 448-453.

Hansen T. A. (1994) Metabolism of sulfate-reducing prokaryotes. Antonie Van Leeuwenhoek 66, 165-185.

Hedin, R. S., Watzlaf, G. R., \& Nairn, R. W. (1994). Passive treatment of acid mine drainage with limestone. Journal of Environmental Quality, 23(6), 1338-1345.

Hochella, M. F., Moore, J. N., Golla, U., \& Putnis, A. (1999). A TEM study of samples from acid mine drainage systems: Metal-mineral association with implications for transport. Geochimica et Cosmochimica Acta, 63(19), 3395-3406. 
Hua Z.-S., Han Y.-J., Chen L.-X., Liu J., Hu M., Li S.-J., Kuang J.-L., Chain P. S., Huang L.-N. and Shu W.-S. (2014). Ecological roles of dominant and rare prokaryotes in acid mine drainage revealed by metagenomics and metatranscriptomics. ISME J. 9, 1280-1294.

Huisman J. L., Schouten G. and Schultz C. (2006) Biologically produced sulphide for purification of process streams, effluent treatment and recovery of metals in the metal and mining industry. Hydrometallurgy 83, 106-113.

Janssen, P. H., \& Schink, B. (1995). Metabolic pathways and energetics of the acetone-oxidizing, sulfate-reducing bacterium, Desulfobacterium cetonicum. Archives of microbiology, 163(3), 188194.

Johnson, D. B., \& Hallberg, K. B. (2005). Acid mine drainage remediation options: a review. Science of the total environment, 338(1), 3-14.

Kaksonen, A. H., Plumb, J. J., Franzmann, P. D., \& Puhakka, J. A. (2004). Simple organic electron donors support diverse sulfate-reducing communities in fluidized-bed reactors treating acidic metal-and sulfate-containing wastewater. FEMS Microbiology Ecology, 47(3), 279-289.

Kalin, M. (2001). Closure with ecological engineering of a remote $\mathrm{Cu} / \mathrm{Zn}$ concentrator: overview of 10 years R \& D field program. In Proceedings of the Fourth International Symposium on Waste Processing and Recycling in Mineral and Metallurgical Industries, MET SOC 40 th Annual Conference of Metallurgists of CIM, "Waste Processing and Recycling in Mineral and Metallurgical Industries IV", Toronto, August (pp. 26-29).

Kallmeyer, J., Pockalny, R., Adhikari, R. R., Smith, D. C., \& D’Hondt, S. (2012). Global distribution of microbial abundance and biomass in subseafloor sediment. Proceedings of the National Academy of Sciences,109(40), 16213-16216.

Koryak, M., Shapiro, M. A., \& Sykora, J. L. (1972). Riffle zoobenthos in streams receiving acid mine drainage. Water Research, 6(10), 1239-1247.

Labrenz M. (2000) Formation of Sphalerite (ZnS) Deposits in Natural Biofilms of Sulfate-Reducing Bacteria. Science (80-. ). 290, 1744-1747.

Lefticariu, L., Walters, E. R., Pugh, C. W., \& Bender, K. S. (2015). Sulfate reducing bioreactor dependence on organic substrates for remediation of coal-generated acid mine drainage: Field experiments. Applied Geochemistry, 63, 70-82.

Lewis A. E. (2010) Review of metal sulphide precipitation. Hydrometallurgy 104, 222-234.

Luptakova, A., \& Kusnierova, M. (2005). Bioremediation of acid mine drainage contaminated by SRB. Hydrometallurgy, 77(1), 97-102.

Luptakova, A., Spaldon, T., \& Balintova, M. (2007, July). Remediation of acid mine drainage by means of biological and chemical methods. InAdvanced Materials Research (Vol. 20, pp. 283286). Trans Tech Publications. 
Luptakova, A., Ubaldini, S., Macingova, E., Fornari, P., \& Giuliano, V. (2012). Application of physical-chemical and biological-chemical methods for heavy metals removal from acid mine drainage. Process Biochemistry,47(11), 1633-1639.

McCauley C., O'Sullivan A., Weber P. and Trumm D. (2010) Variability of Stockton Coal Mine drainage chemistry and its treatment potential with biogeochemical reactors. New Zeal. J. Geol. Geophys. 53, 211-226.

Miroshnichenko, M. L., Rainey, F. A., Hippe, H., Chernyh, N. A., Kostrikina, N. A., \& BonchOsmolovskaya, E. A. (1998). Desulfurella kamchatkensis sp. nov. and Desulfurella propionica sp. nov., new sulfur-respiring thermophilic bacteria from Kamchatka thermal environments. International Journal of Systematic and Evolutionary Microbiology, 48(2), 475479.

Mogensen, G. L., Kjeldsen, K. U., \& Ingvorsen, K. (2005). Desulfovibrio aerotolerans sp. nov., an oxygen tolerant sulphate-reducing bacterium isolated from activated sludge. Anaerobe, 11(6), 339-349.

Moran M. A. (2009) Metatranscriptomics: Eavesdropping on Complex Microbial Communities. Microbe 4, 329-335.

Moran M. A., Satinsky B., Gifford S. M., Luo H., Rivers A., Chan L., Meng J., Durham B. P., Shen C., Varaljay V. a, Smith C. B., Yager P. L. and Hopkinson B. M. (2013) Sizing up metatranscriptomics. ISME J. 7, 237-43.

Morasch, B., Schink, B., Tebbe, C. C., \& Meckenstock, R. U. (2004). Degradation of o-xylene and $\mathrm{m}$-xylene by a novel sulfate-reducer belonging to the genus Desulfotomaculum. Archives of Microbiology, 181(6), 407-417.

Mulligan, C., in: Hartmans, S., Lens, P. (2000), 4th Int. Symp. on Environm. Biotechn., Noordwijkerhout, The Netherlands, 201-204.

Muyzer G. and Stams A. J. M. (2008) The ecology and biotechnology of sulphate-reducing bacteria. Nat. Rev. Microbiol. 6, 441-54.

Neculita, C. M., Zagury, G. J., \& Bussière, B. (2007). Passive treatment of acid mine drainage in bioreactors using sulfate-reducing bacteria. Journal of Environmental Quality, 36(1), 1-16.

Nordstrom D. K. and G. Southam. 1997. Geomicrobiology of sulfide mineral oxidation. Geomicrobiology: Interactions between Microbes and Minerals 35: 361-390.

Postgate, J. R. (1979). The sulphate-reducing bacteria. CUP Archive.

Radhika V., Subramanian S. and Natarajan K. A. (2006) Bioremediation of zinc using Desulfotomaculum nigrificans: Bioprecipitation and characterization studies. Water Res. 40, 3628-3636.

Rees, G. N., Harfoot, C. G., \& Sheehy, A. J. (1997). Amino acid degradation by the mesophilic sulfate-reducing bacterium Desulfobacterium vacuolatum. Archives of microbiology, 169(1), 7680. 
Roback, S. S., \& Richardson, J. W. (1969). The effects of acid mine drainage on aquatic insects. Proceedings of the Academy of Natural Sciences of Philadelphia, 81-107.

Salomons, W. (1995). Environmental impact of metals derived from mining activities: processes, predictions, prevention. Journal of Geochemical Exploration, 52(1), 5-23

Sass, A., Rütters, H., Cypionka, H., \& Sass, H. (2002). Desulfobulbus mediterraneus sp. nov., a sulfate-reducing bacterium growing on mono-and disaccharides. Archives of Microbiology, 177(6), 468-474.

Sánchez-Andrea I., Sanz J. L., Bijmans M. F. M. and Stams A. J. M. (2014) Sulfate reduction at low $\mathrm{pH}$ to remediate acid mine drainage. J. Hazard. Mater. 269, 98-109.

Schrenk MO, Edwards KJ, Goodman RM, Hamers RJ, Banfield JF. (1998). Distribution of Thiobacillus fer-rooxidans and Leptospirillum ferrooxidans: implica-tions for generation of acid mine drainage. Science 279: 1519-1522.

Sigalevich, P., Meshorer, E., Helman, Y., \& Cohen, Y. (2000). Transition from anaerobic to aerobic growth conditions for the sulfate-reducing bacterium Desulfovibrio oxyclinae results in flocculation. Applied and environmental microbiology, 66(11), 5005-5012.

Silverman M.P. and H. L. Ehrlich. (1964). Microbial formation and degradation of minerals. Advances in Applied Microbiology 6: 153-206.

Simon C. and Daniel R. (2011) Metagenomic Analyses: Past and Future Trends. Appl. Environ. Microbiol. 77, 1153-1161.

Sparks, D. L. (2005). Toxic metals in the environment: the role of surfaces. Elements 1, 193-196.

Spring, S., \& Rosenzweig, F. (2006). The genera Desulfitobacterium and Desulfosporosinus: taxonomy. In The Prokaryotes (pp. 771-786). Springer US.

Stams, A. J. M., Hansen, T. A., \& Skyring, G. W. (1985). Utilization of amino acids as energy substrates by two marineDesulfovibrio strains. FEMS Microbiology Letters, 31(1), 11-15.

Tan G. L., Shu W. S., Hallberg K. B., Li F., Lan C. Y. and Huang L. N. (2007) Cultivation-dependent and cultivation-independent characterization of the microbial community in acid mine drainage associated with acidic $\mathrm{Pb} / \mathrm{Zn}$ mine tailings at Lechang, Guangdong, China. FEMS Microbiol. Ecol. $59,118-126$.

Sun, B., Cole, J. R., \& Tiedje, J. M. (2001). Desulfomonile limimaris sp. nov., an anaerobic dehalogenating bacterium from marine sediments. International journal of systematic and evolutionary microbiology, 51(2), 365-371.

Tremblay GA, Hogan CM (eds) (2001) Mine Environment Neutral Drainage (MEND) Manual 5.4.2d: Prevention and Control. Canada Centre for Mineral andEnergy Technology, Natural Resources Canada, Ottawa, 352 pp

Trumm D. and Ball J. (2010) Use of sulfate-reducing mussel shell reactors in New Zealand for treatment of acid mine drainage. 
Tuttle, J. H., Dugan, P. R., Macmillan, C. B., \& Randles, C. I. (1969). Microbial dissimilatory sulfur cycle in acid mine water. Journal of Bacteriology, 97(2), 594-602.

Urrutia, M. M., \& Beveridge, T. J. (1994). Formation of fine-grained metal and silicate precipitates on a bacterial surface (< i> Bacillus subtilis</i>). Chemical Geology, 116(3), 261-280.

Vasquez, Y., Escobar, M. C., Neculita, C. M., Arbeli, Z., \& Roldan, F. (2016). Selection of reactive mixture for biochemical passive treatment of acid mine drainage. Environmental Earth Sciences, 75(7), 1-11.

Wassel, R. A., \& Mills, A. L. (1983). Changes in water and sediment bacterial community structure in a lake receiving acid mine drainage. Microbial ecology, 9(2), 155-169.

Weber, P., Weisener, C., DiLoreto, Z., \& Pizey, M. (2015). Passive Treatment of ARD Using Mussel Shells-Part I: System Development and Geochemical Processes. In The Proceedings of the 10th International Conference on Acid Rock Drainage, Santiago Chile (p. 203).

Weijma, J., Copini, C. F. M., Buisman, C. J. N., Schultz, C. E., \& Lens, P. (2002). Biological recovery of metals, sulfur and water in the mining and metallurgical industry. Water Recycling and Recovery in Industry, IWA Publishing: London, 2002; pp 605-622.

Whitman, W. B., Coleman, D. C., \& Wiebe, W. J. (1998). Prokaryotes: the unseen majority. Proceedings of the National Academy of Sciences, 95(12), 6578-6583.

Widdel, F. (2006). The genus Desulfotomaculum. In The prokaryotes (pp. 787-794). Springer US. Yoon S. J., Yáñez C., Bruns M. A., Martínez-Villegas N. and Martínez C. E. (2012) Natural zinc enrichment in peatlands: Biogeochemistry of ZnS formation. Geochim. Cosmochim. Acta 84, 165-176.

Zbinden, M., Martinez, I., GUYOT, F., Cambon-Bonavita, M. A., \& Gaill, F. (2001). Zinc-iron sulphide mineralization in tubes of hydrothermal vent worms. European Journal of Mineralogy, 13(4), 653-658.

Zbinden, M., Le Bris, N., Compère, P., Martinez, I., Guyot, F., \& Gaill, F. (2003). Mineralogical gradients associated with alvinellids at deep-sea hydrothermal vents. Deep Sea Research Part I: Oceanographic Research Papers, 50(2), 269-280.

Zhang M. and Wang H. (2016) Preparation of immobilized sulfate reducing bacteria (SRB) granules for effective bioremediation of acid mine drainage and bacterial community analysis. Miner. Eng. 92, 63-71.

Ziemkiewicz, P. F., Skousen, J. G., \& Simmons, J. (2003). Long-term performance of passive acid mine drainage treatment systems. Mine Water and the Environment, 22(3), 118-129 


\section{Chapter II: Physico-Chemical Investigations During bacterially-mediated ZnS precipitation}

\subsection{Introduction}

Reducing dissolved metal concentrations is one of the primary objectives in the remediation of Acid Mine Drainage (AMD), regardless of the treatment approach (Akcil et al., 2006; Johnson et al., 2005). Traditional active treatment options which apply neutralizing agents are effective in both increasing drainage $\mathrm{pH}$ and facilitating the removal of trivalent metals such as $\mathrm{Fe}^{3+}$ or $\mathrm{Al}^{3+}$ via the precipitation of metal hydroxides and/or metal carbonates. Alternatively, the induced precipitation of sulfide minerals is more effective for immobilization of divalent metals, such as copper, nickel and zinc, due to their lower solubility. Thus, these reactions are more favourable when low cost and low maintenance passive system approaches are taken for AMD treatment (Johnson et al., 2005; Sheoran et al., 2010; da Silveira et al., 2009; Luptakova et al., 2012; Wei et al., 2005). The most effective means of divalent metal precipitation in this context of passive treatment systems is via reaction with biologically-generated hydrogen sulfide, shown in Equation 2.1, where the aqueous metal $\left(\mathrm{M}^{2+}\right)$ reacts favourably with the hydrogen sulfide species ( $\mathrm{HS}^{-}$or $\mathrm{S}^{2-}$ ) to form insoluble metal-sulfides:

$\mathrm{M}^{2+}+\mathrm{HS}^{-} \leftrightarrow \mathrm{MS}_{(\mathrm{s})}+\mathrm{H}^{+}$

One of the biological catalysts of hydrogen sulfide production is sulfate-reducing prokaryotes, commonly sulfate-reducing bacteria (SRB) that generate sulfide species as a by-product of the reduction of sulfate, coupled with the oxidation of hydrogen (Equation 2.2) or fatty acids including, but not limited to, acetate, lactate, butyrate, or propionate (Equation 2.3) (Muyzer et al., 2008).

$\mathrm{SO}_{4}^{2-}+4 \mathrm{H}_{2}+\mathrm{H}^{+} \leftrightarrow \mathrm{HS}^{-}+4 \mathrm{H}_{2} \mathrm{O}$

(Eq. 2.2) 
$\mathrm{SO}_{4}^{2-}+\mathrm{C}_{2} \mathrm{H}_{3} \mathrm{O}_{2}^{-}$(Acetate) $\leftrightarrow \mathrm{HS}^{-}+2 \mathrm{HCO}_{3}^{-}$(Eq. 2.3)

Past recent studies have concentrated on the immobilization of $\mathrm{Zn}$ through this biotic-driven mechanism via the precipitation of zinc sulfide (ZnS) minerals by SRB guilds (Equation 2.4).

$\mathrm{Zn}^{2+}+\mathrm{HS}^{-} \leftrightarrow \mathrm{ZnS}+\mathrm{H}^{+}$

Natural examples of this phenomenon have been exhibited in the flooded Piquette lead-zinc mine in Wisconsin, where biofilms rich in ZnS mineral precipitates were shown to have a strong correlation with SRB communities in the family Desulfobacteriaceae. High dissolved metal concentrations, circumneutral-pH buffering by carbonate host rocks, and episodic bacterial sulfate reduction were believed to drive ZnS generation in this system (Druschel et al., 2002; Labrenz et al., 2000; Labrenz et al., 2004). The mineralized precipitates formed in this environment consisted of 1-5 micron-sized spherical aggregates comprising nanocrystalline lattices of sphalerite and wurtzite (Moreau et al., 2008). Individual nano-particles were often associated with cells and organics comprising the extracellular polymeric substance (EPS) of the biofilms, however, it is still unclear to what extent these moieties serve as mineralization and/or growth templates, and whether this mechanism is similar in engineered passive treatment systems. Yoon et al. observed comparable mineral structures in peatlands and detected a variety of SRB as facilitators of sulfide precipitation (Yoon et al., 2012). Other laboratory-based studies have isolated enrichments of SRB's from abandoned mining districts and developed batch experiments to examine the potential for ZnS mineral formation and concurrent metal removal. In one study, investigators reported that zinc concentrations decreased from $260 \mathrm{mg} \mathrm{L}^{-1}$ to below detection limits in the presence of a mixed inoculum of metal-resistant SRB collected from mining districts of the Iberian Pyrite Belt, Spain, correlating with the formation of sphalerite and wurtzite (Castillo et al., 2012). Other studies have shown that mixed SRB cultures are not only capable of 
reducing high dissolved zinc concentrations (e.g. $>150 \mathrm{mg} \mathrm{L}^{-1}$ ), but that the sulfides produced appear to be more resistant to re-oxidation than their abiotically-produced counterparts (Azabou et al., 2007; Peltier et al., 2011; Utgikar et al., 2002).

SRB have been applied in passive AMD treatment technologies at various scales over the last 30 years, including ex-situ sulfidogenic bioreactors (Christensen et al., 1996; Foucher et al., 2001; Huisman et al., 2006; Neculita et al., 2007; Radhika et al., 2006; Sánchez-Andrea et al., 2014; Weijma et al., 2002) and in-situ anaerobic reactors (Blowes et al., 2000; Burns et al., 2012; Eger et al., 1994; Papirio et al., 2013; White and Gadd., 1996). However mining environments, specifically AMD environments, can vary in their site characteristics, including local geology and mineralogy, climate, $\mathrm{pH}$, redox conditions, sulfate, salinity, flow rates, particle size, and thermal conductivity (Amos et al., 2015; Jamieson et al., 2015) and there is agreement across the scientific community that the passive treatment system implemented should take into account these parameters for a successful design (Hedin et al., 1994 Luptakova et al., 2012; Skousen et al., 1997). Furthermore, review and monitoring of the performance of passive systems and mechanistic function, after implementation, are integral parts of the remediation plan.

This research builds on existing knowledge of a passive in situ technology being used at the Stockton Coal Mine of New Zealand. In this case a novel approach using mussel shells as the primary component of a passive treatment system has been implemented to buffer the influent acidity and serve as a carbon substrate to sustain communities of SRB. At this site, crushed green lipped mussel shell material was used to fill in a trapezoidal pit designed to intercept acidic coal mine drainage with the goals of reducing metal loads, primarily $\mathrm{Al}, \mathrm{Fe}, \mathrm{Ni}, \mathrm{Tl}$, and $\mathrm{Zn}$, and decreasing influent pH (DiLoreto et al., 2016a,b). Analysis has shown that a geochemical gradient develops within the bioreactor, going from oxic, to suboxic, to reducing with depth. The redox change is concomitant with distinct reaction layers, including an upper allochthonous sediment 
zone, an iron-rich oxidized zone, an aluminum-rich zone, and a lower, unreacted shell material zone at the bottom (DiLoreto et al., 2016a). Bacterial communities in the reducing zone are hypothesized to contribute to metal removal (primarily $\mathrm{Zn}, \mathrm{Tl}$, and $\mathrm{Ni}$ ) via biogenic sulfide precipitation, however this biotic mechanism has yet to be explored thoroughly within the bioreactor.

This data chapter will assess the physico-chemical potential of enriched bacterial communities to decrease $\mathrm{Zn}$ and $\mathrm{Tl}$ loads, metals of concern at the Stockton site, in batch lab experiments. Material from the reduced layers of the Stockton mussel shell bioreactor will provide the source of the bacterial inoculum, as this is the region where SRB species have been detected (DiLoreto et al., 2016b). It is hypothesized that enrichments from the bioreactor will harbour active SRB that will lower initial $\mathrm{Zn}$ and $\mathrm{TI}$ concentrations in lab experiments, and that this will occur in tandem with observable precipitation of biogenic Zn-sulfide minerals, in accordance with afore mentioned research investigations. In parallel with lab-based batch experiments, raw material from the bioreactor layer of interest will be analyzed visually and chemically for evidence of in-situ ZnS formation, and compared to lab-generated products. To our knowledge, this is the first research to investigate SRB-mediated metal-sulfide precipitation as a component of metal reduction in both an established passive treatment system as well as in lab experiments. Furthermore, ZnS precipitation has only been investigated in either mixed or pure cultures of SRB. This study will assess zinc mineralization by SRB within a community of various bacterial groups (not SRB exclusively) in a scenario more analogous to a natural, or in the case of passive treatment systems for AMD, pseudo-natural environment.

\subsection{Methods}

\subsubsection{Site Characterization and Sample Collection}


The mussel shell bioreactor (MSB) is located on the west coast of the South Island of New Zealand where it is implemented at the opencast Stockton Coal Mine at $-41.6606^{\circ} \mathrm{N}$ and $171.8757^{\circ} \mathrm{E}$. The mining region overlays the Brunner coal Measure (BCM) which is characterized by up to 1 wt. \% sulfur, with overlying mudstones containing up to $5 \%$ pyrite $\left(\mathrm{FeS}_{2}\right)$. The area experiences an average annual temperature of $\sim 8^{\circ} \mathrm{C}$ and receives approximately $7000 \mathrm{~mm} \mathrm{y}^{-1}$ rainfall, contributing to Acid Mine Drainage (AMD) production. Numerous AMD seeps are associated with excavated overburden at the Stockton site (McCauley et al., 2010). The MSB in question intercepts AMD effluent from a source termed the Whirlwind Seep, which generates drainage of $\mathrm{pH} 3.3$ containing high concentrations of $\mathrm{Fe}, \mathrm{Al}, \mathrm{Zn}, \mathrm{Ni}, \mathrm{Mn}$ and trace metals including As, Cd, Cu, Pb, and Tl (Pope et al., 2010; Pope et al., 2015). The treatment system consists of three cells; a primary sediment settling pond, a second cell comprising the MSB where effluent is treated, and a third cell for aeration and sediment settling before discharge (Figure 1.2). The MSB cell consists of a trapezoidal pit filled with $~ 362$ T of green-lipped mussel shell waste, a product of the local seafood industry. The mussel shell material provides a source of alkalinity, with the accompanying shell meat and organics serving as a carbon substrate for bacterial communities. Effluent flows from top down through the bioreactor and exits via a central PVC pipe drain (DiLoreto et al., 2016). Sampling was performed on the bioreactor cell after 20 months of operation in June 2014, with sediment samples being taken from several depths of the reactor, representing the various chemical and redox zones. Material from the reduced layer of the bioreactor was used as a source for bacterial enrichments. The zone is characterized by an Eh of less that $-55 \mathrm{mV}$ and $\mathrm{pH}$ ranging from 7.1 to 8.3 , with targeted extractions showing a strong association with metal sulfides of $\mathrm{Zn}, \mathrm{TI}$, and Ni. Past $16 \mathrm{~S}$ rRNA amplicon sequencing analysis based on extracted DNA confirmed the presence of sulfate-reducers in the layer.

\subsubsection{Bacterial Community Enrichment Conditions}


A combined $5 \mathrm{~g}$ of material was taken from the reduced layer of the mussel shell bioreactor and placed into an autoclaved $115 \mathrm{~mL}$ glass crimp-top bottle. Postgate Medium C was autoclaved, adjusted to $\mathrm{pH} 7.5$, and bubbled under Nitrogen gas and used to fill the crimp vial leaving zero headspace to limit oxygen diffusion and serve as an analogue of the sulfate-rich and circumneutral chemical environment of the reduced zone of the bioreactor. The medium contains per litre of deionized water $1.0 \mathrm{~g} \mathrm{NH}_{4} \mathrm{Cl}_{2}, 0.06 \mathrm{~g} \mathrm{CaCl}_{2} \cdot 2 \mathrm{H}_{2} \mathrm{O}, 0.5 \mathrm{~g} \mathrm{KH}_{2} \mathrm{PO}_{4}, 4.5 \mathrm{~g} \mathrm{Na}_{2} \mathrm{SO}_{4}, 0.06$ $\mathrm{g} \mathrm{MgSO}_{4} \cdot 7 \mathrm{H}_{2} \mathrm{O}, 0.004 \mathrm{~g} \mathrm{FeSO}_{4} \cdot 7 \mathrm{H}_{2} \mathrm{O}, 0.3 \mathrm{~g}$ Sodium Citrate, $1.0 \mathrm{~g}$ Yeast Extract, and $6.0 \mathrm{~g}$ Sodium Lactate (Postgate, 1979). The enrichment bottle was sealed with a PTFE/silicon headspace septa and left in an anaerobic chamber for 11 days at room temperature and periodically monitored for cell growth by counting using using a haemocytometer and a Leica CTR fluorescent light microscope, and for hydrogen sulfide production using a $\mathrm{H}_{2} \mathrm{~S}-500$ Unisense microsensor which has a $\mathrm{HS}^{-}$detection limit of $<20 \mathrm{nM}$. Samples were removed for analysis with a sterile 23GTW needle on a $10 \mathrm{~mL}$ syringe. Cells were deemed metabolically active after seeing steady increases in both cell numbers (concentration of $\sim 7.0 \times 10^{7}-2.0 \times 10^{8}$ cells $\mathrm{mL}^{-1}$ ) and hydrogen sulfide production analogous to prior growth curve observations. Aliquots were then removed for addition to precipitation experiments.

\subsubsection{ZnS Precipitation Experiments}

The ZnS precipitation experiments consisted of 6 treatments, each performed in triplicate in separate $120 \mathrm{~mL}$ glass crimp-top bottles. Treatments for the precipitation experiments are summarized in Table 2.1, and included; "Abiotic control" containing $120 \mathrm{~mL}$ Postgate Medium C, "Abiotic Zn" containing $120 \mathrm{~mL}$ Postgate Medium C with $50 \mathrm{mg} \mathrm{L}^{-1} \mathrm{Zn}$, "Biotic Control" containing $115 \mathrm{~mL}$ Postgate Medium C with $5 \mathrm{~mL}$ of bacteria, "Biotic Zn" containing $115 \mathrm{~mL}$ Postgate Medium C, $50 \mathrm{mg} \mathrm{L}^{-1} \mathrm{Zn}$, with $5 \mathrm{~mL}$ of bacteria, "Biotic $\mathrm{ZnTl}_{1}$ " containing $115 \mathrm{~mL}$ Postgate Medium C, 50 $\mathrm{mg} \mathrm{L}^{-1} \mathrm{Zn}, 5 \mathrm{~mL}$ bacteria, and $1 \mathrm{mg} \mathrm{L}^{-1}$ Thallium, and "Biotic $\mathrm{ZnTl}_{25}$ " containing $115 \mathrm{~mL}$ Postgate 
Medium C, $50 \mathrm{mg} \mathrm{L}^{-1} \mathrm{Zn}, 5 \mathrm{~mL}$ bacteria, and $25 \mathrm{mg} \mathrm{L}^{-1}$ Thallium. Fresh Postgate Medium $\mathrm{C}$ was autoclaved, adjusted to $\mathrm{pH} 7.5$, and bubbled under Nitrogen gas before transfer to the crimp-top bottles. $5 \mathrm{~mL}$ bacterial aliquots were taken from the enrichment culture, and $\mathrm{Zn}$ was added as $\mathrm{ZnSO}_{4} \cdot 7 \mathrm{H}_{2} \mathrm{O}$. A concentration of $50 \mathrm{mg} \mathrm{L}^{-1}$ zinc was chosen as an approximate to ensure a high enough concentration for ZnS precipitation while being below a limit that would be lethal to the bacteria. Thallium was added as $\mathrm{Tl}_{2} \mathrm{SO}_{4}$ and concentrations of $1 \mathrm{mg} \mathrm{L}^{-1}$ and $25 \mathrm{mg} \mathrm{L}^{-1}$ were chosen as a low and high baseline, respectively. Bottles were sealed with PTFE/silicon headspace septum and stored in an anaerobic chamber. The experiment was carried out over 888 hours (37 days) with sampling points carried out from $0-480$ hours, then once at 888 hours. A larger proportion of sampling was weighted towards the first 96 hours of the experiment to characterize solution chemistry and gene expression through the exponential growth phase, where cellular metabolism was expected to be most pronounced.

\subsubsection{Analytical Methods}

At each sampling time point, analysis was performed for $\mathrm{pH}$, redox potential (Eh), hydrogen sulfide, sulfate, and cell counts, and samples were taken for total RNA extraction as well as for metals analysis by inductively coupled plasma-optical emission spectroscopy (ICP-OES). pH and Eh were measured using an Orion 3 Star Meter with a 9107BN Low Maintenance pH Triode and a 9179BNMD Low Maintenance ORP Triode, respectively (Thermo Scientific). $5 \mathrm{~mL}$ of liquid was removed from crimp-top bottles with a sterile 23GTW needle on a $10 \mathrm{~mL}$ syringe and transferred to a sterile test tube where measurements were performed immediately. Hydrogen sulfide was measured using the same removal procedure with a $\mathrm{H}_{2} \mathrm{~S}-500$ Unisense microsensor. Sulfate concentrations were measured using the Sulfate protocol for the Orion AQUAfast AQ4000 Colorimeter. $2 \mathrm{~mL}$ of sample was removed and filtered through a $0.2 \mu \mathrm{m}$ nylon membrane filter and acidified with $1 \% \mathrm{HNO}_{3}$ and stored for metal analysis by ICP-OES. Cell counts were performed 
as stated previously, but performed only on the Biotic Control, Biotic $\mathrm{Zn}$, and Biotic $\mathrm{ZnTl}_{25}$ treatments. All treatments were performed and measured in triplicate.

\subsubsection{RNA Extraction and Quantitative PCR}

A total of $5 \mathrm{~mL}$ of sample was removed at time $0,24,96,288,360$, and 888 hours and immediately flash frozen in liquid nitrogen in cryo tubes, and stored at $-80^{\circ} \mathrm{C}$ until nucleic acid extraction. RNA was extracted using the PowerSoil Total RNA Isolation Kit (MoBio Laboratories Inc. Carlsbad, CA, USA, Cat No:12866-25) following the manufacturer's instructions. After extraction, samples aliquots were quality control checked for concentration and purity on an Agilent 2100 Bioanalyzer, with samples showing good quality (RNA Concentration $>100 \mathrm{ng}^{-1} \mathrm{l}^{-1}$, RNA Integrity Number (RIN) >6.5) being chosen for further processing. RNA was converted to cDNA using a High Capacity cDNA Reverse Transcription Kit (Applied Biosystems) according to the manufacturer's instructions using $10 \mu \mathrm{L}$ of RNA sample. cDNA products were used in qPCR runs targeting the bacterial V5-V6 variable SSU rRNA region of the 16S rRNA gene, with forward primer V5F (5 -ACCTGCCTGCCGATTAGATACCCNGGTAG- 3$)$ and reverse primer V6R (5 ACGCCACCGAGCCGACAGAGCCATGCANCACCT- 3). Total reaction volumes consisted of $20 \mu \mathrm{L}$, containing $10 \mu \mathrm{L}$ POWER SYBR Green (Applied Biosystems), $0.5 \mu \mathrm{L}$ of each primer, $1.0 \mu \mathrm{L}$ of cDNA, and 8.0 $\mu \mathrm{L} \mathrm{dH2O}$. Cycle threshold $\left(\mathrm{C}_{\mathrm{t}}\right)$ values were used to compare the relative amounts of the target gene across samples. $C_{t}$ values represent the number of qPCR cycles until a signal is detected, thus a lower $C_{t}$ value represents higher initial concentrations of the target gene.

\subsubsection{Microscopy}

Samples for Scanning Electron Microscopy (SEM) were removed from precipitation experiments in the same manner as for solution chemistry analysis and placed on glass slides and allowed to air dry briefly. Material was examined using a FEI Quanta 200F ESEM under low vacuum 
at ranges of 5 to $17 \mathrm{kV}$ with an $\mathrm{EDAX}^{\circledR}$ SiLi detector. EDAX ${ }^{\circledR}$ soft- ware was used for collecting energy dispersive $x$-ray analyses. Raw, un-manipulated sludge samples were also analysed from the reduced layers of the MSB for comparison to experimental treatments. A portion of the raw material was analysed at the Canadian Centre for Electron Microscopy (CCEM) at McMaster University, Canada, using a Zeiss NVision 40 cross-beam instrument comprised of a Focused lon Beam (FIB) milling instrument and a Schottky Field Emission Gun (FEG) filament SEM.

\subsubsection{Statistical Analysis}

Solution chemistry parameters were subjected to statistical analysis across treatments when deemed appropriate. Single classification Model I ANOVA was performed to assess variability among treatments, resulting in an F-statistic and its associated degrees of freedom and p-value. P-values between 0.05 and 0.001 were considered significant, and values less than 0.001 were considered highly significant. Subsequent pairwise comparisons were performed using Tukey's method to assess differences between treatments, with the same assigned significance values as for ANOVAs.

\subsection{Results and Discussion}

\subsubsection{Cell Activity and Potential}

Bacterial community growth and activity were monitored using cell count comparisons in the Biotic Control, Biotic $\mathrm{Zn}$, and Biotic $\mathrm{ZnTl}_{25}$ treatments (Figure 2.1) as well as relative $\mathrm{C}_{\mathrm{t}}$ values of $16 \mathrm{~S}$ rRNA concentrations by quantitative real-time polymerase chain reaction (qPCR) based off the whole community RNA extraction in the respective Biotic Control and Biotic $\mathrm{Zn}$ treatments (Figure 2.2). Counts were only performed in the higher of the two TI-spiked treatments to observe the response due to a maximum stress scenario. During the experiments 16S rRNA analysis was only applied to the Biotic Control and Biotic Zn (to compare a control and metal-amended 
scenario) due to resource and time constraints. It is noted that $\mathrm{C}_{\mathrm{t}}$ values alone cannot provide quantitative measurements of the amount of the respective rRNA present, however in this case they are used for relative comparison between concentrations in parallel samples. $C_{t}$ values $<25$ indicate abundant nucleic acids while values $>25$ indicate minimal amounts, thus values are displayed in Figure 2.2 as their inverse (multiplied by a factor of -1 ) to show that lower values are indicative of higher concentrations of nucleic acid. The Biotic Control showed an increase from 0 to $1.84 \times 10^{7}$ cells $\mathrm{mL}^{-1}$ from 0 to 24 hours, coinciding with an increase in concentration of $16 \mathrm{~S}$ rRNA over the same period indicated by a $C_{t}$ value increase from -38.2 to -13.9 . This region likely corresponds with the transition of the dominant bacterial population from the lag phase to exponential growth phase, which occurs through 10 to 24 hours after inoculation based off previous growth curve observations. Cell division requires protein synthesis, and thus is reliant on ribosomes, and by association, the $16 \mathrm{~S}$ rRNA component of the ribosomal 30S, small subunit. Thus, 16S rRNA concentrations generally correlate positively with bacterial growth (Bremer et al., 2008). There are, however, documented exceptions where rRNA concentration do not always scale linearly with growth, such as within strains of the Synechococcus and Prochlorococcus, and species of Aphanizomenon, and Vibrio where in fact a negative correlation exists (Binder et al., 1998; Kerkhof et al., 1999; Sukenik et al., 2012). In the first 24 hours of the experiment, species that could exhibit this behaviour are either non-existent or overshadowed by bacterial guilds that do exhibit increased 16S rRNA with increase growth. A more detailed analysis of bacterial activity linked to taxonomy will be performed in Chapter 3 of this Thesis. rRNA concentrations began to decrease after 24 hours in the Biotic Control, likely aligning with the stationary phases of the majority of bacterial species present. Total accumulated cell numbers peaked at 96 hours at $1.54 \times 10^{8}$ cells $\mathrm{mL}^{-1}$, representing all cells, both active and inactive, followed by a steady decline 
in cells at the end of the experiment ( 888 hours), indicative of cell lysis. This time period corroborated a decline in 16S rRNA, linked to lessened cell activity.

In the Biotic Zn treatment, which was supplemented with $50 \mathrm{mg} \mathrm{L}^{-1}$ zinc, a similar trend to the Biotic Control was observed within the first 24 hours, with cell numbers and rRNA concentration increasing in tandem. However, cell counts numbered $1.04 \times 10^{7}$ cells mL ${ }^{-1}$ after 24 hours, approximately $77 \%$ less compared to the Biotic Control, inferring some form of heavy metal inhibition on the bacterial community. Heavy metals are known to have harmful effects on microorganisms, affecting both cell growth and diversity by replacing essential metals in binding sites and/or through interactions with ligands (Bååth et al., 1989; Bruins et al., 2000; Gans et al., 2005; Giller et al., 1998; Sterritt et al., 1980). Despite having relatively lower toxicity compared to other chalchophilic metals, aqueous $\mathrm{Zn}$ (present as the ion $\mathrm{Zn}^{2+}$ in solution) can inhibit electron transport and has shown to be toxic from a few mg L-1 up to $100 \mathrm{mg} \mathrm{L}^{-1}$ (Wolicka et al., 2015). The Biotic $\mathrm{ZnTl}_{25}$ treatment, amended with $50 \mathrm{mg} \mathrm{L}^{-1} \mathrm{Zn}$ and $25 \mathrm{mg} \mathrm{L}^{-1} \mathrm{Tl}$, exhibited even lower cell counts at 24 hours, at $7.38 \times 10^{6}$ cells $\mathrm{mL}^{-1}, 149 \%$ less counts than the Biotic Control, confirming toxicity effects of $\mathrm{Zn}$ and a possible synergistic effect in combination with TI. Despite less early cell counts, the Biotic Zn treatment showed similar rRNA measurements to the Biotic Control at 24 hours. This observation suggests that there may be a larger concentration of ribosomes per cell, and/or perhaps a higher rate of translation per cell in the bacterial community in the metalamended treatment, potentially a result of possible upregulated stress-response gene pathway activation (Schimel et al., 2007). Despite a high potential for protein synthesis as indicated by $16 \mathrm{~S}$ rRNA concentrations, the $\mathrm{Zn}$-amended treatment only reached a total cell count of $7.2 \times 10^{7}$ cells $\mathrm{mL}^{-1}$ after 96 hours, less than half of the cell count compared to the biotic control. However, cell counts appeared to rebound after 96 hours in the Biotic $\mathrm{Zn}$ treatment compared to the overall decrease that was observed in the Biotic Control for the same time period. Total rRNA 
concentrations were also maintained compared to the biotic control. It is hypothesized that this lag and then rebound in activity was due to $\mathrm{Zn}$ toxicity fixated primarily on the early bacterial community, where colonizing bacteria could have been obstructed by $\mathrm{Zn}$ intake into the cell and/or by adsorption to cell surfaces. Late generation cells (after 96 hours) benefited at the expense of earlier generations, the latter of which experienced increased mortality from $\mathrm{Zn}$ related toxicity mechanisms. Castillo et al., came to a similar conclusion from a mixed SRB enrichments in the presence of $\mathrm{Zn}$, although this was attributed more to the formation of biofilms as a defence mechanism (Castillo et al., 2012). The rebound of the community could have also resulted from the proliferation of more metal-resistant species throughout the first 96 hours. Bacterial enrichments were sourced from a passive bioreactor system treating acid mine drainage where influent water chemistry showed elevated concentrations of $\mathrm{Al}, \mathrm{Fe}, \mathrm{Zn}, \mathrm{Ni}$, and $\mathrm{Mn}$ and a flow rate of 1-6 L s$~^{-1}$ (DiLoreto et al., 2016a), thus, established microorganisms within the bioreactor were likely metal-tolerant, as is often exhibited in enrichments obtained from metalladen environments (Azabou et al., Bao et al., 2006; Castillo et al., 2012). In comparison, the Biotic $\mathrm{ZnTI}_{25}$ showed the least cell counts after 96 hours, yet mirrored near-identically the trend observed in the Biotic Zn treatment, again pointing to a synergistic effect of both Zn and TI on cell toxicity, while also inferring some level of metal-resistance and rebound within the community. Cell counts and rRNA levels did not increase after 300 hours in both the Biotic Control and the Biotic $\mathrm{Zn}$ treatment, signalling a slowdown in microbial growth and metabolism. The experiment was designed as a closed system and treatments were not supplemented with any additional carbon (sodium-lactate), nutrient, or metal sources after the initial dosage. This design was performed to resolve early community function in an environment similar to that of the sourced mussel shell bioreactor. Under field conditions, the mussel shell bioreactor at the Stockton mine would be continually recharged with various substrates from the breakdown of organics and 
chitinous material associated with mussel shell material, leading to constant or near-constant microbial activity until the substrates were exhausted. Thus, the eventual shut down of the microbial community in the batch experiments does not reflect the longevity of the bioreactor itself, but rather sheds light on the establishment of the metabolic and community structure. As has been agreed upon in other investigations, these results point to the importance of metalresistant characteristics of bacteria in the implementation of biotechnological processes. Metal efflux mechanisms in metal-tolerant bacteria allow these guilds to function in extreme environments, and these species may be better suited in technologies that breakdown organic contaminants, xenobiotics, or participate in heavy metal precipitation (Azabou et al., 2007; Nies et al., 2000; Rajbanshi et al., 2009). Despite metal concentrations shown to be otherwise toxic to bacteria, the community managed to maintain a degree of activity until the carbon substrate was seemingly exhausted.

\subsubsection{Solution Chemistry}

Bacterial-metal interactions are a vital factor in a successful passive treatment system, making it important to test and track the fate of metals in experimental settings that seek to simulate and optimize treatment technologies. In this research, the fate of the metals $\mathrm{Zn}$ and $\mathrm{Tl}$ were tested against a bacterial community enriched from the Stockton Coal Mine Mussel Shell Bioreactor. In addition, hydrogen sulfide and sulfate concentrations were measured throughout the duration of the experiment, as the activity of sulfate-utilizing microbes is important with respect to bacterially-induced metal-sulfide precipitation as a metal removal mechanism. Metal removal values from solution were calculated by Equation 2.5:

\footnotetext{
Metal Removed (\%) $=\frac{\mathrm{Mi}-\mathrm{Mt}}{\mathrm{Mi}} \times 100 \quad$ (Eq. 2.5)
} 
$M_{i}$ represents the initial metal concentration in solution where $M_{t}$ is the metal concentration at a specific time point during the experiment. Metal removal values are summarized in Table 2.2 and displayed over time in Figure 2.3. Outputs of statistical analyses can be found in Appendix A. There was a high significant difference in zinc removal among all treatments amended with $\mathrm{Zn}$ $\left(F_{3,7}=1108, \mathrm{p}<0.001\right)$ (Figure $\left.\mathrm{S} 1\right)$, attributed to differences between the control (no cells) and biotic treatments (with cells). All Zn-amended treatments with cells exhibited a decline in aqueous Zn concentration over the experiment (888 hours) that was significant compared to the control without cells. The Biotic $\mathrm{Zn}$ treatment showed a $\mathrm{Zn}$ removal of $52.2 \%$, from an initial concentration of $50.7 \mathrm{mg} \mathrm{L}^{-1}$ to $24.3 \mathrm{mg} \mathrm{L}^{-1}$, compared to $3.1 \%$ in the control $(\mathrm{p}<0.001)$. This was similar to $\mathrm{Zn}$ removal values observed in both the $1 \mathrm{mg} \mathrm{L}^{-1} \mathrm{Tl}$-spiked treatment (Biotic $\mathrm{ZnTl}_{1}$ ) and $25 \mathrm{mg} \mathrm{L}^{-1} \mathrm{TI}-$ spiked treatment (Biotic $\mathrm{ZnTl}_{25}$ ) at $53.1 \%$ and $50.3 \%$, respectively, over the entirety of the experiment. $\mathrm{TI}$ removal values for Biotic $\mathrm{ZnTl}_{1}$ and Biotic $\mathrm{ZnTl}_{25}$ were $38.9 \%$ and $38.8 \%$, respectively. Metal removal of both $\mathrm{Zn}$ and $\mathrm{Tl}$ in all metal-amended samples was the most pronounced in the first 24 hours. This precipitous drop coincided with the exponential growth phase of the community as exhibited from cell counts and rRNA concentrations. Bacterial cells are known to absorb aqueous metal cations due to the abundance of charged surface sites in combination with their high surface area to volume ratio (Beveridge et al., 1989). Teichioic, teichuronic, and lipoteichoic acids as well as negatively charged functional groups associated with cell wall peptidoglycan serve as primary metal binding sites on gram positive bacteria (Sherbet et al., 1978; Yee et al., 2001). Anionic functional groups include carboxyl, phosphate, and hydroxyl sites that participate in deprotonation reactions in circumneutral $\mathrm{pH}$ environments as indicated in Equations 2.6, 2.7, and 2.8, respectively, where "cell" represents a bacterial cell surface component (Fein et al., 1997).

Cell-COOH $\leftarrow \rightarrow$ R-COO ${ }^{-}+\mathrm{H}^{+} \quad$ (Eq. 2.6) 
Cell- $-\mathrm{PO}_{4} \mathrm{H} \leftarrow \rightarrow \mathrm{R}-\mathrm{PO}_{4}^{-}+\mathrm{H}^{+}$

Cell-OH $\leftarrow \rightarrow \mathrm{R}^{-} \mathrm{O}^{-}+\mathrm{H}^{+}$
(Eq. 2.7)

(Eq. 2.8)

During logarithmic growth phase of the bacterial community, the number of accessible binding sites for $\mathrm{Zn}$ and $\mathrm{Tl}$ would also grow exponentially with cell numbers. This is likely reflected in the sharp drop in metal concentrations in the first 24 hours. $\mathrm{pH}$ values did not decrease below 6 in the experiments, and thus substantial deprotonated adsorption sites were available. Similar electrostatic adsorption may occur in gram-negative bacteria on cell wall peptidoglycan, phospholipids, and lipopolysaccharide, as well as any extracellular polysaccharides (EPS) in both gram-negative and gram-positive species (Bhaskar et al., 2006; Decho et al., 1990; McLean et al., 1990). Adsorption serves as an important metal removal mechanism in combination with metalsulfide generation, however cell lysis may result in re-release of metals co-adsorbed to bacterial cells or biofilms, whereas sulfidic minerals may have higher stability under the same conditions due to their low solubility. After the sharp drawdown at 24 hours, metal concentrations continued to decrease gradually. As cell activity lessened in the latter stages of the experiment (beyond 300 hours), additional avenues of metal removal were likely present, such as immobilization of $\mathrm{Zn}$ during nucleation and precipitation of $\mathrm{Zn}$ sulfides due to the production of hydrogen sulfide by sulfate-reducing bacteria.

Sulfate/sulfide assays showed evidence of bacterial sulfate reduction in all biotic treatments. Sulfate removal was calculated in the same fashion as for metals (Equation 2.5), with sulfur chemistry summarized in Table 2.3 and displayed in Figure 2.4. There was a significant difference in sulfate concentration change among all 6 treatments $\left(F_{5,12}=8.746, \mathrm{p}<0.01\right)$ (Figure S2), likely driven by the differences between biotic and abiotic treatments. The Biotic Control exhibited $10.5 \%$ sulfate removal, significantly higher $(p<0.05)$ than both abiotic controls $(1.3 \%$ 
for the Abiotic Control, 1.7\% for the Abiotic Zn), with sulfate concentration decreasing by $412 \mathrm{mg}$ $\mathrm{L}^{-1}$ through the experiment from an initial measurement of $3859 \mathrm{mg} \mathrm{L}^{-1}$. A sulfur removal rate of $116 \pm 42.6 \mathrm{nmol} \mathrm{mL}^{-1}$ day $^{-1}$ was calculated for the duration of the experiment, with removal being most pronounced from 24 to 360 hours. Biotic Zn, BioticZnTl ${ }_{1}$, and Biotic $\mathrm{ZnTl}_{25}$ treatments showed similar sulfate removal values to the Biotic Control, at $13.8 \%, 7.3 \%$, and $11.6 \%$, respectively, with sulfate removal rates of $148.1 \pm 23.3,81.1 \pm 36.3$, and $121.9 \pm 20.1 \mathrm{nmol} \mathrm{mL}^{-1}$ day $^{-1}$. These values were deemed statistically no different than the Biotic Control, thus sulfate removal was relatively constant across all treatments with bacteria, regardless of metal content. These sulfate removal percentages were low compared to similar studies using pure or mixed cultures of sulfatereducing bacteria (SRB), where in some cases $75-100 \%$ sulfate removal was achieved (Castillo et al., 2012; Hiibel et al., 2011). The bacterial inoculum in this study did not consist of purely SRB species, but members of multiple taxa, and thus complete sulfate removal was not expected. More energetically favourable metabolic pathways would dominate during early succession. For example, the metabolizing of lactate by fermentative bacteria will result in accelerated acetate production, which may not rely on dissimilatory sulfate reduction (Equation 2.9).

Lactate $^{-}+2 \mathrm{H}_{2} \mathrm{O} \rightarrow$ Acetate $^{-}+\mathrm{HCO}_{3}^{-}+\mathrm{H}^{+}+2 \mathrm{H}_{2}$

Despite this constraint on sulfur reduction, sulfate removal rates were within ranges typically measured for passive treatment technologies, specifically, which are often comprised of multiple bacterial groups (DiLoreto et al., 2016a). However, an additional consideration with mixed bacterial enrichments is that total sulfate removal may not be translated directly into hydrogen sulfide production, i.e., the sulfate removal rate cannot be quantified as the sulfur reduction rate. This is because there may be other biotic mechanisms responsible for sulfate removal. This was proposed in this experiment, where mass balance calculations showed an overwhelming large sulfate removal compared to measured hydrogen sulfide production. Sulfur transformation from 
sulfate to sulfide is considered a 1:1 stoichiometric conversion, thus in control treatments where no metals are present to react with sulfide species, the moles of sulfate reacted is expected to equal the moles of sulfide produced (Edwards et al., 1992). Focusing on the Biotic Control, where no $\mathrm{Zn}$ was present to react with any sulfide generated, the final measured soluble sulfide concentration was $17.5 \mu \mathrm{mol} \mathrm{L}-1$ (peaking at $36.3 \mu \mathrm{mol} \mathrm{L}^{-1}$ ) resulting in a generation rate of 0.5 $\mathrm{nmol} \mathrm{mL} \mathrm{L}^{-1} \mathrm{day}^{-1}$, while over the same period the sulfate removal rate was calculated at $116 \pm 42.6$ $\mathrm{nmol} \mathrm{mL} \mathrm{L}^{-1}$ day ${ }^{-1}$. Thus, sulfide conversion accounted for only $0.43 \%$ of sulfate removal. It is likely that a portion of soluble sulfide volatized and was lost during sampling periods as observed in similar experimental scenarios (Gonçalves et al., 2007; Jong et al., 2003; Nagpal et al., 2000). However, this would not account for the entire mass balance discrepancy observed. Metatranscriptomic analysis of total mRNA detected metabolic pathways responsible for the reduction of sulfate to adenosine-phosphosulphate (APS) in the first 96 hours of the experiment, primarily by the potential activation of sulfate adenyltransferase (SAT). This enzyme is key in the preliminary activation of sulfate in both the dissimilatory and assimilatory sulfate reduction pathways in prokaryotes (Figure 2.5). Downstream genes in the assimilatory sulfate reduction pathway were also detected that function to incorporate sulfur into amino acids. However, genes involved in the eventual conversion of sulfite to sulfide in the dissimilatory route were not detected during the same time frame. This observation shows that despite the activation of genes in the microbial community that could activate sulfate, the expression of downstream genes for hydrogen sulfide production and liberation from cells was not detected during early experimental time points. This would explain the inconsistency in sulfur mass balance calculations in the biotic control. High sulfate concentrations were likely only upregulating sulfate adenyltransferases, driving the consumption of sulfate, however the complete reduction of sulfur to sulfide species was not occurring, at least not in the first 96 hours (Peck et al., 1961). It is likely that this 
phenomenon occurred in Zn-amended treatments as well, due to a similar observed discrepancy in sulfate/sulfide chemistry.

Soluble sulfide concentrations were very low compared to the corresponding sulfate removal rates in the Biotic $\mathrm{Zn}$, Biotic $\mathrm{ZnTl}_{1}$, and Biotic $\mathrm{ZnTl}_{25}$ treatments, with sulfide concentrations peaking at $11.2,14.8$, and $15.6 \mu \mathrm{mol} \mathrm{L}^{-1}$, respectively. Dissolved hydrogen sulfide concentrations from these metal-amended treatments varied slightly between $\mathrm{Zn}$ and $\mathrm{Tl}$ treatments but were overall significantly lower than the Biotic Control (all $p<0.001$ ) (Figure S4). As sulfur-removal percentages were similar across the Biotic Control and metal treatments (between 7-14\%), lessened measured $\mathrm{H}_{2} \mathrm{~S}$ in the Biotic $\mathrm{Zn}$, Biotic $\mathrm{ZnTl}_{1}$, and Biotic $\mathrm{ZnTl}_{25}$ batches was likely due to a separate removal pathway for sulfide, as opposed to lessened sulfate utilization by bacterial activity. This is also confirmed from consistent 16S rRNA values in the Biotic Control vs Biotic Zn treatment reported previously. Metal-sulfide precipitation was predicted to be a pathway for hydrogen sulfide removal in the Zn-dosed batches. ZnS generation is a 1:1 stoichiometric ratio between $\mathrm{Zn}$ and $\mathrm{S}$, thus the difference in sulfide concentrations between treatments with and without zinc (Biotic Control Vs. Biotic $\mathrm{Zn}$, Biotic $\mathrm{ZnTl}_{1}$, Biotic $\mathrm{ZnTl}_{25}$ ) is equated to the amount to have reacted with aqueous $\mathrm{Zn}$ (Table 2.4). It is calculated that in the Biotic $\mathrm{Zn}$, Biotic $\mathrm{ZnTl}_{1}$, and Biotic $\mathrm{ZnTl}_{25}$ treatments, $14.2,13.7$, and $14.2 \mu \mathrm{mol} \mathrm{L}^{-1}$ of sulfide reacted with $\mathrm{Zn}$, respectively, and vice versa. This equates to $1.11 \times 10^{-4}, 1.07 \times 10^{-4}$, and $1.11 \times 10^{-4} \mathrm{~g}$ of $\mathrm{Zn}$ to have been removed via $\mathrm{ZnS}$ precipitation in the Biotic $\mathrm{Zn}$, Biotic $\mathrm{ZnTl}_{1}$, and Biotic $\mathrm{ZnTl}_{25}$ treatments, respectively. This equals $1.83 \%, 1.75 \%$, and $1.87 \%$ of the initial $\mathrm{Zn}$ load, and $3.5 \%, 3.3 \%$, and $3.7 \%$ of the total $\mathrm{Zn}$ that was removed, respectively. The remaining missing balance of $\mathrm{Zn}$ is considered to have been removed via adsorption mechanisms on cells as stated previously. Despite the decrease in cell counts experienced in the Biotic $\mathrm{ZnTI}_{25}$ treatment, there appeared to be no effect on $\mathrm{H}_{2} \mathrm{~S}$ production. Both maximum and final hydrogen sulfide concentrations were deemed not 
significantly different across the Biotic $\mathrm{Zn}$, Biotic $\mathrm{ZnTl}_{1}$, and Biotic $\mathrm{ZnTI}_{25}$ treatments (Figure S3, S4). This is evidence that sulfate-reducing bacteria were likely not members of the groups that were affected by treatments with Thallium. Taxonomy was not analysed in the TI-spiked treatments, so this cannot be confirmed by omic techniques, however SRB species were identified in the Biotic Control and Biotic Zn treatments that showed similar sulfide generation to Tl-amended batches, and it likely that sulfide generation in these batches was also a result of SRB metabolism. Proliferation of SRB through metal toxicity was theorized to be caused by either inherent metal resistance, sacrifice of earlier generations of cells, or a combination of both. The observation that sulfide generation did not peak until late in the experiment gives weight to the early sacrifice theory, though metal-resistance mechanisms cannot be ruled out. Thallium removal over time was likely due to a blend of adsorption and possible incorporation into $\mathrm{ZnS}$ as a trace element (Cook et al., 2009).

\subsubsection{Scanning Electron Microscopy and Solid Phase Investigations}

Samples were removed from all treatments for visualization by scanning electron microscopy (SEM) to confirm potential biogenic ZnS precipitation as an additional removal pathway for aqueous Zn. Micron-scale, metallic, rounded grains were identified after 450 hours in all treatments amended with Zn, but not the Biotic Control. Precipitates exhibited a size range of 2-5 microns, were often isolated from each other, and were in some cases in association with bacterial cells (Figure 2.6 A-D). Energy dispersive spectroscopy (EDS) analysis confirmed that the aggregates were composed of zinc and sulfur (wt\% range of 0.71:1 to 0.99:1 for Z and S) (Figure

2.6 E). Peaks for oxygen, sodium, phosphorus, and potassium were also detected in analysis of spherical grains but were attributed to high concentrations of these elements within salts in the liquid medium used. This is supported by the detection of these elements in areas of samples where no spherical precipitates were present, indicating a high background concentration. The 
possibility that the metal precipitates visualized were abiotically formed Hopeite $\left(\mathrm{Zn}_{3}\left(\mathrm{PO}_{4}\right)_{2}\right.$. $4 \mathrm{H}_{2} \mathrm{O}$ ) was ruled out, since no precipitates were observed in either the Abiotic $\mathrm{Zn}$ treatment or the Biotic Control without Zn (Wolicka et al., 2015). The mineralization occurred in tandem with sulfate removal and hydrogen sulfide production, thus there is confidence that the precipitates represent a ZnS mineral phases formed as a result of bacterial sulfate reduction within the treatments. The presence of zinc sulfide minerals explains lower final hydrogen sulfide concentrations in Zn-spiked treatments over controls, despite a similar sulfate removal rate, as sulfide was likely scavenged by reaction with aqueous $\mathrm{Zn}$. ZnS aggregates were identified between 3-7 days after the lowest recorded redox potential, indicating that sulfate-reducing species were influencing the chemical environment. Eh measurements were in the range of $-150 \mathrm{mV}$ to -330 $\mathrm{mV}$ and coincide with peak hydrogen sulfide generation just prior to the formation of the $\mathrm{ZnS}$ aggregates across treatments. This observation supports other research with similar redox conditions noted in biogenic ZnS investigations (Castillo et al., 2012, Gonçalves et al., 2007; Radhika et al., 2006). As stated previously, no ZnS phases were observed in the Abiotic Control that was amended with Zn but with no addition of cells, thus it is unlikely that any metal-sulfide generation can be attributed to abiotic factors. Abiotic, thermochemical sulfate reduction is proposed by some authors to occur only at temperatures above $100^{\circ} \mathrm{C}$ (Machel et al., 1995 ; Machel, 2001) or within a range of $175^{\circ} \mathrm{C}$ to $225^{\circ} \mathrm{C}$ (Goldhaber et al., 1995) whereas bacterial driven reduction dominates at low temperatures (Druschel et al., 2002). Therefore, any metalsulfide generation in this experiment is attributed to enzymatic action of bacteria. ZnS spherical grains, though present, were scarce in numbers in contrast to observations from comparable studies. This observation aligns with the low production of hydrogen sulfide measured in all bacterial treatments, credited to the relatively low influence of sulfate reducers within the community as a whole. Other species likely dominated during early experimental time points (0- 
96 hours), with SRB thriving afterward, possibly utilizing the degradation products of the early community. These bacterial interactions will be investigated further in Chapter 3.

For comparison, raw material was collected from the reduced layer of the Mussel Shell Bioreactor treating the Whirlwind Seep and analyzed under SEM to compare any ZnS in the treatment setting to that within these lab experiments. ZnS precipitates have previously been identified in a similar Mussel Shell Bioreactor prototype at the Stockton mine in operation from June 2009 to March 2012 (Crombie et al., 2011; DiLoreto et al., 2016b). SEM characterization and Focus lon beam (FIB) milling of samples was performed at the Canadian Centre for Electron Microscopy (CCEM), McMaster University. Clusters of ZnS aggregates were analysed by EDS in the raw material and were present in higher abundances than lab experiments (Figure 2.7). Natural precipitates exhibit a similar size range to their lab-generated counterparts (1-5 $\mu \mathrm{m})$, however smaller grains $(<1 \mu \mathrm{m})$ were also present (Figure 2.7B). Precipitates formed in concentrated, grape-like clusters (i.e. botryoidal habit), made up of many aggregated grains. Minerals appeared to form with and around organics and other constituents, material derived from the ground mussel shells and associated mussel shell meat. This association, also observed by Moreau et al. in the analysis of biofilms from an abandoned flooded $\mathrm{Pb}-\mathrm{Zn}$ mine, and Yoon et al., from $\mathrm{Zn}$ enriched peatlands, infers that organics, biofilms, and extracellular polymeric substances (EPS) serve to some extent as nucleation sites in these settings (Moreau et al., 2004; Yoon et al., 2012). The presence of organics in these environments have shown to lower interfacial free energy and thus promote crystal nucleation on the nanoscale, serving as stabilizing ligands and aiding in alignment and attachment (Cho et al., 2005; De Yoreo et al., 2015; Dey et al., 2010). It is suggested in this work that the availability of these growth templates in the bioreactor at the Stockton mine was a factor in promoting grander ZnS nucleation, as these constituents were absent in lab experiments, where lessened mineralization was observed. Other attributes of the bioreactor 
could include a higher and more diverse group of SRB and a more reducing microenvironment, where easily degradable carbon sources were more readily and frequently available. Higher Zn concentrations are also a possibility, as the Whirlwind Seep serving as the source for the MSB in question was characterized by a $\mathrm{Zn}$ concentration of $0.26 \mathrm{mg} \mathrm{L}^{-1}( \pm 0.05)$ and an influent flow rate and residence time of 1-6 $\mathrm{L} \mathrm{s}^{-1}$ and 0.37-2.2 days (dependent on seasonality), respectively, enough to saturate the bioreactor with high levels of metals. Furthermore, targeted extractions identified $\mathrm{Zn}$ as being highly associated with reducible phases at the depth of the bioreactor analyzed (DiLoreto et al., 2016a; DiLoreto et al., 2016b). Surprisingly, few cells were observed associated with $\mathrm{ZnS}$ phases in the raw bioreactor material, a stark contrast to observations in other work (Moreau et al., 2004). The material was analyzed by microscopy several months after extraction, which could have contributed to cell death and lysis over time, however it is more likely that organics and shell material serve a more important role in nucleation than cell surfaces in this scenario. In this case, cells may have also avoided encrustation/inhibition by ZnS minerals, as observed in other research, allowing for continual intake of sulfate into the cell and resulting sulfide production, contributing to nucleation events (Utgikar et al., 2002). Thus, cells may not have served as direct scaffolds for mineralization. This distinction in mineral formation in association with organisms is discussed in detail by Dupraz and colleagues, where direct mineralization, such as in the external and internal skeletons of calcifying mollusks or algae, is defined as "biologically-controlled mineralization", and indirect mineralization termed as "biologically-induced" or "biologically-influenced" mineralization (Dupraz et al., 2009). ZnS generation in the presence of SRB may cross boundaries between the latter two mechanisms, as ZnS mineralization is not always biotic, but at low temperature settings is considered to dominate, and considered to play a major role in sulfide ore deposits (Bastin et al., 1926; Druschel et al., 2002; Spirakis \& Heyl., 1995). 
To resolve the potential for organics to represent core nucleation centres for $\mathrm{ZnS}$, a Focused lon Beam (FIB) milling device comprised of a Zeiss NVision 40 cross-beam instrument and a Schottky Field Emission Gun (FEG) filament SEM was used to cut and analyse a cross-section of a ZnS outcrop from the raw bioreactor material. Figure 2.8 shows a before and after image of the cut-away section as well as magnified images. Multiple individual minerals were visualized in cross section, and it is shown that $\mathrm{ZnS}$ spherical grains are solid throughout, with the exception of minor porous regions represented by darker spots. EDS analysis revealed that minerals are composed of nearly pure $\mathrm{Zn}$ and S. Various sized precipitates are agglomerated together, potentially representing multiple individual yet local nucleation events. Smaller sized particles $(0.5-1 \mu \mathrm{m})$ were more frequently associated together than larger particles $(2-5 \mu \mathrm{m})$. Excision of a section of the ZnS blooms was attempted using a high vacuum sputter coater, freeze fracturing/etching device, that would allow for further processing for analysis by Transmission Electron Microscopy (TEM). However, material proved too delicate and could not be manipulated successfully, thus nano-structure information could not be gained for this Thesis.

In a summary report in Science, Labrenz and colleagues applied selected area electron diffraction (SAED) patterns to determine that biogenic ZnS in biofilms from a flooded mine were composed of randomly oriented, yet finely crystalline sphalerite (Labrenz et al., 2000). Research by Peltier et al., found similar results through X-ray absorption Spectroscopy (XAS), where a sphalerite-type ZnS phases was determined for precipitates formed by the action of Desulfovibrio spp., a common sulfate-reducing bacterium. These minerals proved to be more impervious to reoxidation than chemically-synthesized counterparts, credited to greater short-range crystal order (Peltier et al., 2011). Based on these findings, a sphalerite-like bulk mineral phase is probable in both the lab and field analyzed samples in this work. This is further backed by the system parameters, where low temperature and pressure favour bulk sphalerite (Zhang et al., 2003). 
However, research has shown that at the nano-scale, the ZnS polymorphs wurtzite and sphalerite both exist, with Moreau et al., identifying crystal patterns of both within ZnS biofilms, represented by disordered stacking sequences, stacking faults, and lattice fringes (Moreau et al., 2004). Nanoparticles of both mineral phases were also identified by Castillo and colleagues (Castillo et al., 2012). These results point to precipitation events where nanoparticles and aggregates, ranging from 3-20 nm, combine to ultimately form micron-scale ZnS grains, a mechanism termed crystallization by particle attachment (CPA), as opposed to traditional atom-by-atom or monomer-by-monomer crystallization (De Yoreo et al., 2015). Although nano-structure observations are beyond the realm of this thesis work, knowledge from these cited reports can lend insight into particle nucleation and coarsening within the mussel shell bioreactor, as well as provide data on re-oxidation and/or stability of metal-immobilizing sulfide mineral phases.

From parallel research on biogenic ZnS structure, a nucleation scenario is proposed for the nucleation of sulfides in the lab-generated and bioreactor-derived samples. It is theorized from the observations in this thesis in conjunction with other work that ZnS nucleation in lab experiments was dominated by traditional monomer-by-monomer synthesis in lab experiments, primarily through Ostwald ripening, where large individual particles have coarsened at the expense of smaller particles. This would explain the presence of relatively larger (2-5 $\mu \mathrm{m})$, singular precipitates and the absence of smaller ones (0.5-1 $\mu \mathrm{m})$; a consequence of the system evolving towards a state of lower overall energy. In contrast, bioreactor-derived ZnS precipitates exhibit a wider size range, and these variable-sized moieties coexist within the organic matrix. These minerals are theorized to be influenced by crystallization by particle attachment, where larger nanocrystals and aggregates combine to form the largest visualized precipitates, with available organics serving as initial nucleation sites for growth of nanoparticles before moieties coarsened together into micron-scale spheres. The SEM micrographs of various sized ZnS particles in the raw 
bioreactor material could be the result of multiple stages of this process occurring simultaneously. This nucleation hypothesis could be tested by characterization of the nano-structure of both sets of precipitates, where greater crystallinity revealed by greater short range order may be revealed in lab samples over raw bioreactor samples, but this is allocated to future work.

\subsubsection{Conclusions}

In this data chapter, the following null hypotheses were to be tested:

1) Changes in sulfate, sulfide, and metal concentrations will not be significantly different between abiotic and biotic treatments.

2) Bacterial activity will not be significantly different between treatments amended with metals and non-amended treatments.

3) Any zinc sulfide mineral precipitation in batch experiments will be similar in quantity, structure, and composition to minerals observed in raw bioreactor material.

The bacterial community enriched from the passive treatment Mussel Shell bioreactor consisted of species capable of sulfate reduction, as evidence from comparison with control treatments. Sulfate removal, hydrogen sulfide production, and $\mathrm{Zn}$ removal was significantly different in bacterial treatments compared to abiotic counterparts, thus the $1^{\text {st }}$ null hypothesis may be rejected, and it can be said that SRB were components of the community, and that bacteria were able to significantly reduce metal loads compared to controls. However, hydrogen sulfide generation and subsequent $\mathrm{ZnS}$ production in experimental treatments was much lower than anticipated, thus these species contributed to only a minor portion of the community, and were active only after more dominant bacterial guilds were metabolically satisfied, evidence of which will be presented in Chapter 3. A decrease in zinc concentration was observed in all biotic treatments, and this was attributed majorly to adsorption events on bacterial cells by mass 
balance calculations, but also to a lesser extent by reaction with $\mathrm{H}_{2} \mathrm{~S}$ and subsequent ZnS mineral nucleation and coarsening, confirmed visually by scanning electron microscopy. Decreases in TI concentrations was potentially due to trace metal incorporation into sulfides, however future analytic work is required to confirm this. Although metal-amended experimental treatments yielded lower cell counts, sulfate reduction rates were unaffected, thus SRB specifically did not appear to be inhibited, rather earlier members of the bacterial community succumbed to the detrimental effects of Zn and/or TI. Thus, the $2^{\text {nd }}$ hypothesis was somewhat satisfied in that some bacteria were affected, while others were not. This hypothesis could be revised in future work to test metal toxicity on specific genera of bacteria. Abundant ZnS mineralization was confirmed in raw bioreactor material, thus species responsible for influencing nucleation within the employed treatment system were successfully enriched in lab experiments. However, the mechanisms of nucleation may have varied based on the availability and/or absence of organics as templates for mineralization. ZnS varied considerably in size and frequency between experimental treatments and raw material, thus the $3^{\text {rd }}$ null hypothesis is rejected, and it is confirmed that the varying environments within batches and raw material had a great influence on the nucleation outcome of ZnS phases. 
Table 2.1: Zinc ( $\mathrm{Zn})$ and Thallium ( $\mathrm{Tl})$ concentrations used in experimental treatments. Treatments were performed in Postgate Medium C. Total volumes were $120 \mathrm{~mL}$. Biotic treatments were amended with $5 \mathrm{~mL}$ of bacterial-enriched media.

\begin{tabular}{lccc} 
Treatment & Zn $\left(\mathbf{m g ~ L}^{-1}\right)$ & Tl $\left(\mathbf{m g ~ L}^{-1}\right)$ & Cells (+ present, - absent) \\
\hline Abiotic Control & 0 & 0 & - \\
Abiotic Zn & 50 & 0 & - \\
Biotic Control & 0 & 0 & + \\
Biotic Zn & 50 & 0 & + \\
Biotic ZnTI & 50 & 1 & + \\
Biotic ZnTI & & 25 & + \\
\hline
\end{tabular}


Table 2.2: $\mathrm{Zn}$ and TI Solution chemistry values for all 6 treatments. Values are calculated based off

triplicate analysis. Abiotic and Biotic Controls were not amended with metals.

\begin{tabular}{|c|c|c|c|c|c|c|c|c|c|c|}
\hline Treatment & $\begin{array}{l}\text { Zn int. } \\
\left(\mathrm{mg} \mathrm{t}^{-1}\right)\end{array}$ & $\begin{array}{c}\text { Zn final. } \\
\left(\mathrm{mg} \mathrm{L}^{-1}\right)\end{array}$ & $\begin{array}{l}\text { Zn diff } \\
\left(\mathrm{mg} \mathrm{L}^{-1}\right)\end{array}$ & $\begin{array}{c}\text { Zn diff } \\
(\mathrm{g})\end{array}$ & $\begin{array}{c}\% \mathrm{Zn} \\
\text { Removal }\end{array}$ & $\begin{array}{c}\text { Zn Removal } \\
\text { Rate (nmol mL } \\
\begin{array}{c}\text { day } \\
\text { da })\end{array}\end{array}$ & $\begin{array}{l}\text { Tl int. } \\
\left(\mathrm{mg} \mathrm{t}^{-1}\right)\end{array}$ & $\begin{array}{c}\mathrm{Tl} \\
\text { final } \\
\left(\mathrm{mg} \mathrm{L}^{-1}\right)\end{array}$ & $\begin{array}{l}\text { TI diff } \\
\left(\mathrm{mg} \mathrm{L}^{-1}\right)\end{array}$ & $\begin{array}{c}\% \mathrm{TI} \\
\text { Removal } \\
\end{array}$ \\
\hline Abiotic & - & - & - & & - & & - & - & - & - \\
\hline Abiotic Zn & 49.9 & 48.4 & -1.5 & 0.00018 & $3.1 \%$ & $0.63 \pm 0.02$ & - & - & - & - \\
\hline Biotic Control & - & - & - & & - & & - & - & - & - \\
\hline Biotic Zn & 50.7 & 24.3 & -26.5 & 0.00318 & $52.2 \%$ & $10.9 \pm 0.16$ & - & - & - & - \\
\hline Biotic $\mathrm{ZnTl}_{1}$ & 51.2 & 24.0 & -27.2 & 0.00326 & $53.1 \%$ & $11.2 \pm 0.45$ & 1 & 0.6 & -0.39 & $38.9 \%$ \\
\hline Biotic $\mathrm{ZnTl}_{25}$ & 49.5 & 24.6 & -24.9 & 0.00299 & $50.3 \%$ & $10.3 \pm 0.15$ & 25 & 15.3 & -9.70 & $38.8 \%$ \\
\hline
\end{tabular}

Table 2.3: Initial and final Sulfate $\left(\mathrm{SO}_{4}^{-2}\right)$ and Hydrogen Sulfide $\left(\mathrm{H}_{2} \mathrm{~S}\right)$ concentrations for all 6 treatments with calculated rates of removal and generation. Values are calculated based off triplicate analysis. $\mathrm{H}_{2} \mathrm{~S}$ generation rates are calculated over 888 hours (1) and to peak sulfide production (2).

\begin{tabular}{|c|c|c|c|c|c|c|c|c|c|}
\hline Treatment & $\begin{array}{l}\mathrm{SO}_{4} \\
\text { int. } \\
\text { max } \\
\left(\mathrm{mg} \mathrm{t}^{-1}\right)\end{array}$ & $\begin{array}{l}\mathrm{SO}_{4} \\
\text { final } \\
\left(\mathrm{mg} \mathrm{L}^{-1}\right)\end{array}$ & $\begin{array}{l}\mathrm{SO}_{4} \\
\text { diff. } \\
\text { (mg t-1) }\end{array}$ & $\begin{array}{l}\% \mathrm{SO}_{4} \\
\text { removal }\end{array}$ & $\begin{array}{l}\mathrm{SO}_{4} \text { removal } \\
\text { rate } \\
\left(\mathrm{nmol} \mathrm{mL}^{-1} \mathrm{day}^{-1}\right)\end{array}$ & $\begin{array}{l}\mathrm{H}_{2} \mathrm{~S} \\
\max . \\
(\mu \mathrm{M})\end{array}$ & $\begin{array}{r}\mathrm{H}_{2} \mathrm{~S} \\
\text { final. } \\
(\mu \mathrm{M})\end{array}$ & $\begin{array}{l}\mathrm{H}_{2} \mathrm{~S} \text { generation } \\
\text { rate }^{1} \\
\left(\mathrm{nmol} \mathrm{mL}^{-1} \mathrm{day}^{-1}\right)\end{array}$ & $\begin{array}{l}\mathrm{H}_{2} \mathrm{~S} \text { generation } \\
\mathrm{rate}^{2} \\
\left(\mathrm{nmol} \mathrm{mL}^{-1} \text { day }^{-1}\right)\end{array}$ \\
\hline Abiotic & 3794 & 3743.3 & -50.7 & $1.3 \%$ & $32.6 \pm 10.4$ & 3.5 & 1.7 & 0.05 & 0.35 \\
\hline Abiotic Zn & 3874.5 & 3807.6 & -66.9 & $1.7 \%$ & $18.8 \pm 15.2$ & 1.6 & 1.6 & 0.04 & 0.04 \\
\hline Biotic Control & 3859.8 & 3447.5 & -412.3 & $10.5 \%$ & $116.0 \pm 42.6$ & 36.3 & 17.5 & 0.50 & 2.42 \\
\hline Biotic Zn & 3810.1 & 3283.7 & -526.4 & $13.8 \%$ & $148.1 \pm 23.3$ & 11.2 & 3.3 & 0.09 & 1.12 \\
\hline Biotic $\mathrm{ZnTl}_{1}$ & 3910.2 & 3621.8 & -288.4 & $7.3 \%$ & $81.1 \pm 36.3$ & 14.8 & 3.8 & 0.10 & 0.99 \\
\hline Biotic $\mathrm{ZnTl}_{25}$ & 3707.2 & 3273.9 & -433.3 & $11.6 \%$ & $121.9 \pm 20.1$ & 16.3 & 3.3 & 0.09 & 1.09 \\
\hline
\end{tabular}


Table 2.4: Mass balance estimations of $\mathrm{Zn}$ removed from $\mathrm{Zn}$-amended treatments by reaction with hydrogen sulfide $\left(\mathrm{H}_{2} \mathrm{~S}\right)$, forming insoluble $\mathrm{ZnS}$.

\begin{tabular}{|c|c|c|c|c|c|}
\hline A & B & C & D & $\mathbf{E}$ & $\mathbf{F}$ \\
\hline Treatment & $\begin{array}{l}{\left[\mathrm{H}_{2} \mathrm{~S}\right]} \\
\text { Biotic } \\
\text { Control } \\
(\mu \mathrm{M})\end{array}$ & $\begin{array}{l}{\left[\mathrm{H}_{2} \mathrm{~S}\right]} \\
\text { Treatment } \\
(\mu \mathrm{M})\end{array}$ & $\begin{array}{l}{\left[\mathrm{H}_{2} \mathrm{~S}\right] \operatorname{diff}(\mu \mathrm{M})} \\
(\mathrm{B}-\mathrm{C})\end{array}$ & $\mathrm{H}_{2} \mathrm{~S}$ diff (mol) & $\begin{array}{l}\mathrm{Zn} \text { removed by } \mathrm{ZnS} \text { (g) } \\
\text { (1:1 ratio with } \mathrm{H}_{2} S \text { diff) }\end{array}$ \\
\hline Biotic Zn & 17.5 & 3.3 & 14.2 & $1.70 \mathrm{E}-06$ & 1.11E-04 \\
\hline Biotic $\mathrm{Tl}_{1}$ & 17.5 & 3.8 & 13.7 & $1.64 \mathrm{E}-06$ & 1.07E-04 \\
\hline Biotic $\mathrm{ZnTI}_{25}$ & 17.5 & 3.3 & 14.2 & $1.70 \mathrm{E}-06$ & 1.11E-04 \\
\hline \multirow[t]{2}{*}{$\mathbf{G}$} & $\mathbf{H}$ & $\mathbf{I}$ & $\mathrm{J}$ & $K$ & $\mathbf{L}$ \\
\hline & $\begin{array}{l}{[\mathrm{Zn}] \text { initial }} \\
\left(\mathrm{mg} \mathrm{L}^{-1}\right)\end{array}$ & Zn initial (g) & $\begin{array}{l}\mathrm{Zn} \text { initial - } \mathrm{Zn} \\
\text { removed by } \mathrm{ZnS}(\mathrm{g}) \\
(\mathrm{I}-\mathrm{F})\end{array}$ & $\begin{array}{l}\% \text { of } \mathrm{Zn} \text { int. } \\
\text { removed by } \mathrm{ZnS}\end{array}$ & $\begin{array}{l}\% \text { of } \mathrm{Zn} \text { diff removed by } \\
\mathrm{ZnS}\end{array}$ \\
\hline Biotic Zn & 50.7 & 0.00609 & 0.00598 & $1.83 \%$ & $3.5 \%$ \\
\hline Biotic $\mathrm{Tl}_{1}$ & 51.2 & 0.00614 & 0.00603 & $1.75 \%$ & $3.28 \%$ \\
\hline Biotic $\mathrm{ZnTI}_{25}$ & 49.5 & 0.00594 & 0.00583 & $1.87 \%$ & $3.71 \%$ \\
\hline
\end{tabular}




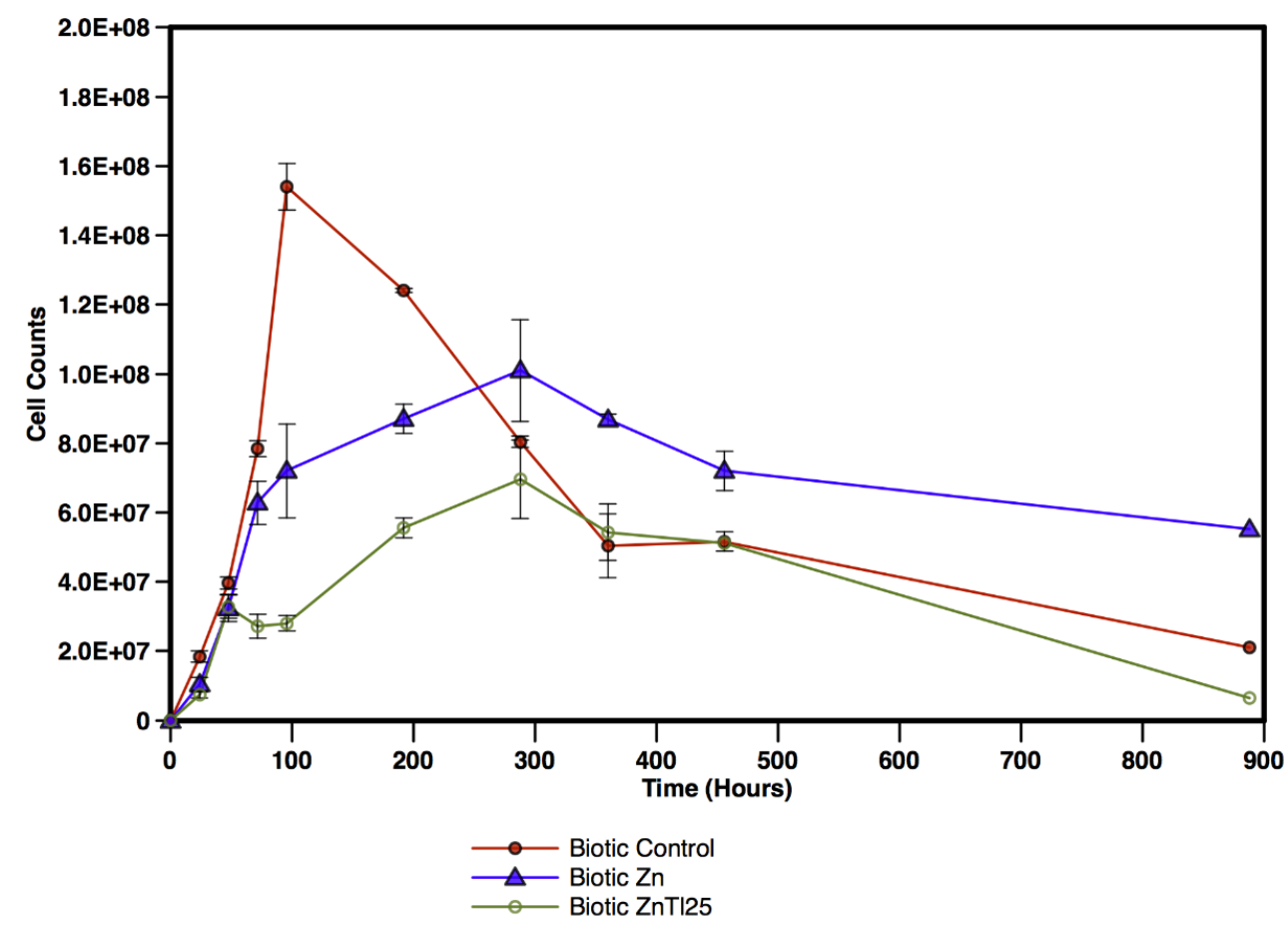

Figure 2.1: Cell counts over time for the Biotic Control (red circles), Biotic Zn (blue triangles) and Biotic $\mathrm{ZnTl}_{25}$ (open green circles) treatments. Values are averages of triplicate counts.

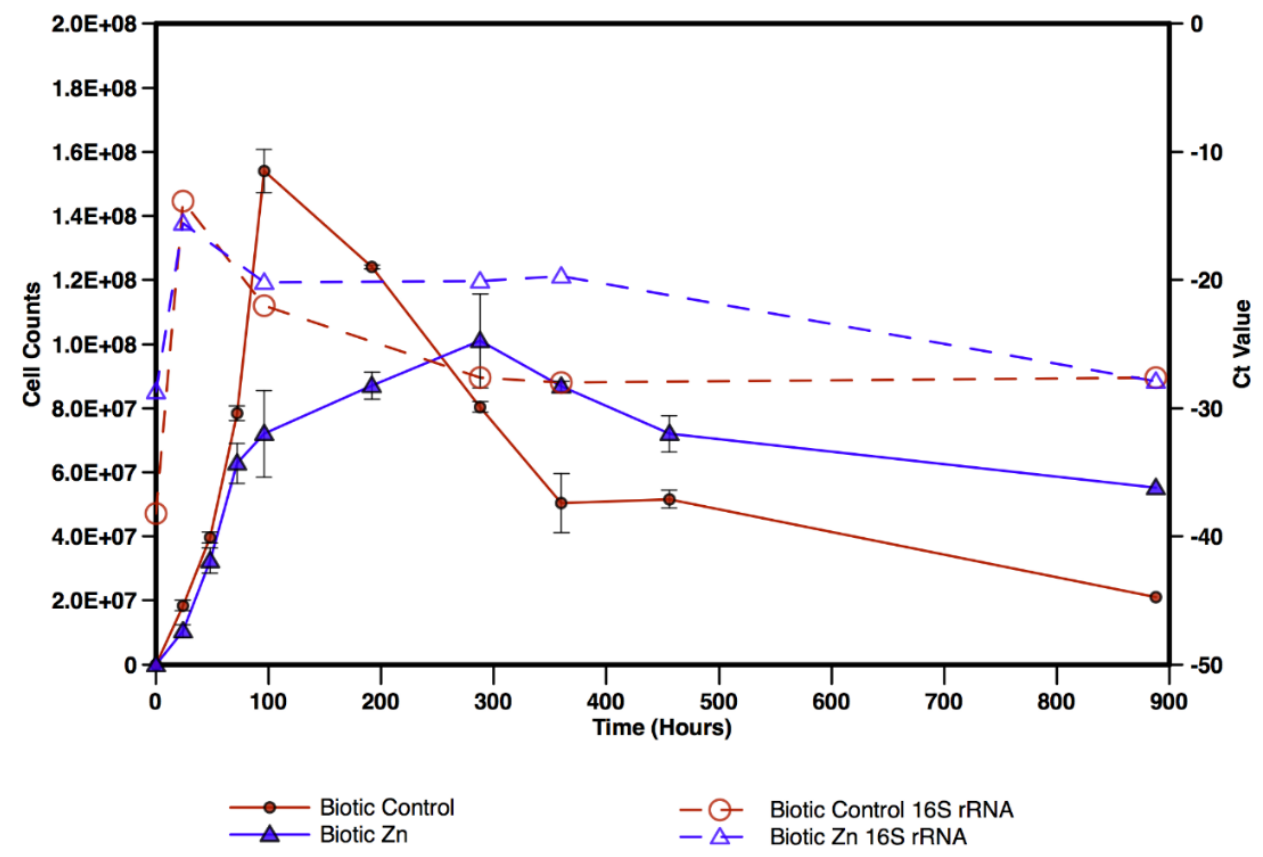

Figure 2.2: Cell counts over time for the Biotic Control (red circles) and Biotic Zn (blue triangles) against corresponding inverted $\mathrm{Ct}$ values from qPCR. 

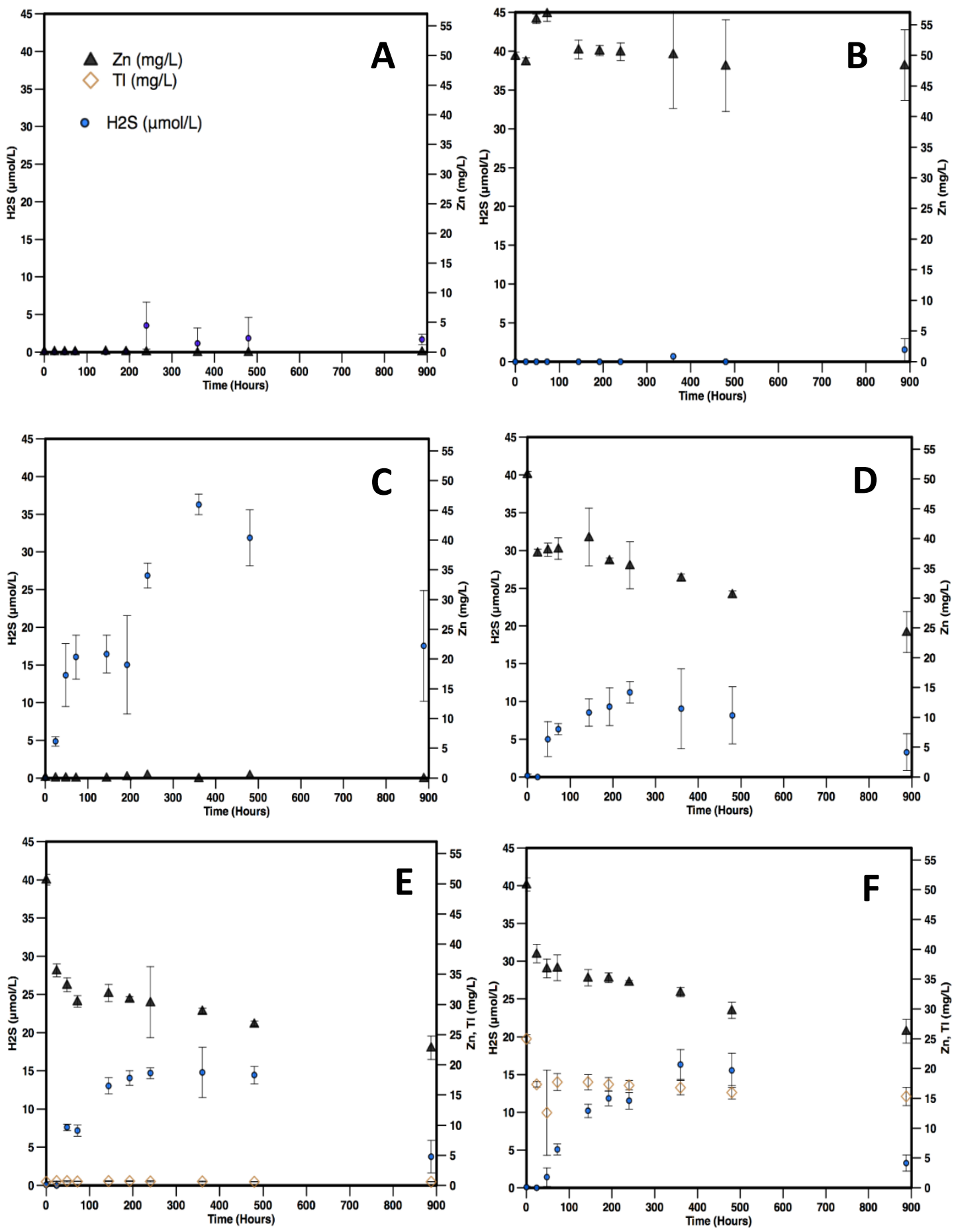

Figure 2.3: Hydrogen Sulfide $\left(\mathrm{H}_{2} \mathrm{~S}\right)$ and metal concentrations ( $\mathrm{Zn}$ and/or $\left.\mathrm{TI}\right)$ over time. A) Abiotic Control B) Abiotic Zn C) Biotic Control D) Biotic Zn E) Biotic $\mathrm{ZnTl}_{1}$ F) Biotic $\mathrm{ZnTl}_{25}$. Values are calculated based off triplicate analysis. 

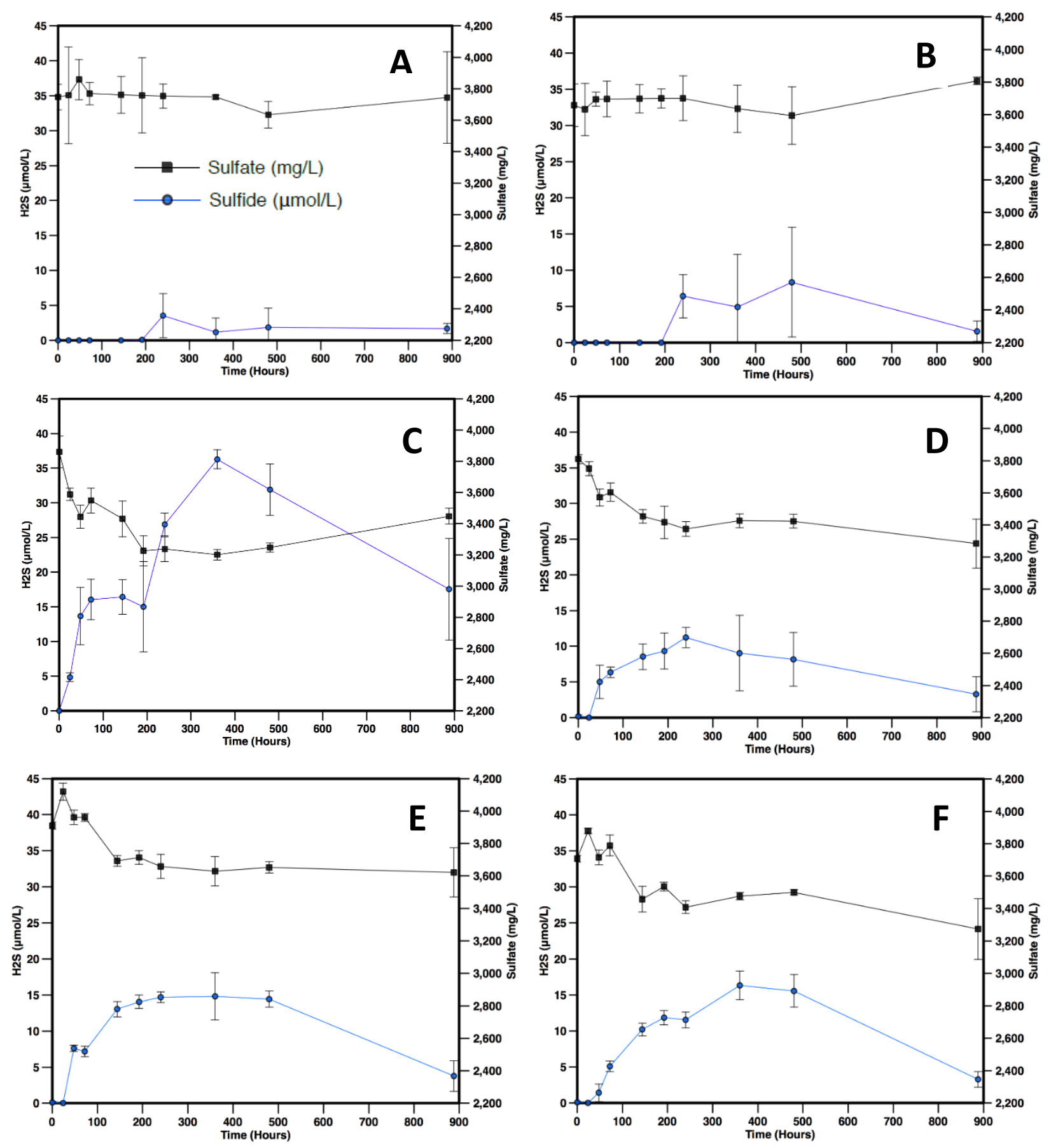

Figure 2.4: Hydrogen Sulfide $\left(\mathrm{H}_{2} \mathrm{~S}\right)$ and Sulfate $\left(\mathrm{SO}_{4}^{-2}\right)$ concentrations over time. A) Abiotic Control B) Abiotic Zn C) Biotic Control D) Biotic Zn E) Biotic $\mathrm{ZnTl}_{1}$ F) Biotic $\mathrm{ZnTl}_{25}$. Values are calculated based off triplicate analysis. 


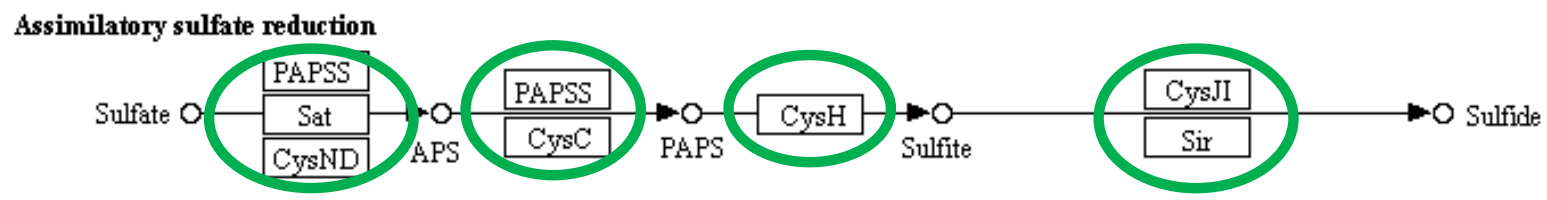

Dissimilatory sulfate reduction and oxidation

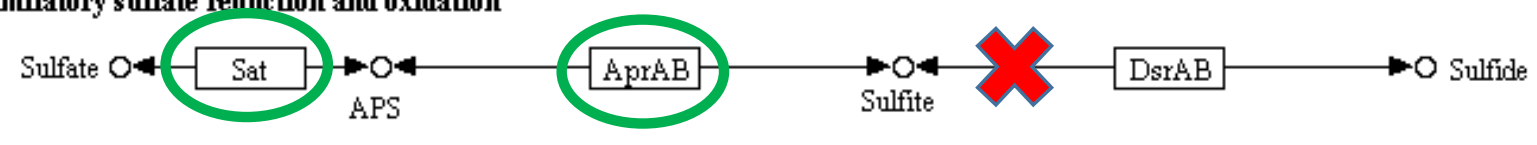

Sat (met3) - sulfate adenylyltransferase (E.C. 2.7.7.4)

PAPSS (cysNC) - 3'-phosphoadenosine 5'-phosphosulfate synthase (E.C. 2.7.7.4 2.7.1.25)

CysND/CysC - associated enzymes of E.C. 2.7.7.4 2.7.1.25

CysH - phosphoadenosine phosphosulfate reductase (phosphoadenyly-sulfate reductase E.C. 1.8.4.8)

CysJ - assimilatory sulfite reductase (NADPH) (E.C. 1.8.1.2)

Sir - assimilatory sulfite reductase (ferredoxin) (E.C. 1.8.7.1)

AprAB - adenylyl-sulfate reductase (E.C. 1.8.99.2)

DsrAB - dissimilatory sulfite reductase (E.C. 1.8.99.5)

Figure 2.5: Enzyme and enzyme groups detected by metatranscriptomics analysis in two primary prokaryotic sulfate activating pathways. Green circles indicate enzyme and enzyme groups detected through mRNA. Enzymes to the right of the red " $X$ " were not detected. Enzyme names and enzyme commission numbers (E.C.) are displayed. 

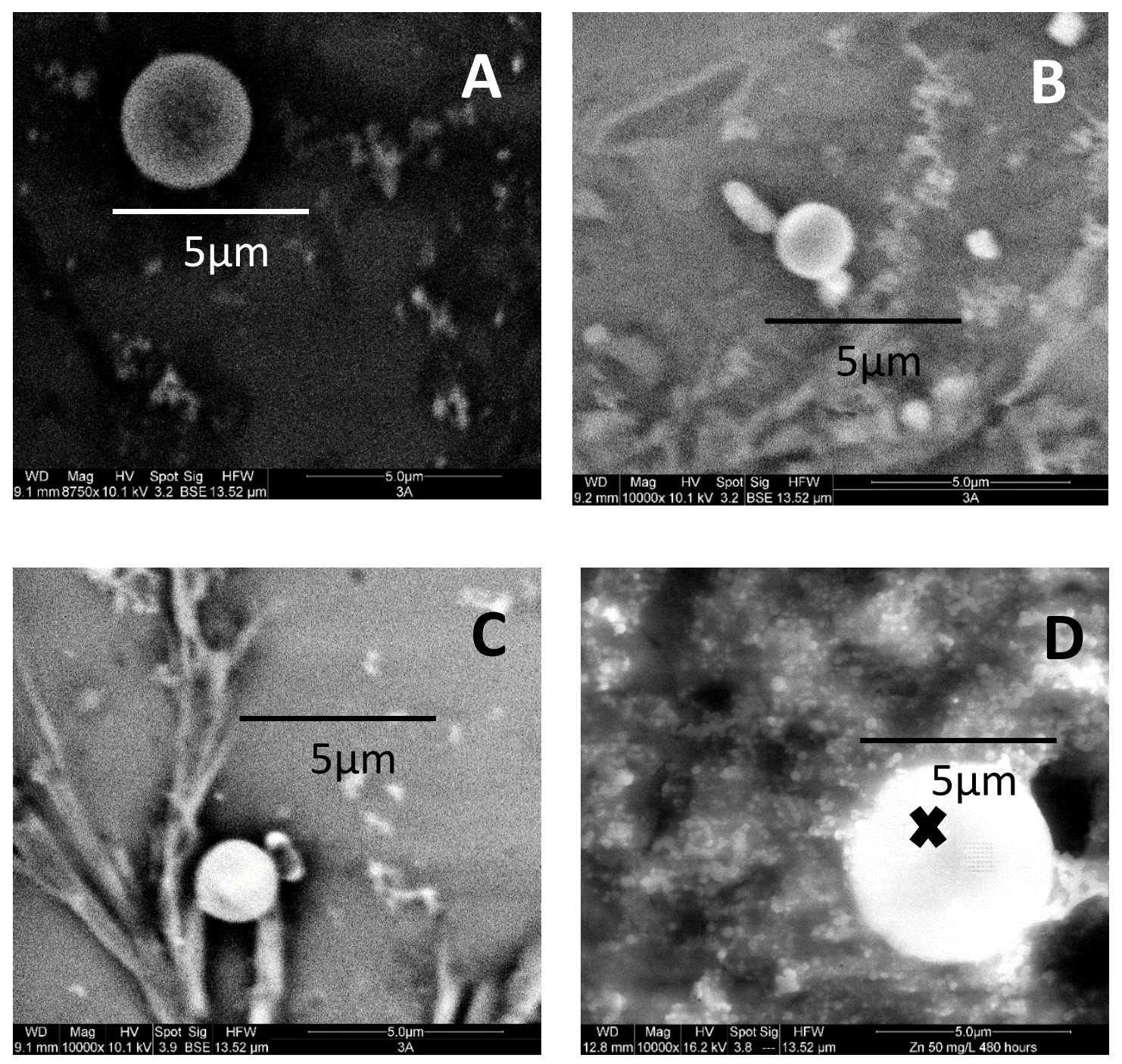

EDS Spot 1

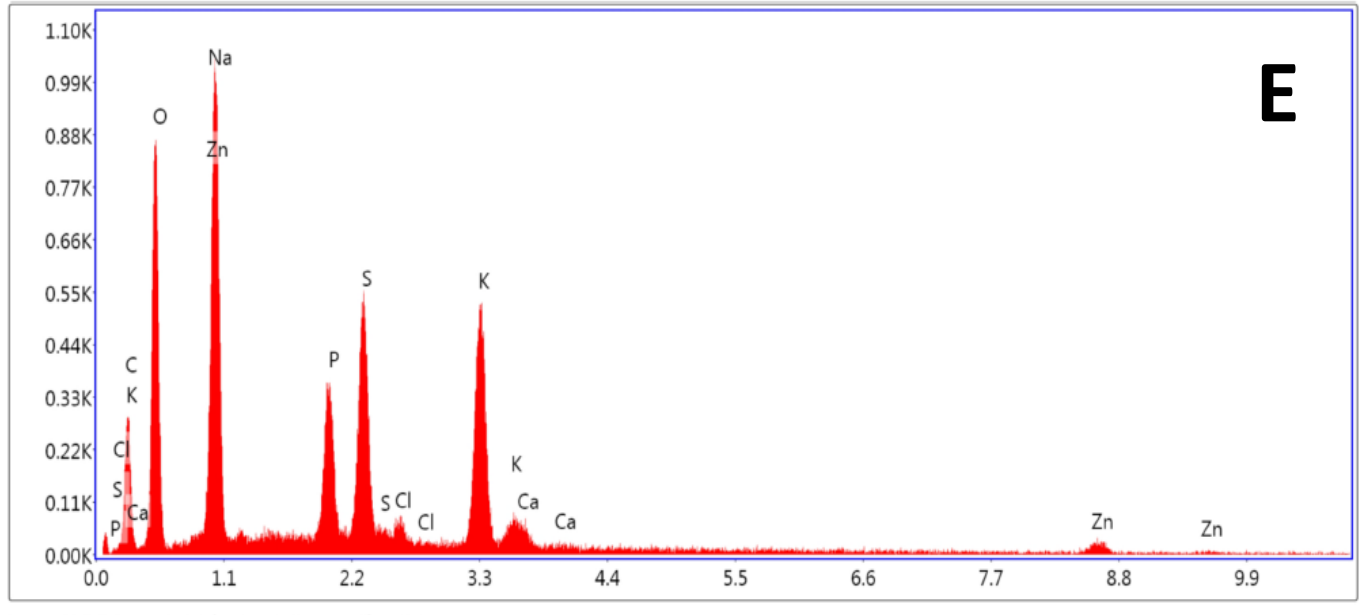

Lsec: 30.00 Cnts $0.000 \mathrm{keV}$ Det: Octane Plus Det

Figure 2.6: A, B, C, D) SEM images of ZnS precipitates at time 450 hours. E) EDS spectrum of the spot marked by the " $X$ " in image " $D$ ". 


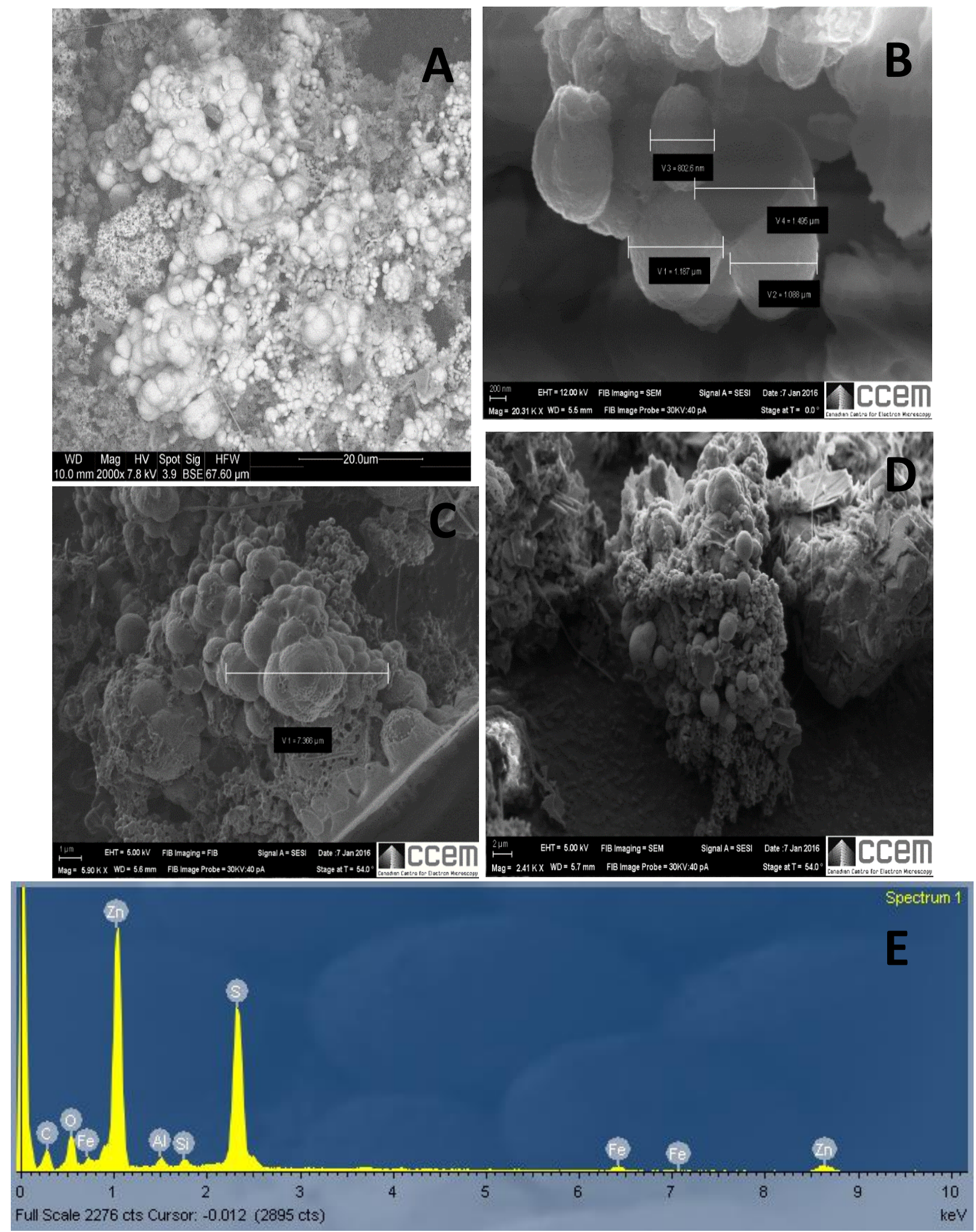

Figure 2.7: SEM images of raw Mussel Shell Bioreactor material taken from the Whirlwind reactor at the Stockton Coal Mine, New Zealand. A) Bright spheres represent outcrops of a ZnS mineral phases. B) Spheres on the smaller size range, from $0.8 \mu \mathrm{m}$ to $1.5 \mu \mathrm{m}$. C, D) Variable-sized spherical aggregations associated with organic material. E) EDS spectrum from a region within image " $C$ " showing minerals are composed primarily of zinc and sulfur. 


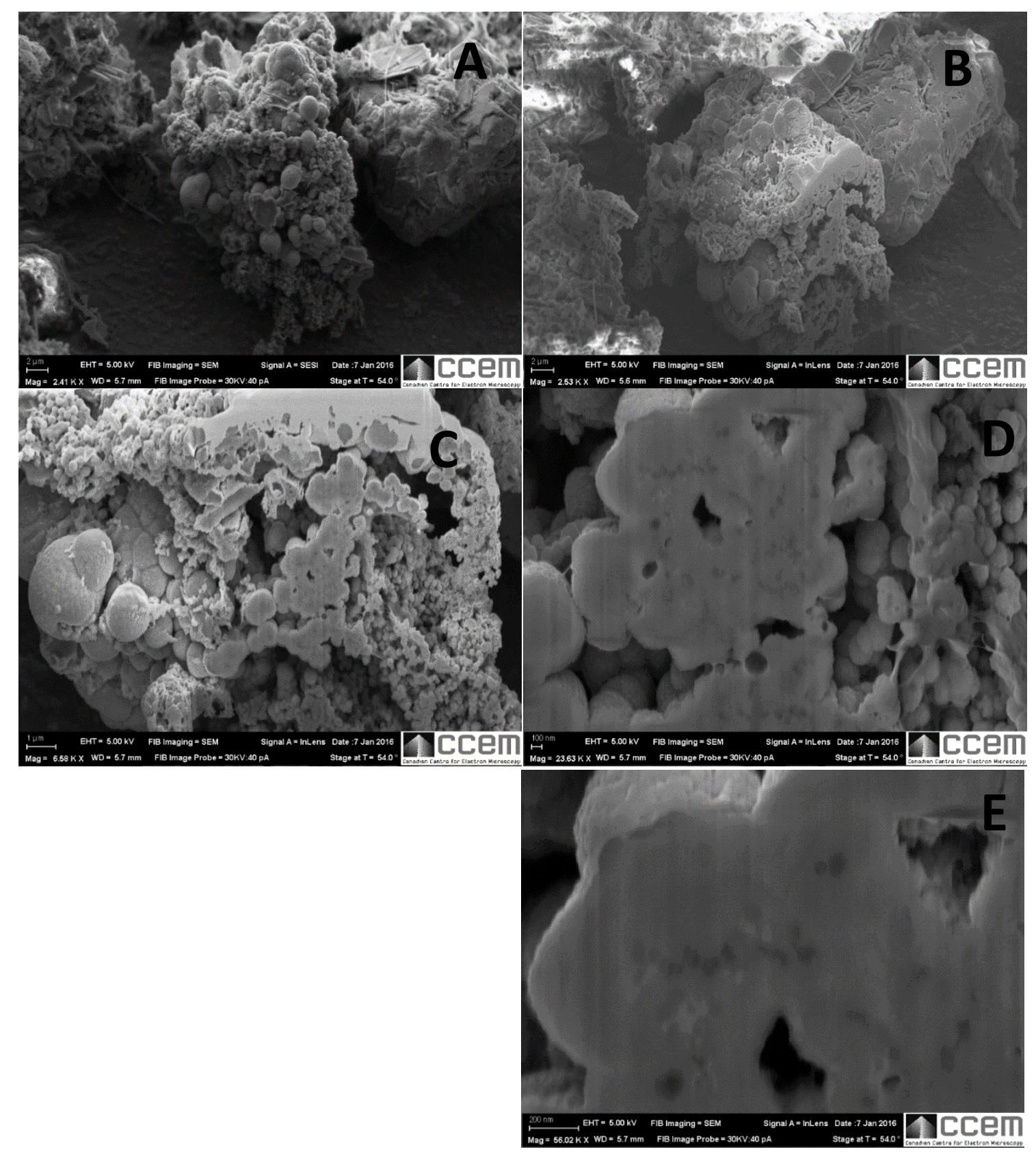

Figure 2.8: SEM images of FIB-exposed ZnS. A) A region before cross sectioning with a Focussed lon Beam (FIB) B) The region in A after sectioning. C, D, E) Magnified images of the cross section face showing interiors of ZnS precipitates. Thicker bright coatings near the top of image " $\mathrm{C}$ " represent Tungsten sputtered onto the sample for structural integrity prior to milling. 


\subsection{References}

Akcil A. and Koldas S. (2006) Acid Mine Drainage (AMD): causes, treatment and case studies. J. Clean. Prod. 14, 1139-1145

Amos R. T., Blowes D. W., Bailey B. L., Sego D. C., Smith L. and Ritchie A. I. M. (2015) Waste-rock hydrogeology and geochemistry. Appl. Geochemistry 57, 140-156.

Azabou S., Mechichi T. and Sayadi S. (2007) Zinc precipitation by heavy-metal tolerant sulfatereducing bacteria enriched on phosphogypsum as a sulfate source. Miner. Eng. 20, 173-178.

Bååth, E. (1989) Effects of heavy metals in soil on microbial processes and populations (a review). Water, Air, and Soil Pollution, 47(3-4), 335-379.

Bao, Z., Sato, Y., Kubota, M., \& Ohta, H. (2006) Isolation and characterization of thalliumtolerant bacteria from heavy metal-polluted river sediment and non-polluted soils. Microbes and Environments, 21(4), 251-260.

Bastin, E. S. (1926) A hypothesis of bacterial influence in the genesis of certain sulphide ores. The Journal of Geology, 773-792.

Beveridge, T. J. (1989) Role of cellular design in bacterial metal accumulation and mineralization. Annual Reviews in Microbiology, 43(1), 147-171.

Bhaskar, P. V., \& Bhosle, N. B. (2006) Bacterial extracellular polymeric substance (EPS): a carrier of heavy metals in the marine food-chain. Environment International, 32(2), 191-198.

Binder, B. J., \& Liu, Y. C. (1998) Growth Rate Regulation of rRNA Content of a Marine Synechococcus (Cyanobacterium) Strain. Applied and environmental microbiology, 64(9), 33463351.

Blowes, D. W., Ptacek, C. J., Benner, S. G., McRae, C. W., Bennett, T. A., \& Puls, R. W. (2000) Treatment of inorganic contaminants using permeable reactive barriers. Journal of Contaminant Hydrology, 45(1), 123-137.

Bremer, H., \& Dennis, P. P. (2008) Modulation of chemical composition and other parameters of the cell at different exponential growth rates. EcoSal Plus, 3(1).

Bruins, M. R., Kapil, S., \& Oehme, F. W. (2000) Microbial resistance to metals in the environment. Ecotoxicology and environmental safety, 45(3), 198-207.

Burns, A. S., Pugh, C. W., Segid, Y. T., Behum, P. T., Lefticariu, L., \& Bender, K. S. (2012) Performance and microbial community dynamics of a sulfate-reducing bioreactor treating coal generated acid mine drainage. Biodegradation, 23(3), 415-429.

Castillo J., Pérez-López R., Caraballo M. A., Nieto J. M., Martins M., Costa M. C., Olías M., Cerón J. C. and Tucoulou R. (2012) Biologically-induced precipitation of sphalerite-wurtzite nanoparticles 
by sulfate-reducing bacteria: Implications for acid mine drainage treatment. Sci. Total Environ. 423, 176-184.

Cho, K. S., Talapin, D. V., Gaschler, W., \& Murray, C. B. (2005) Designing PbSe nanowires and nanorings through oriented attachment of nanoparticles. Journal of the American Chemical Society, 127(19), 7140-7147.

Christensen, B., Laake, M., \& Lien, T. (1996) Treatment of acid mine water by sulfate-reducing bacteria; results from a bench scale experiment. Water Research, 30(7), 1617-1624.

Cook N. J., Ciobanu C. L., Pring A., Skinner W., Shimizu M., Danyushevsky L., Saini-Eidukat B. and Melcher F. (2009) Trace and minor elements in sphalerite: A LA-ICPMS study. Geochim.

Cosmochim. Acta 73, 4761-4791.

Crombie, F.M.,Weber, P.A., Lindsay, P., Thomas, D.G., Rutter, G.A., Shi, P., Rossiter, P., Pizey, M.H., (2011) Passive treatment of acid mine drainage using waste mussel shell, Stockton Coal Mine, New Zealand. Proceedings of the Seventh Australian Workshop on Acid and Metalliferous Drainage, Darwin, Northern Territory, pp. 393-405

da Silveira, A. N., Silva, R., \& Rubio, J. (2009) Treatment of acid mine drainage (AMD) in South Brazil: comparative active processes and water reuse. International Journal of Mineral Processing, 93(2), 103-109.

Decho, A. W. (1990) Microbial exopolymer secretions in ocean environments: their role (s) in food webs and marine processes. Oceanogr. Mar. Biol. Annu. Rev, 28(7), 73-153.

De Yoreo J. J., Gilbert P. U. P. A., Sommerdijk N. A. J. M., Penn R. L., Whitelam S., Joester D., Zhang H., Rimer J. D., Navrotsky A., Banfield J. F., Wallace A. F., Michel F. M., Meldrum F. C., Colfen H. and Dove P. M. (2015) Crystallization by particle attachment in synthetic, biogenic, and geologic environments. Science (80-. ). 349

Dey, A., Bomans, P. H., Müller, F. A., Will, J., Frederik, P. M., de With, G., \& Sommerdijk, N. A. (2010) The role of prenucleation clusters in surface-induced calcium phosphate crystallization. Nature materials, 9(12), 1010-1014.

DiLoreto Z. A., Weber P. A., Olds W., Pope J., Trumm D., Chaganti S. R., Heath D. D. and Weisener C. G. (2016a) Novel cost effective full scale mussel shell bioreactors for metal removal and acid neutralization. J. Environ. Manage.

DiLoreto Z. A., Weber P. A. and Weisener C. G. (2016b) Solid phase characterization and metal deportment in a mussel shell bioreactor for the treatment of AMD, Stockton Coal Mine, New Zealand. Appl. Geochemistry 67, 133-143.

Druschel G. K., Labrenz M., Thomsen-Ebert T., Fowle D. a. and Banfield J. F. (2002) Geochemical modeling of ZnS in biofilms: An example of ore depositional processes. Econ. Geol. 97, 13191329. 
Dupraz C., Reid R. P., Braissant O., Decho A. W., Norman R. S. and Visscher P. T. (2009) Processes of carbonate precipitation in modern microbial mats. Earth-Science Rev. 96, 141-162.

Edwards E. a., Wills L. E., Reinhard M. and Grbic-Galic D. (1992) Anaerobic degradation of toluene and xylene by aquifer microorganisms under sulfate-reducing conditions. Appl. Environ. Microbiol. 58, 794-800.

Eger, P. (1994). Wetland treatment for trace metal removal from mine drainage: the importance of aerobic and anaerobic processes. Water Science and Technology, 29(4), 249-256.

Fein, J. B., Daughney, C. J., Yee, N., \& Davis, T. A. (1997) A chemical equilibrium model for metal adsorption onto bacterial surfaces. Geochimica et Cosmochimica Acta, 61(16), 3319-3328.

Foucher S., Battaglia-Brunet F., Ignatiadis I. and Morin D. (2001) Treatment by sulfate-reducing bacteria of Chessy acid-mine drainage and metals recovery. Chem. Eng. Sci. 56, 1639-1645.

Gans, J., Wolinsky, M., \& Dunbar, J. (2005) Computational improvements reveal great bacterial diversity and high metal toxicity in soil. Science, 309(5739), 1387-1390.

Giller, K. E., Witter, E., \& Mcgrath, S. P. (1998) Toxicity of heavy metals to microorganisms and microbial processes in agricultural soils: a review. Soil Biology and Biochemistry, 30(10), 13891414.

Goldhaber, M. B., \& Orr, W. L. (1995) Kinetic controls on thermochemical sulfate reduction as a source of sedimentary H2S. In ACS symposium series (Vol. 612, No. 6, pp. 412-425). Washington, DC: American Chemical Society,[1974]-.

Gonçalves M. M. M., da Costa A. C. A., Leite S. G. F. and Sant'Anna G. L. (2007) Heavy metal removal from synthetic wastewaters in an anaerobic bioreactor using stillage from ethanol distilleries as a carbon source. Chemosphere 69, 1815-1820.

Hedin, R. S., Nairn, R. W., \& Kleinmann, R. L. (1994) Passive treatment of coal mine drainage (Vol. 9389). US Dept. of the Interior, Bureau of Mines.

Hiibel S. R., Pereyra L. P., Breazeal M. V. R., Reisman D. J., Reardon K. F. and Pruden A. (2011) Effect of Organic Substrate on the Microbial Community Structure in Pilot-Scale SulfateReducing Biochemical Reactors Treating Mine Drainage. Environ. Eng. Sci. 28, 563-572.

Huisman J. L., Schouten G. and Schultz C. (2006) Biologically produced sulphide for purification of process streams, effluent treatment and recovery of metals in the metal and mining industry. Hydrometallurgy 83, 106-113.

Jamieson H. E., Walker S. R. and Parsons M. B. (2015) Mineralogical characterization of mine waste. Appl. Geochemistry 57, 85-105.

Johnson D. B. and Hallberg K. B. (2005) Acid mine drainage remediation options: a review. Sci. Total Environ. 338, 3-14. 
Jong T. and Parry D. L. (2003) Removal of sulfate and heavy metals by sulfate reducing bacteria in short-term bench scale upflow anaerobic packed bed reactor runs. Water Res. 37, 3379-3389.

Kerkhof, L., \& Kemp, P. (1999) Small ribosomal RNA content in marine Proteobacteria during non-steady-state growth. FEMS microbiology ecology, 30(3), 253-260.

Labrenz M. (2000) Formation of Sphalerite (ZnS) Deposits in Natural Biofilms of Sulfate-Reducing Bacteria. Science (80-. ). 290, 1744-1747.

Labrenz M. and Banfield J. F. (2004) Sulfate-reducing bacteria-dominated biofilms that precipitate ZnS in a subsurface circumneutral-pH mine drainage system. Microb. Ecol. 47, 20517.

Luptakova, A., Ubaldini, S., Macingova, E., Fornari, P., \& Giuliano, V. (2012) Application of physical-chemical and biological-chemical methods for heavy metals removal from acid mine drainage. Process Biochemistry,47(11), 1633-1639.

Machel, H. G., Krouse, H. R., \& Sassen, R. (1995) Products and distinguishing criteria of bacterial and thermochemical sulfate reduction. Applied geochemistry, 10(4), 373-389.

Machel, H. G. (2001) Bacterial and thermochemical sulfate reduction in diagenetic settings-old and new insights. Sedimentary Geology, 140(1), 143-175.

McCauley C., O'Sullivan A., Weber P. and Trumm D. (2010) Variability of Stockton Coal Mine drainage chemistry and its treatment potential with biogeochemical reactors. New Zeal. J. Geol. Geophys. 53, 211-226.

McLean, R. J., Beauchemin, D., Clapham, L., \& Beveridge, T. J. (1990) Metal-binding characteristics of the gamma-glutamyl capsular polymer of Bacillus licheniformis ATCC 9945. Applied and environmental microbiology, 56(12), 3671-3677.

Moreau, J. W., Webb, R. I., \& Banfield, J. F. (2004) Ultrastructure, aggregation-state, and crystal growth of biogenic nanocrystalline sphalerite and wurtzite. American Mineralogist, 89(7), 950960.

Nagpal, S., Chuichulcherm, S., Livingston, A., Peeva, L., (2000) Ethanol utilization by sulfatereducing bacteria: An experimental and modeling study. Biotechnol. Bioeng. 70, 533-543.

Neculita, C. M., Zagury, G. J., \& Bussière, B. (2007) Passive treatment of acid mine drainage in bioreactors using sulfate-reducing bacteria. Journal of Environmental Quality, 36(1), 1-16.

Nies, D. H. (2000) Heavy metal-resistant bacteria as extremophiles: molecular physiology and biotechnological use of Ralstonia sp. CH34. Extremophiles, 4(2), 77-82.

Papirio, S., Villa-Gomez, D. K., Esposito, G., Pirozzi, F., \& Lens, P. N. L. (2013) Acid mine drainage treatment in fluidized-bed bioreactors by sulfate-reducing bacteria: a critical review. Critical Reviews in Environmental Science and Technology, 43(23), 2545-2580.

Peck, H. D. (1961) Enzymatic basis for assimilatory and dissimilatory sulfate reduction. Journal of bacteriology, 82(6), 933-939. 
Peltier E., Ilipilla P. and Fowle D. (2011) Structure and reactivity of zinc sulfide precipitates formed in the presence of sulfate-reducing bacteria. Appl. Geochemistry 26, 1673-1680.

Pope, J., Newman, N., Craw, D., Trumm, D., Rait, R., (2010) Factors that influence coal mine drainage chemistry, West Coast, South Island, NZ. N. Z. J. Geol. Geophys. 53, 115e128.

Pope, J., \& Trumm, D. (2015) Controls on Zn Concentrations in Acidic and Neutral Mine Drainage from New Zealand's Bituminous Coal and Epithermal Mineral Deposits. Mine Water and the Environment, 34(4), 455-463.

Postgate, J. R. (1979) The sulphate-reducing bacteria. CUP Archive.

Radhika V., Subramanian S. and Natarajan K. A. (2006) Bioremediation of zinc using Desulfotomaculum nigrificans: Bioprecipitation and characterization studies. Water Res. 40, 3628-3636.

Rajbanshi, A. (2009) Study on heavy metal resistant bacteria in Guheswori sewage treatment plant. Our Nature, 6(1), 52-57.

Sánchez-Andrea I., Sanz J. L., Bijmans M. F. M. and Stams A. J. M. (2014) Sulfate reduction at low $\mathrm{pH}$ to remediate acid mine drainage. J. Hazard. Mater. 269, 98-109.

Schimel, J., Balser, T. C., \& Wallenstein, M. (2007) Microbial stress-response physiology and its implications for ecosystem function. Ecology, 88(6), 1386-1394.

Sheoran, A. S., Sheoran, V., \& Choudhary, R. P. (2010). Bioremediation of acid-rock drainage by sulphate-reducing prokaryotes: a review. Minerals Engineering, 23(14), 1073-1100.

Sherbet, G. V. (1978) biophysical characterisation of the cell surface. Academic Press.

Skousen, J. (1997) Overview of passive systems for treating acid mine drainage. Green Lands, 27(4), 34-43.

Spirakis, C. S., \& Heyl, A. V. (1995) Evaluation of proposed precipitation mechanisms for Mississippi Valley-type deposits. Ore Geology Reviews, 10(1), 1-17.

Sterritt, R. M., \& Lester, J. N. (1980) Interactions of heavy metals with bacteria. Science of the Total Environment, 14(1), 5-17.

Sukenik, A., Kaplan-Levy, R. N., Welch, J. M., \& Post, A. F. (2012) Massive multiplication of genome and ribosomes in dormant cells (akinetes) of Aphanizomenon ovalisporum (Cyanobacteria). The ISME journal, 6(3), 670-679.

Utgikar V. P., Harmon S. M., Chaudhary N., Tabak H. H., Govind R. and Haines J. R. (2002) Inhibition of sulfate-reducing bacteria by metal sulfide formation in bioremediation of acid mine drainage. Environ. Toxicol. 17, 40-8.

Wei, X., Viadero Jr, R. C., \& Buzby, K. M. (2005) Recovery of iron and aluminum from acid mine drainage by selective precipitation. Environmental Engineering Science, 22(6), 745-755. 
Weijma, J., Copini, C. F. M., Buisman, C. J. N., Schultz, C. E., \& Lens, P. (2002) Biological recovery of metals, sulfur and water in the mining and metallurgical industry. Water Recycling and Recovery in Industry, IWA Publishing: London, 2002; pp 605-622.

White, C., \& Gadd, G. M. (1996) Mixed sulphate-reducing bacterial cultures for bioprecipitation of toxic metals: factorial and response-surface analysis of the effects of dilution rate, sulphate and substrate concentration. Microbiology, 142(8), 2197-2205.

Wolicka D., Borkowski A., Jankiewicz U. and Stępień W. (2015) Biologically-Induced Precipitation of Minerals in a Medium with Zinc Under Sulfate-Reducing Conditions. Polish Journal of Microbiology 64, 149-155.

Yee, N., \& Fein, J. (2001) Cd adsorption onto bacterial surfaces: a universal adsorption edge?. Geochimica et Cosmochimica Acta, 65(13), 2037-2042.

Yoon S. J., Yáñez C., Bruns M. A., Martínez-Villegas N. and Martínez C. E. (2012) Natural zinc enrichment in peatlands: Biogeochemistry of ZnS formation. Geochim. Cosmochim. Acta 84, 165-176.

Zhang, H., Huang, F., Gilbert, B., \& Banfield, J. F. (2003) Molecular dynamics simulations, thermodynamic analysis, and experimental study of phase stability of zinc sulfide nanoparticles. The Journal of Physical Chemistry B, 107(47), 13051-13060. 


\section{Chapter III: Bacterial Community Characterization and Functional Analysis Contributing to ZnS Formation Assessed through Amplicon Sequencing and Metatranscriptomics}

\subsection{Introduction}

The influence of microbes over their chemical environment, and vice versa, may be termed microbial geochemistry, a subclass of the broader field of biogeochemistry. The previous chapter of this work focused primarily in this regard, with an emphasis on bacterial influences on the solubility of potentially toxic metals in treatment technologies. However, the control that bacteria exhibit on their surroundings is not limited to investigations on a discretely physicochemical basis. Much knowledge can be gained from combining traditional biogeochemical analysis with novel genomic techniques, shedding light on bacterial taxonomy, diversity, and gene expression/regulation. These tools together can provide a greater understanding of microbial mechanisms of worldly importance, for example, in the sustainable recovery, use, and processing of fossil fuels, the treatment and supply of fresh water resources, the effects of climate change, and the responsible management of waste from the extraction and refining of materials we rely on as a society (Druschel \& Dick., 2014). This research investigates the causes and treatments for Acid Rock Drainage (ARD), associated with the mining/milling and metallurgical industries. Bacteria play a large role in the generation of ARD primarily in mineral oxidation reactions, but also serve as key protagonists in passive treatments systems used to treat acidic and metal-laden effluents. Within this context it is important to understand which bacterial genes and gene pathways are activated during these conditions. Genomic techniques continue to shed light on

which species are present and active, and by extension, which species are important to the dominant biogeochemical reactions (Hua et al., 2014). 
Genomic techniques for these investigations vary in their target, cost, and specificity. Traditionally, the sequencing of species-specific genes from DNA extraction, primarily the highly conserved $16 \mathrm{~S}$ rRNA gene, has been the standard for microbial taxonomic surveys. Much of what is known about bacterial diversity in ARD environments has been elicited through this and similar approaches, where acidophilic, iron and sulfur oxidizing species have shown to be dominant (Baker et al., 2003; Bond et al., 2000; Schippers et al., 2010; Tan et al., 2007). Investigations into ARD environments are considered to have moved the field of microbial community ecology forward as a whole, as their relatively low diversity and defined chemistry allow for accurate modelling and testing of microbial ecology techniques, as well as the accuracy of bioinformatics software and pipelines (Denef et al., 2010).

Community surveys using targeted amplicon sequencing of 16S rRNA genes have not only been performed in ARD generating regions themselves, but have also gained momentum in the analysis of passive treatment systems that aim to ameliorate ARD. These systems, that aim to neutralize $\mathrm{pH}$ and immobilize metals as a result of bacterial action, may be improved by microbial surveys. Various bacterial guilds have been revealed that contribute to contaminant reduction, including those that participate in the anaerobic metabolic processes of methanogenesis (methane-producing), sulfidogenesis (sulfide-producing), and acetogenesis (acetate-producing) (Dar et al., 2007). Research on bacterial communities and sulfate reduction upon degradation of various carbon substrates used in passive ARD treatment systems has indicated high microbial diversity at the Operational Taxonomic Unit (OTU) level, with sulfate-reducing bacteria (SRB) of the genera Desulfovibrio, Desulfonema, Desulfomicrobium and Desulfotomaculum identified along with other abundant bacteria within the phyla Bacteroidetes and Firmicutes (Schmidtova et al., 2011). A similar study observed Desulfovibrio and Desulfomicrobium persisting in ethanol fed pilot-scale bioreactors, yet low levels of methanogens (Hiibel et al., 2011). These studies, as well 
as others (Labrenz et al., 2004; Ozuolmez et al., 2015; Paulo et al., 2015) highlight two important interactions in anaerobic settings; SRB competition with methanogenic archaea for substrates, and SRB reliance on the degradation production of fermentive acetogens. Both scenarios contribute to successful passive treatment systems for ARD, as they influence the livelihood of the primary metal-immobilizing agents, sulfate reducing bacteria. Methanogens show relatively limited capacity in their choice of substrate compared to SRB. These microbes are mainly sustained by carbon dioxide, hydrogen, and/or acetate, and are typically out-competed by SRB in high-sulfate environments. Thus, the presence of sulfate as well as the available carbon source are key factors in interactions (Muyzer et al., 2008). In terms of beneficial associations, fermentive bacteria such as acetogens within the class Clostridia utilize sugars, amino acids, long-chain fatty acids, or reduced propionate, butyrate, or lactate to produce acetate, an accessible carbon source for many SRB (Table 1.1).

Many studies have applied DNA-based analyses to determine community structure for active bioreactors treating ARD for a better understanding of the bacterial assemblage (Baldwin et al., 2015; DiLoreto et al., 2016). DiLoreto et al. looked specifically at a novel passive treatment approach using a Mussel Shell Bioreactor (MSB), where they observed guilds of "opportunistic microbes" that take advantage of the chemical and redox gradient which develops with depth in the bioreactor (DiLoreto et al., 2016). The community was dominated by Bacteroidetes, mainly the metabolically versatile Flavobacterium, as well as Acidovorax spp. and Sideroxydans lithotrophicus of the Proteobacteria. These two latter organisms facilitate nitrate reduction coupled to iron oxidation. In the more chemically reduced layers, Desulfotomaculum acetoxidans were detected as the primary SRB, but in low relative abundance (1-5\%).These particular SRB organisms are significant in their ability to form spores and use acetate as a carbon source, derived from the decomposition of chitin associated with the mussel shells. Though many studies 
have investigated and tracked SRB enrichments of single species with respect to metal-sulfide generation as a remediation pathway, few have investigated the entire microbial community. It has been observed that SRB benefit from fermentative bacteria that initiate metal removal and/or provide reduced carbon substrates, and that this interaction promotes SRB activity, and by extension, metal removal by sulfide generation (Alexandrino et al., 2014; Zhang et al., 2016). However, these studies have used total DNA extractions as the basis for analysis, and although this approach yields information on the entire bacterial community present, no studies to our knowledge have been undertaken that utilize RNA as a basis for unravelling microbial function.

The objective of this chapter is to identify and track the taxonomic and functional changes of the bacterial community, with a focus on microorganisms that participate in or influence the biogeochemical transformations discussed in chapter II, i.e. the immobilization of $\mathrm{Zn}$ as a result of zinc-sulfide nucleation. To do this, RNA rather than DNA was extracted from experimental treatments and used as the basis for taxonomic identification through $16 \mathrm{~S}$ rRNA amplicon sequencing and metatranscriptomic analysis.

Total DNA extractions target the double stranded DNA composed in the circular bacterial chromosome, and subsequent amplification of the 16S rRNA gene region of that chromosome may give a wide breadth of potential microbial culprits in any given environment. However, DNAbased taxonomy analysis cannot distinguish between active or inactive, or even live or dead cells, providing less insight into the metabolically active guilds. Alternatively, total RNA extractions target the transcription product of DNA, single stranded RNA. This includes the precursors of protein, messenger RNA (mRNA), as well as the more abundant ribosomal RNA (rRNA), the primary component of bacterial ribosomes. mRNA sequences can provide information on what genes a cell or group of cells are transcribing, while rRNA sequences can be used for taxonomic identification of which bacteria are actively translating that mRNA. Due to its folding structure, 
rRNA has a higher stability than mRNA in the cellular environment. Despite this difference, rRNA degradation has still shown to be appreciable upon cell starvation and death, and thus the analysis of both rRNA and mRNA from a total RNA extraction can still give information on the more active species in a specific place, at a specific time (Deutscher 2003; Deutscher 2006). It should be noted that in defining taxonomy, the use of RNA for 16S rRNA analysis and the use of DNA for 16S rRNA analysis are mutually exclusive techniques and should not be confused with each other. DNAbased techniques target the 16S rRNA "gene" itself from the bacterial chromosome, as opposed to RNA-based techniques that target the single stranded rRNA of the bacterial ribosomes.

The sequencing of total mRNA derived from the total extracted RNA from an environment allows for the shotgun sequencing of the total transcriptome, providing a snapshot of all the "blueprints" present for protein synthesis within the bacterial community. In this type of analysis, rRNA is usually depleted from the total RNA pool, increasing the relative concentration of mRNA. This is the essence of metatranscriptomics. The metabolic state of the microbial community can be inferred from this information, providing greater resolution than from $16 \mathrm{~S}$ amplicon sequencing (either from DNA or RNA) alone.

Using both rRNA as a basis for microbial taxonomy and mRNA as a basis for microbial function, the early microbial conditions (24-96 hours) of the Biotic and Biotic $\mathrm{Zn}$ treatments will be assessed to unravel the interactions that exist leading to a community capable of sustaining sulfate reducers and resulting ZnS biogenesis. These investigations will provide information on how anaerobic metabolizers co-exist in a mixed inoculum derived from a passive treatment technology treating AMD. The null hypotheses set out in Chapter 1 will be tested and the results discussed. 


\subsection{Methods}

\subsubsection{RNA Extraction and Community Analysis of 16S rRNA}

Samples for RNA analysis were removed from the crimp-top bottles at 24, 48, 72, and 96 hours with a sterile $23 \mathrm{GTW}$ needle on a $10 \mathrm{~mL}$ syringe, flash frozen in liquid nitrogen immediately in $2.5 \mathrm{~mL}$ cryo tubes, and stored at $-80^{\circ} \mathrm{C}$ until extraction. Aliquots were taken from 2 of the 3 triplicates and combined prior to extraction to ensure an adequate amount of biomass. RNA was extracted using the PowerSoil Total RNA Isolation Kit (MoBio Laboratories Inc. Carlsbad, CA, USA, Cat No:12866-25) following the manufacturer's instructions. Samples for bacterial community analysis were quality control checked for concentration and purity on an Agilent 2100 Bioanalyzer. Samples that showed good quality were chosen for further processing. RNA was converted to cDNA using a High Capacity cDNA Reverse Transcription Kit (Applied Biosystems) according to the manufacturer's instructions using $10 \mu \mathrm{L}$ of RNA sample. PCR $_{1}$ amplification of the bacterial V5V6 variable SSU rRNA region of the CDNA was performed with primers V5F (5 ACCTGCCTGCCGATTAGATACCCNGGTAG- 3) $\quad$ and ACGCCACCGAGCCGACAGAGCCATGCANCACCT- 3). The $\mathrm{PCR}_{1}$ reaction mix consisted of $1 \mu \mathrm{L}$ template cDNA, $0.5 \mu \mathrm{L}$ of each primer, $2.5 \mu \mathrm{L}$ 10X buffer, $1 \mu \mathrm{L} \mathrm{MgCl}_{2}, 0.5 \mu \mathrm{L}$ DMSO, $0.5 \mu \mathrm{L}$ BSA. $0.5 \mu \mathrm{L}$ dNTP, $0.1 \mu \mathrm{L}$ Taq DNA polymerase, and $\mathrm{ddH}_{2} \mathrm{O}$ to a final volume of $25 \mu \mathrm{L}$. The $\mathrm{PCR}_{1}$ thermocycler profile consisted of an initial denaturation for $5 \mathrm{~min}$. at $94^{\circ} \mathrm{C} ; 25 \mathrm{cycles}$ of $15 \mathrm{sec}$. at $94^{\circ} \mathrm{C}$; $15 \mathrm{sec}$. at $55^{\circ} \mathrm{C}$; and $30 \mathrm{sec}$. at $72^{\circ} \mathrm{C}$; with a final extension for $1 \mathrm{~min}$ at $72^{\circ} \mathrm{C}$. Products were purified using AMPure bead purification, following the manufacturer's protocol. A unique barcode was adapted to each sample through a second PCR run for downstream sequencing of samples in multiplex. The thermocycler profile consisted of an initial denaturation for $5 \mathrm{~min}$. at $95^{\circ} \mathrm{C} ; 7 \mathrm{cycles}$ of $15 \mathrm{sec}$. at $94^{\circ} \mathrm{C} ; 15 \mathrm{sec}$. at $60^{\circ} \mathrm{C}$; and $30 \mathrm{sec}$. at $72^{\circ} \mathrm{C}$; with a final extension for $1 \mathrm{~min}$ at $72^{\circ} \mathrm{C}$. Products of the second PCR were ran on an agarose gel and then excised, pooled, and purified 
using a Qiagen Gel Extraction kit. Samples were diluted to $25 \mathrm{ng} \mathrm{LL}^{-1}$ and sequenced using an lon Torrent Personal Genome Machine (Life Technologies). Taxonomic analysis for bacterial community composition was performed using the Mac Qiime (Quantitative Insights Into Microbial Taxonomy) pipeline (http://qiime.org/). Submitted sequences were assigned into Operational taxonomic units (OTUs) using open-reference picking at 99\% similarity. Taxonomy was assigned to OTUs using the uclust algorithm against the Greengenes database, as per the default settings of Mac Qiime, with a minimum cut-off of 50 hits. Reads were normalized to a percent abundance based off the total number of hits of each sample.

\subsubsection{Diversity Statistics}

Species diversity and richness statistics were calculated for 16S rRNA amplicon community data through MacQiime using the Shannon Diversity Index $(H)$ and the Chao1 Index. The Shannon Diversity Index value is calculated through quantifying both the relative abundance of a species and the total number of species into a single value through Equation 3.1, where $p_{i}$ represents the species abundance

$H=-\sum \mathrm{p}_{i} \ln \mathrm{p}_{\mathrm{i}} \quad$ (Eq. 3.1)

The higher the $H$ value, the higher the diversity of the system, with values $<1.5$ and $>3.5$ representing relatively low, and high diversity, respectively. The Chao1 index calculates diversity based on the number of rare taxa, represented by only 1 or 2 OUT's (Equation 3.2), where Sobs represents the observed number of species, and $n_{1}$ and $n_{2}$ represent the number of species observed by only 1 , or 2 hits respectively.

$$
\mathrm{S}_{\text {chao } 1}=\mathrm{S}_{\text {obs }}+\frac{\left(\mathrm{n}_{1}^{2}\right)}{\left(2 \mathrm{n}_{2}\right)} \quad \text { (Eq. 3.2) }
$$


If a sample contains many singletons (single hits) the Chao1 index will estimate higher species richness, as it predicts a higher number of rare OTUs likely exist. Higher Chao1 values represent higher diversity.

\subsubsection{Metatranscriptomic Analysis}

Duplicate samples were taken from the Biotic Control at 24 and 96 hours and from the Biotic Zn treatment at 24 hours for metatranscriptomic analysis. Total RNA was extracted as described earlier using PowerSoil Total RNA Isolation Kits. Samples were checked on an Agilent 2100 Bioanalyzer for concentration and quality. An RNA concentration of at least $100 \mathrm{ng} \mathrm{LL}^{-1}$ and an RNA integrity value (RIN) greater than 7.0 (scale 1-10) was required for further processing. RNA aliquots that passed in-house quality control were sent to McGill University and Génome Québec Innovation Centre (http://www.genomequebec.com/en/home.html) for metatranscriptome preparation, consisting of an rRNA depletion, cDNA reverse transcription, and shotgun sequencing of resultant DNA derived from the total mRNA pool. Data outputted in a fastq file format for each sample was uploaded to the online bioinformatics pipeline MG-RAST (Metagenomics analysis server) for metatranscriptomics analysis (http://metagenomics.anl.gov/) using a minimum phred score of 30 for high-base confirmation.

Functional gene analysis was performed by annotating sequences against the KEGG (Kyoto Encyclopedia of Genes and Genomes) database with a minimum \%-identity cut off of 60\%, e-value (expect value) of $1-e^{-5}$, and an alignment length of 15 base pairs. The number of hits for each protein transcript identified were normalized by dividing by the number of hits of the RNApolymerase subunit B, yielding a normalized \% abundance value (Fortunato et al., 2015). Abundance values from duplicate samples were averaged and used for data interpretation. Additional taxonomy analysis from metatranscriptome data was performed by annotating sequences against the NCBI (National Center for Biotechnology Information) RefSeq database 
using the same parameters as used against the KEGG database. The number of hits for each bacterial grouping were divided by the total number of hits to achieve percent abundance values (\% abundance). \% abundance values from duplicate samples were averaged for analysis.

\subsection{Results and Discussion}

\subsubsection{Community Diversity}

Shannon $\mathrm{H}$ and Chao1 diversity indices were calculated for time points 24, 48, 72, and 96 hours in the Biotic and Biotic Zn treatments and are summarized in Table S1 and shown in Figure 3.1. Bacterial diversity was high across time points in the Biotic Control $(H>3.44)$, though decreased from 24 hours to 96 hours, falling from 5.05 to 3.49. Chao1 Index values for the Biotic Control remained relatively constant, though was highest at 48 hours (300.54) and lowest at 96 hours (250.06). Lower overall diversity at 96 hours coincided with a slow down in microbial activity indicated by decreased $16 \mathrm{~S}$ rRNA concentrations discussed in Chapter 2 , and it is likely that the community was beginning to degrade in diversity. In the Biotic $\mathrm{Zn}$ treatment, an opposite trend was observed. Shannon $H$ values increased over time from 2.21 to 4.20 from 24 to 96 hours, with Chao1 values increasing from 118.56 to 282.67 over the same period. As the only difference between the two treatments was the addition of $50 \mathrm{mg} \mathrm{L}^{-1} \mathrm{Zn}$ to the Biotic $\mathrm{Zn}$ treatment, it is likely that lower diversity at 24 hours was due to metal toxicity effects. This is reflected in relative cell counts, where metals were shown to contribute to lower cell numbers, which consequently would lead to less species, and lower diversity and richness. The observation that diversity began to rebound at 96 hours in the Biotic $\mathrm{Zn}$ treatment lends evidence to the hypothesis that metal toxicity effects were experienced primarily by the early community ( 24 hours), as cell counts and $16 \mathrm{~S}$ rRNA concentrations also exhibited a rebound after 96 hours, as concluded in Chapter 2.

\subsubsection{Microbial Taxonomy}


Samples for community analysis were taken in duplicate from the Biotic and Biotic $\mathrm{Zn}$ treatments at times $24,48,72$, and 96 hours to resolve early community composition in a control and $\mathrm{Zn}$-amended sample. Ion torrent sequencing of the V5 V6 region of the $16 \mathrm{~S}$ rRNA amplified from extracted RNA yielded 1,699,886 raw sequences from all samples, which was reduced to 424,371 after filtering, with an average size of 35364 sequences per sample (Table S2). The $16 \mathrm{~S}$ rRNA community analysis showed both treatments were dominated by groups within the phyla Firmicutes and Proteobacteria (Figure 3.2), primarily by bacteria within the class Clostridiales and family Pseudomonadaceae, respectively (Figure 3.3).

In the Biotic control, relative abundance of Clostridiales remained high, with the exception of a drop at 48 hours, peaking at $63 \%$ of the total community at 96 hours. Clostridium spp. were the most dominant members constituting the Clostridiales, comprising $88 \%$ and $77 \%$ of the group at 24 and 96 hours (Figure 3.4A), respectively, corresponding to $46 \%$ and $35 \%$ of all bacteria at the same time points. Sulfate reducing bacteria were detected from metatranscriptomic data at 24 and 96 hours (Figure 3.4B). At 24 hours, species of Desulfitobacterium and Desulfotomaculum of the Firmicutes were the most prevalent, at $0.22 \%$ and $0.18 \%$ of the total bacterial community ( $46 \%$ and $38 \%$ of total SRB), respectively, with SRB from the Deltaproteobacteria being less abundant. The abundance values for Desulfitobacterium (0.22\%) and Desulfotomacculum (0.18\%), though low, are within the top 25 most abundant genera in the samples, thus low percentages are a reflection of the high diversity in the samples. At 96 hours, Desulfitobacterium and Desulfotomaculum abundances increased to $0.52 \%$ and $0.30 \%$ of the total community $(49 \%$ and $29 \%$ of SRB) with Desulfitobacterium hafniense, Desulfotomaculum reducens, and Desulfotomaculum acetoxidans detected as the most abundant species.

With the exception of unclassified bacteria, Pseudomonas spp. of the Pseudomonadaceae family were the most dominant next to Clostridium spp. at both 24 and 96 hours according to $16 \mathrm{~S}$ 
rRNA and metatranscriptome data, with 16S rRNA analysis also showing the prevalence of bacteria of the Moraxellaceae, Lachnospiraceae, and Xanthomonadaceae families through the Biotic Control. Overall, a more diverse and even distribution of bacterial groupings was observed at 24 hours and 48 hours compared to 72 and 96 hours in the Biotic Control, reflecting the decreasing diversity values from the Shannon $H$ and Chao1 indices calculated prior. The $16 \mathrm{~S}$ rRNA amplicon analysis was used to target the bacterial domain, however metatranscriptomics analysis provided additional information pertaining to the bacterial and archaeal domains. In this case the detection of methanogens was possible. Methanogen numbers were low across the Biotic Control, with the highest abundance being Methanococcus spp. at $0.076 \%$ and $0.066 \%$ for 24 and 96 hours.

The 16S rRNA amplicon data from the Biotic Zn treatment showed that the Proteobacteria contended with the Firmicutes throughout the time points. The most dramatic distinction was at 24 hours, where the family Pseudomonadaceae dominated with 92\% abundance (Figure 3.3). As was observed in the Biotic Control, Pseudomonas spp. were the most abundant within this time, comprising all the Pseudomonadaceae, including Pseudomonas Viridiflava, Pseudomonas Fluorescens, and Pseudomonas Putida. Metatranscriptome analysis showed an enrichment of Proteobacteria at 24 hours, with both Serratia spp. (59\% abundance) and Pseudomonas spp. (23\% abundance) as the principle organisms. Pseudomonas abundance dropped after 24 hours, when Clostridiales became more prevalent. However, it was observed that amongst bacteria within the Clostridiales, it was the Lachnospiraceae which was the dominant organism, opposed to Clostridium spp. that were observed in the Biotic Control. Very low hits for sulfate-reducing bacteria were detected in the Biotic $\mathrm{Zn}$ treatment in the first 96 hours from $16 \mathrm{~S}$ rRNA amplicon data or metatranscriptomics data from 24 hours. Contributions from the Xanthomonadaceae were low, yet consistent across time points of the Biotic $\mathrm{Zn}$, with species of the 
Peptostreptococcaceae showing an influence at 48 hours. The dominant abundance of Pseudomonas and Serratia of the Gammaproteobacteria at 24 hours reflects the lower diversity and richness as indicated by the lowest Shannon $H$ and Chao 1 values at this time point. As this dominance subsided and species distribution become more even over 48, 72, and 96 hours, diversity values increased.

\subsubsection{Functional mRNA Results from Metatranscriptomics}

Duplicate metatranscriptomic datasets for the Biotic Control at 24 and 96 hours and for the Biotic $\mathrm{Zn}$ at 24 hours were processed through the MG-RAST server. Sequence counts pre and post quality control (QC), as well as sequence lengths, identified protein features, rRNA features, and functional categories are summarized in Table S3. Biotic Control samples for 24 hours had averaged post QC sequence counts of 7,680,051, mean sequence length of $119 \pm 32 \mathrm{bp}, 741,126$ identified protein features, and 603,088 annotated identified functional categories, with samples for 96 hours at $6,726,477,117 \pm 30 \mathrm{bp}, 718,050$, and 550,956, respectively.

Relative normalized abundances of duplicate transcript samples are expressed in Table S4, with p-values for changes across time and treatments expressed in Table 3.1. Overall cellular function was similar in relative pathway abundance from 24 hours to 96 hours in the Biotic Control, with the exception of differential expression in fatty acid, sulfur, and carbohydrate metabolism. Acetogenic pathways were higher expressed significantly at 24 hours over 96 hours, indicated by increases in the carbon-monoxide dehydrogenase gene (cooS), and acetyl CoAsynthase genes (cdh) specifically, which encode key enzymes of the primary Wood-Ljungdahl pathway for anaerobic acetogenesis (Figure 3.7) (Müller et al., 2013). cooS genes had relative normalized abundances of $12.7 \%$ and $2.1 \%$ at 24 and 96 hours, respectively, with cdh genes at $11.1 \%$ and $0.9 \%$ for the same time points. The tricarboxylic acid (TCA) cycle, responsible for the 
generation of adenosine triphosphate (ATP) through oxidation of acetyl CoA (also named Krebs cycle or Citric Acid Cycle) showed upregulation at 96 hours over 24 hours, with multiple genes along the pathway increasing in relative functional abundance. Significant gene expression changes in this pathway from $24-96$ hours included isocitrate dehydrogenase IDH1 $(12.4 \%$ to $19.2 \%)$, oxoglutarate dehydrogenase sucA ( $11.6 \%$ to $19.5 \%)$, succinate dehydrogenase sdh $(11.0 \%$ to $15.2 \%)$, SuccinateCoA ligase suc (9.2\% to $14.1 \%)$, citrate (Si)synthase gltA (5.8\% to $10.3 \%)$, and fumarate hydratase fum (5.3\% to $12.3 \%)$. Genes involved in sulfate metabolism were low across the Biotic Control over 24-96 hours, however did show a significant increase over time. Sulfate adenyltransferase met3 (1.2\% to $1.7 \%), 3^{\prime}$-phosphoadenosine $5^{\prime}$-phosphosulfate synthase cysNC (1.6\% to $3.1 \%)$, and assimilatory sulfite reductase (NADPH) $(2.2 \%$ to $3.3 \%)$ showed significant upregulation from 24 to 96 hours. These enzymes are primarily associated with the assimilatory sulfate reduction pathway, whereas the key genes involved in dissimilatory sulfate reduction, aprAB and dsrAB, were below cut off limits or non-existent. Gene pathways controlling methanogenesis were also absent, including those involved in the translation of methyl coenzyme $M$ reductase $(\mathrm{mcr})$, the key and rate limiting enzyme in methane production in methanogens, as well as mtr gene variants (Scheller et al., 2010; Thauer et al., 1990).

For the Biotic Zn treatment, metatranscriptomics data was only available for the time point at 24 hours for incorporation into this Thesis. Samples had averaged post QC sequence counts of $8,713,736$, mean sequence length of $122 \pm 33 \mathrm{bp}, 653,339$ identified protein features, and 590,283 annotated identified functional categories. Acetogenesis was significantly lower at 24 hours in the $\mathrm{Zn}$-amended treatment compared to the Biotic Control at 24 hours, with cooS and cdh genes at $0.07 \%$ and $0.005 \%$ relative abundance, respectively, inferring a low influence of acetogens. TCA cycle genes identified in the control showed higher normalized relative abundance early in the Biotic Zn treatment, including isocitrate dehydrogenase IDH1 (23.5\%), oxoglutarate 
dehydrogenase sucA (39.1\%), succinate dehydrogenase sdh (52.8\%) SuccinateCoA ligase suc (25.1\%), citrate (Si)synthase gltA (15.1\%), and fumarate hydratase fum (19.8\%). Sulfate metabolism genes exhibited generally higher abundance at 24 hours in the Biotic $\mathrm{Zn}$ over the control; sulfate adenyltransferase met3 (2.1\%), 3'-phosphoadenosine 5'-phosphosulfate synthase cysNC (1.7\%) and assimilatory sulfite reductase (NADPH) (7.0\%). The assimilatory sulfite reductase, specifically, showed high relative activity, the enzyme that catalyzes the final step of the assimilatory sulfate reduction pathway, generating sulfide for incorporation into amino acids. As was observed in the Biotic Control, no dissimilatory sulfate reduction genes or key methanogenesis genes were active at 24 hours in the $\mathrm{Zn}$-amended treatment.

\subsubsection{Taxonomic and functional mRNA Interpretation and Analysis}

\subsubsection{Biotic Control}

16S rRNA amplicon sequences and metatranscriptomics analysis together lend insight into the active metabolic state of the treatments. In the Biotic Control, a high relative abundance of vital transcripts of acetogenic genes were observed at 24 hours, including carbon-monoxide dehydrogenase (cooS) and acetyl CoA-synthase (cdh), coinciding with a domination by bacteria within the order Clostridiales as quantified by $16 \mathrm{~S}$ rRNA data. It was further resolved from metatranscriptomic-derived taxonomy that these bacteria were primarily Clostridium species. The genera of Clostridium include many known acetogens, species able to utilize reduced carbon compounds, such as lactate, to derive energy, producing acetate as a by product (Figure 3.5A, Equations 3.3, 3.4) (Muyzer et al., 2008; Thauer et al., 1997).

$$
\begin{array}{ll}
\text { Lactate }^{-}+2 \mathrm{H}_{2} \mathrm{O} \leftrightarrow \mathrm{C}_{2} \mathrm{H}_{3} \mathrm{O}_{2}^{-} \text {(Acetate) }+\mathrm{HCO}_{3}^{-}+\mathrm{H}^{+}+2 \mathrm{H}_{2} & \Delta \mathrm{G}^{\circ \prime}=-4.2 \mathrm{~kJ} / \text { reaction } \\
\text { Lactate } & \text { (Eq.3.3) } \\
\mathrm{SO}_{4}^{2-}+\mathrm{C}_{2} \mathrm{C}_{3} \mathrm{H}_{3} \mathrm{O}_{2}^{-} \text {(Acetate) }+0.5 \mathrm{H}^{+} & \Delta \mathrm{G}^{\circ \prime}=-56.6 \mathrm{~kJ} / \text { reaction (Eq. 3.4) } \\
\text { (Acetate } \leftrightarrow \mathrm{HS}^{-}+2 \mathrm{HCO}_{3}^{-} & \Delta \mathrm{G}^{\circ \prime}=-47.6 \mathrm{~kJ} / \text { reaction (Eq. 3.5) }
\end{array}
$$


Lactate $^{-}+0.5 \mathrm{SO}_{4}^{2-} \leftrightarrow \mathrm{C}_{2} \mathrm{H}_{3} \mathrm{O}_{2}^{-}$(Acetate) $+\mathrm{HCO}_{3}^{-}+0.5 \mathrm{HS}^{-} \quad \Delta \mathrm{G}^{\circ}=-80.2 \mathrm{~kJ} /$ reaction (Eq. 3.6)

These species were likely rapidly consuming lactate, the primary carbon source used in the treatments, within the first 24 hours of the experiment. A decrease in $\mathrm{pH}$ exhibited between 0 and 96 hours supports a generation of acetate (Müller et al., 2013). Clostridum spp. are primarily endospore-forming, obligate anaerobes, thus it is not surprising that they are abundant in material sourced from the anaerobic layer of the mussel shell bioreactor, and persisted through oxygen-deficient enrichments. Clostridium saccharolyticum, a species detected throughout the Biotic Control time points ( $7.4 \%$ and $22.6 \%$ of Clostridium spp. at 24 and 96 hours, respectively), has shown to be important in mutualistic relationships with cellulose degraders, removing toxic secondary metabolites (Murray et al., 1986). These bacteria could have been involved in similar syntrophy in the MSB, while benefiting from the fermented degradation products of chitin and cellulose from mussel shell and associated mussel shell organics. Other abundant Clostridum included Clostridium botulinum and Clostridium difficile, species more associated with human disease, however also spore-forming anaerobes that likely contributed to acetogenesis utilizing lactate (Drake et al., 2008). Similar to the Clostridum, the two main genera of SRBs detected are capable of endospore formation. Desulfitobacterium spp. have been well documented in their role in reductive dechlorination in degradation of halogenated compounds in the environment, growing with lactate as a substrate, but not traditionally acetate (Christiansen et al., 1996; Gerritse et al., 1996). Desulfotomaculum reducens has a similar metabolic capacity, showing preferred growth on lactate over acetate (Della Vecchia et al., 2014; Junier et al., 2009). These species were the most prevalent of the SRB. Other species present show preference for acetate, including Desulfotomaculum acetoxidans, as well as Desulfuromonas acetoxidans. Both of these species showed a strong increase in abundance from 24 hours to 96 hours, and likely responded 
favourably to the production of acetate by abundant Clostridum spp. after 24 hours, as acetateutilizing SRB are known to be beneficiaries in this regard (Labrenz et al., 2004; Sánchez-Andrea et al., 2014). Desulfotomaculum acetoxidans has been detected by DNA extraction from the mussel shell bioreactor in previous investigations (DiLoreto et al., 2016).

Lactate utilization in sulfate reduction is energetically favourable over acetate as an electron donor, as shown from Gibbs free energy values $\left(\Delta G^{\circ}\right)$ in equations 3.5 and 3.6, likely a reason for the prevalence of lactate-utilizing SRB, despite a high probable concentration of acetate in the system derived from abundant acetogenic pathways. It is also possible that SRB utilizing lactate where doing so through similar fermentive pathways to acetogens, and thus contributed, although to a lesser extent, to the abundance of acetogenic transcripts present at 24 hours. In terms of acetate utilization, TCA cycle transcripts were abundant at 96 hours over 24 hours, thus acetate metabolism by SRB likely proceeded through a modified citric acid cycle, as observed in other sulfate reducers (Figure 3.5B) (Brandis-heep et al., 1983). However, an acetylCoA pathway for acetate oxidation, as observed in Desulfotomacculum acetoxidans and several other SRBs, cannot be ruled out, as the vital enzyme formate dehydrogenase showed high relative abundance (Figure 3.6) (Schauder et al., 1986).

It is surprising that Clostridium seemed to outcompete SRB, since in high sulfate environments, sulfate reduction with lactate as the electron donor presents a lower energy hurdle than acetogenesis (equation 3.6) (Muyzer et al., 2008). It is possible that since the primary SRB identified are endospore-forming species, there existed a lag in their activity relative to the more metabolically-diverse Clostridium. This coincides with the lack of dissimilatory sulfate reduction transcripts in the first 96 hours, yet a later peak of hydrogen sulfide production ( 360 hours in the Biotic Control). The low abundance of methanogens and absence of key methanogenic genes can be explained by the chemical species present, as SRBs, even in relatively low numbers, routinely 
outcompete methanogens for acetate when sulfate concentrations are high (Muyzer et al., 2008; Paulo et al., 2015; Stams et al., 2003). Furthermore, methanogens do not generally metabolize lactate, and low temperatures favour acetogens over methanogens when $\mathrm{H}_{2}$ is available as a substrate in fermenting communities, thus the experimental settings were not conducive to methanogen activity (Kotsyurbenko et al., 2001). Regardless, a key observation in the Biotic Control is that the more abundant sulfate reducing genera present at 24 hours were likely lactate fermenters, while acetate-metabolizing species proliferated later in the experiment, likely thriving on degradation products of abundant Clostridium spp.

\subsubsection{Biotic $\mathrm{Zn}$}

The Biotic Zn treatment, amended with $50 \mathrm{mg} \mathrm{L}^{-1}$ zinc, expressed a much lower abundance of acetogenic transcripts at 24 hours compared to the Biotic Control, reflected in the absence of Clostridiales species. Rather, a dominance of Pseudomonas species was observed, as well as the genera Serratia. Pseudomonas cover a wide niche in terms of their metabolic capabilities, and have been observed in metal-contaminated soils in multiple studies (Bao et al., 2006; Ellis et al., 2003; Piotrowska-Seget et al.,2005). Reduced competition due to the inhibition of more sensitive species as well as the modification of metal-uptake mechanisms into the cell are additional cited reasons for Pseudomonas dominance in metal-laden environments (Diaz-Ravina et al., 1996; Norris et al., 1976). The former explanation would also explain the lower diversity values and lower cell counts at this time point, as the high metal concentration likely inhibited a number of species. The prevalence of Serratia species, detected through metatranscriptomic data, could be due to their role as efficient microbial chitin degraders (Monreal et al., 1969; Vaaje-Kolstad et al., 2005). Chitin is an abundant carbon source in the Stockton bioreactor, produced and incorporated into the mussel shells, thus Serratia could play an important role in liberating more 
easily degradable carbon from the primary breakdown of chitinous material in the mussel shell bioreactor (DiLoreto et al., 2016). However, chitin was not present in the experimental treatments, so although Serratia in enrichments were sourced from a chitinous environments, they're growth in the treatments must be due to metabolism of other carbon sources (primarily lactate or acetate), confirming with other studies that these species possess a versatile diet (Shukor et al., 2008). The fact that Serratia were detected in the Zn-amended treatment and not the Biotic Control could be due to similar reasons as Pseudomonas; i.e., less competition from metal-intolerant bacteria, also implying a measure of metal resistance in Serratia.

Coinciding with the dominance of Pseudomonas and Serratia in the Biotic Zn treatment at 24 hours was an abundance of TCA cycle transcripts, having significantly higher relative abundance than the Biotic Control (Figure 3.7). As acetogenic genes and acetogenic and sulfate reducing bacterial species were low in abundance, TCA cycle genes likely corresponded to the oxidation of lactate by the dominant species (Pseudomonas) as opposed to the modified acetate metabolism pathway as proposed in the Biotic Control. From 16S rRNA data, species of the Clostridiales became more abundant in the Biotic $\mathrm{Zn}$ treatment over the time periods, as was observed in the Biotic Control. However, this was due to an increase in the family Lachnospiraceae as opposed to the Clostridiaceae or SRB within the Peptococcaceae, species which were observed in abundance in the Biotic Control. It was confirmed from chemical data that the addition of $\mathrm{Zn}$ did not inhibit SRB species, as sulfate removal rates did not differ between the Biotic Control and Biotic Zn treatments. However, as SRB and dissimilatory sulfate reduction genes were not identified within the first 96 hours from the $\mathrm{Zn}$-amended treatment, it is possible that a lag existed in SRB growth, but that this lag did not affect overall SRB activity. This would explain the identified lag in hydrogen sulfide production compared to the Biotic Control. The rebound and plateau in 16S rRNA concentrations in the Biotic $\mathrm{Zn}$ treatment could have also been an indication of late SRB 
metabolism. Pseudomonas appeared to be outcompeting most other bacteria in the metalamended treatment, and this species would not have been producing acetate from lactate oxidation via the TCA cycle, thus acetate as carbon source for recognized SRB species in the Biotic Control would not have been available until later time points, when acetogens could have persisted after the initial dominance of Pseudomonas. It does appear that an assimilatory sulfate reduction pathway was active at 24 hours in the Biotic $\mathrm{Zn}$ treatment. This pathway reduces inorganic sulfur for incorporation into biological components, primarily the amino acid cysteine. Active bacteria at this time point (mainly Pseudomonas and/or Serratia were likely culprits for this metabolic pathway, as they were the dominant species present. Furthermore, an increase in normalized abundance of cysteine-building gene transcripts, including cysteine synthase and Oacetyltransferase, correlate with increased assimilatory sulfate reduction pathways.

\subsubsection{Conclusions}

Through 16S rRNA amplicon sequencing and metatranscriptomic analysis, it was observed that enrichments simulating early bacterial community establishment of a passive treatment system for Acid Mine Drainage were capable of sustaining sulfate reducing bacteria. In the absence of Zn, Clostridium species proved to be vital in generating acetate by primary oxidation

of lactate, as revealed by metatranscriptomics data. Acetate could then be utilized by SRB, which showed an increase in abundance over time in experimental treatments. Lactate-utilizing SRB were also abundant across early time points, attesting to the kinetically favourable oxidation of lactate over acetate. The dominant SRB present were spore-forming types, a characteristic that would allow them to contend with acidic and metal-laden environments, such as in the mussel shell bioreactor. 
This scenario differed in a Zn-incorporated setting, where SRBs exhibited a lag in growth, although no apparent burden in activity. More metal resistant bacteria showed abundance in these treatments, including those of the genus Pseudomonas. These species utilized lactate through non-acetogenic pathways, thus substrates for SRB were less available, and contributed to their low abundance at the early time points studied.

Key enzymes involved in dissimilatory sulfate reduction were in low abundance or nonexpressed from 24-96 hours in both treatments. Thus, despite the presence of SRB, hydrogen sulfide production by these species was not prevalent until later time points, as indicated by solution chemistry data. At these later time points $\mathrm{Zn}$ could react with dissolved sulfide and precipitate as ZnS minerals, contributing to metal immobilization. Future work on this system could survey taxonomy and metabolic activity by metatranscriptomics throughout the entirety of the experiment (throughout 888 hours or longer) to resolve microbial functioning at later time points and identify the transition of the community from acetogenic to sulfate-reducing. Q-PCR investigations not included in this dissertation showed that dissimilatory sulfate reduction genes, such as the dsr gene, were not expressed at later experimental time points, despite the measured generation of hydrogen sulfide and subsequent sulfide mineral precipitation. It is suspected that dissimilatory sulfate reduction by bacteria occurs intermittently, as postulated in other research by coarsening patterns in ZnS (Moreau et al., 2004). Thus, dsr transcripts can be easily missed when a total RNA extraction is performed at singular time intervals, as single-stranded mRNA molecules are known to have a lifespan of only a few minutes (Moran et al., 2013). A more rigorous sampling regime (multiple sample points per day) may aid in discerning the nature of these cryptic pulses in sulfate reduction in both natural and experimental settings.

In terms of the hypotheses set forth in Chapter 1: 
1) Sulfate-reducing genera will not comprise a significantly different proportion of the bacterial community than any other genus.

2) Dissimilatory sulfate reduction genes transcripts will not change significantly throughout the duration of the experiment.

it is confirmed that SRB did indeed comprise a significant portion of the bacterial community in the Biotic Control, as select groups were represented within the top 25 most abundant genera. However, this was not the case in the metal-amended Biotic $\mathrm{Zn}$ treatment, where no sulfate reducing bacterial genera made up a significant portion of the community, at least not over early experimental time points ( 0 to 96 hours). Thus, the $1^{\text {st }}$ null hypothesis may be rejected for the Biotic Control, but not the Biotic Zn treatment. As for the $2^{\text {nd }}$ hypothesis, dissimilatory sulfate reduction genes were not detected during the sampling period in both the Biotic Control or Biotic $\mathrm{Zn}$ treatment. Although these genes may be detected under a heavier sampling effort over later time points, the $2^{\text {nd }}$ null hypothesis cannot be rejected with respect to the data presented here. 
Table 3.1: Significance values acquired through Tukey's pairwise comparisons for differences in key transcript normalized abundance. Pvalues are displayed for changes in normalized abundance of transcripts between 24 and 96 hours in the Biotic Control and between 24 hours in the Biotic Control and 24 hours in the Biotic Zn treatment. Significant comparisons ( $p$-value $<0.05)$ are shaded, with an up arrow ( $\uparrow$ ) indicting an increase in normalize abundance and a down arrow $(\downarrow)$ indicating a decrease in normalized abundance over the respective time intervals or treatments.

\begin{tabular}{|c|c|c|c|c|c|}
\hline \multirow{3}{*}{ 3'-phosphoadenosine 5'-phosphosulfate synthase } & \multirow{3}{*}{$\begin{array}{l}\text { E.C. number } \\
2.7 .7 .42 .7 .1 .25 \\
1.2 .7 .41 .2 .99 .2\end{array}$} & \multicolumn{2}{|c|}{$\begin{array}{l}\text { Bio Control } 24 \text { to } 96 \text { hours } \\
\text { p-value }\end{array}$} & \multicolumn{2}{|c|}{$\begin{array}{l}\text { Bio Control } 24 \text { to Bio Zn } 24 \\
\text { p-value }\end{array}$} \\
\hline & & $\uparrow$ & 0.004386 & & 0.4126 \\
\hline & & & & & \\
\hline Acetyl-CoA Synthase & 2.3.1.169 & $\downarrow$ & 0.0005638 & $\downarrow$ & 0.00054 \\
\hline Aconitase & 4.2.1.3 4.2.1.99 & $\uparrow$ & 0.002161 & $\uparrow$ & 0.000569 \\
\hline adenylylsulfate reductase & 1.8.99.2 & & 0.13 & & 0.8832 \\
\hline assimilatory sulfite reductase (ferredoxin) & 1.8.7.1 & $\downarrow$ & 0.008662 & $\downarrow$ & 0.00175 \\
\hline assimilatory sulfite reductase (NADPH) & 1.8.1.2 & $\uparrow$ & 0.008989 & $\uparrow$ & 0.002723 \\
\hline carbonmonoxide dehydrogenase (acceptor) & 1.2.99.2 & $\downarrow$ & 0.0007327 & $\downarrow$ & 0.00062 \\
\hline citrate (Si)synthase & 2.3.3.1 & $\uparrow$ & 0.001264 & $\uparrow$ & 0.000569 \\
\hline cysteine synthase & 2.5.1.47 & $\uparrow$ & 0.0193 & $\uparrow$ & 0.000545 \\
\hline dihydrolipoyllysineresidue succinyltransferase & 2.3.1.61 & $\uparrow$ & 0.007535 & $\uparrow$ & 0.000585 \\
\hline formate dehydrogenase & 1.2.1.2 & $\uparrow$ & 0.02383 & $\uparrow$ & 0.000515 \\
\hline fumarate hydratase & 4.2.1.2 & $\uparrow$ & 0.001495 & $\uparrow$ & 0.000755 \\
\hline isocitrate dehydrogenase (NADP+) & 1.1.1.42 & $\uparrow$ & 0.001293 & $\uparrow$ & 0.000667 \\
\hline
\end{tabular}


methyl coenzyme $M$ reductase

oxoglutarate dehydrogenase

(succinyltransferring)(sucA)

phosphoadenylylsulfate reductase (thioredoxin)

serine Oacetyltransferase

succinate dehydrogenase sdh

SuccinateCoA ligase (ADPforming)

sulfate adenylyltransferase
2.8.4.1

1.2.4.2

1.8.4.8

2.3.1.30

1.3.99.1

6.2.1.5

2.7.7.4

\begin{tabular}{rrrr}
$\uparrow$ & 0.0009524 & $\uparrow$ & 0.000515 \\
$\uparrow$ & 0.822 & $\uparrow$ & 0.000517 \\
$\uparrow$ & 0.03848 & $\uparrow$ & 0.000515 \\
$\uparrow$ & 0.0002808 & $\uparrow$ & 0.03625 \\
$\uparrow$ & 0.0091 & $\uparrow$ & 0.000515 \\
& 0.01506 & $\uparrow$ & 0.001062 \\
\hline
\end{tabular}



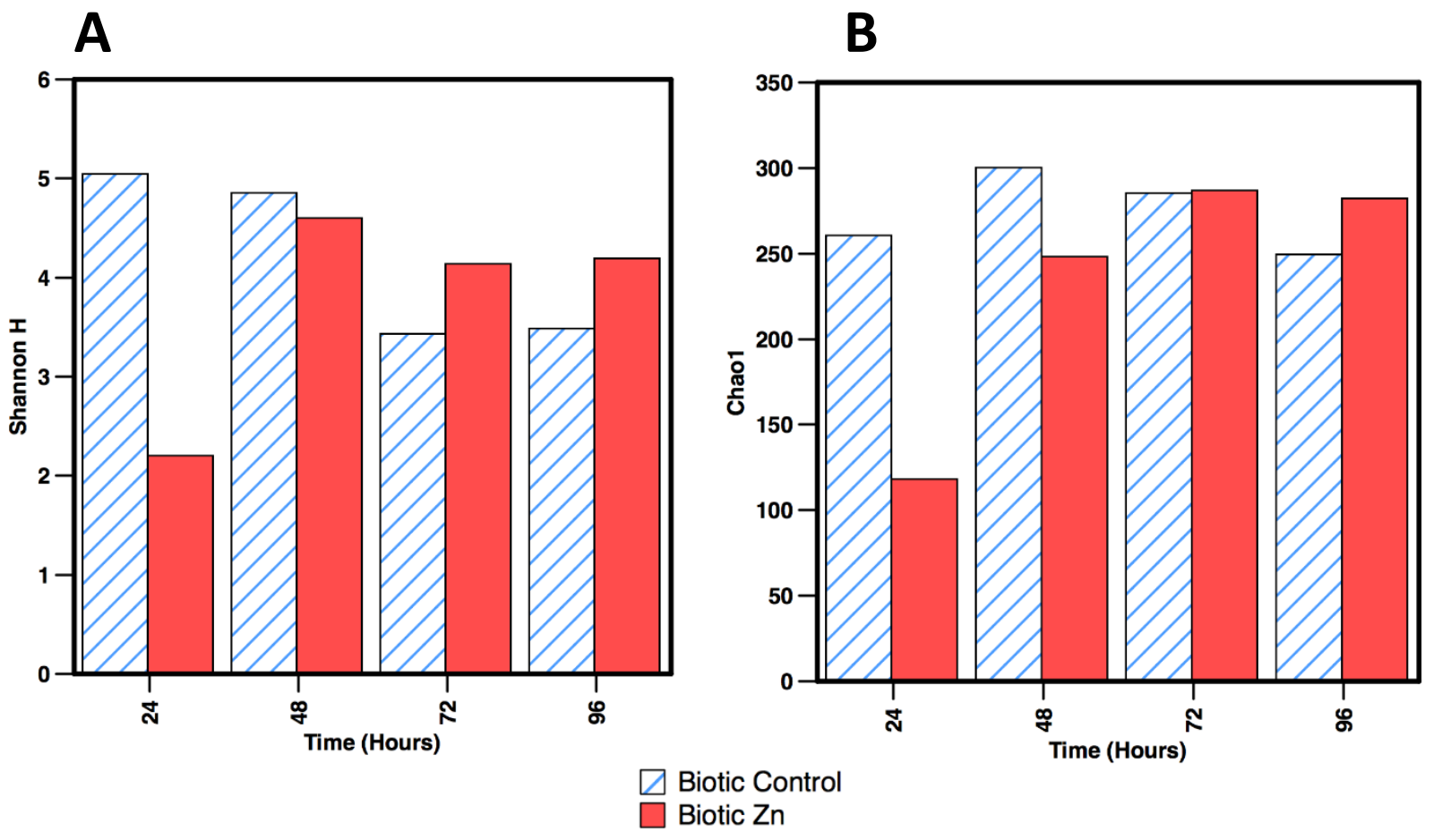

Figure 3.1: Shannon $H(A)$ and Chao1 (B) diversity index values for Biotic Control and Biotic $\mathrm{Zn}$ treatments 

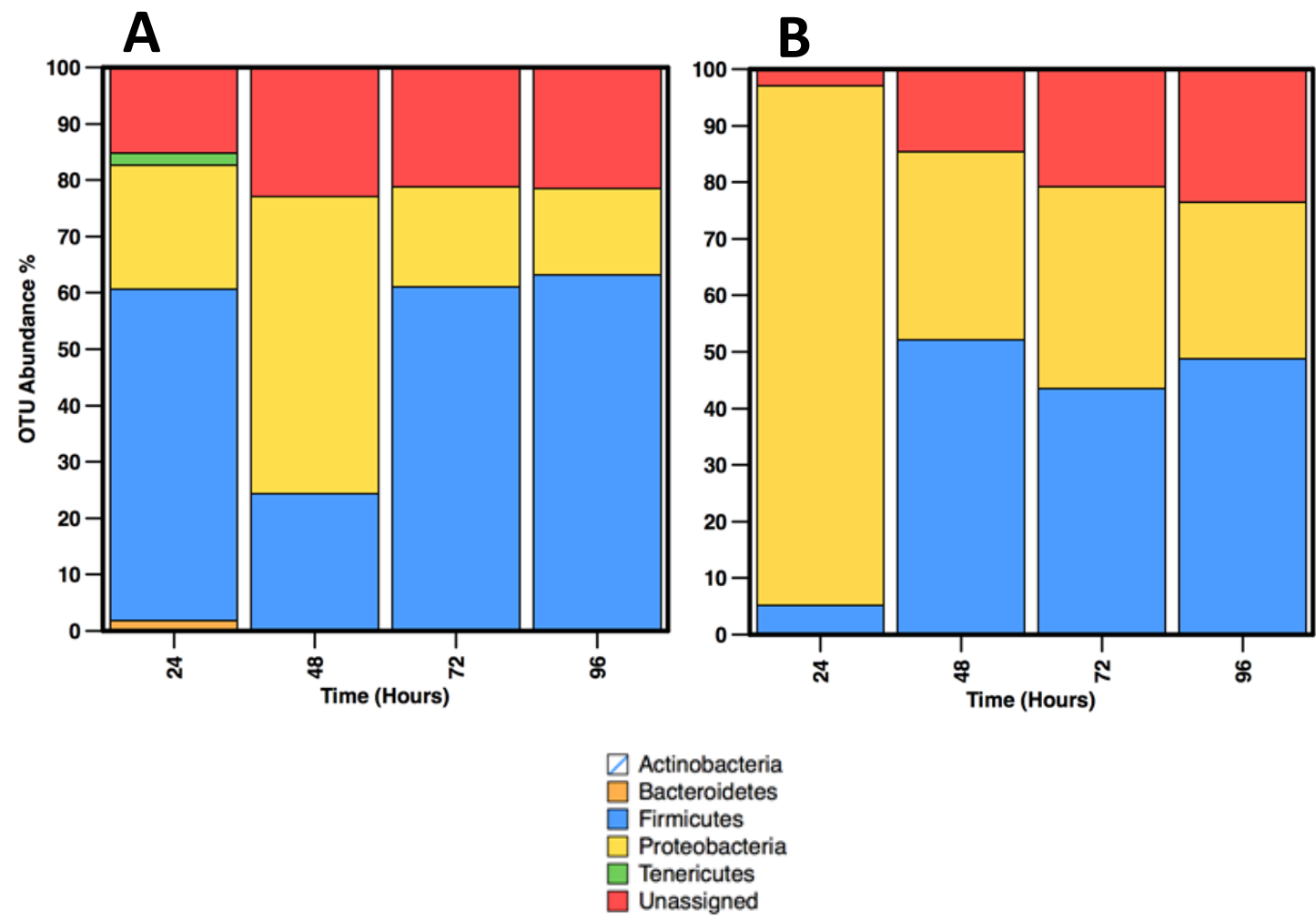

Figure 3.2: Filtered Operational Taxonomic Unit (OTU) relative abundance data at the phylum level. Values based off $16 \mathrm{~S}$ rRNA amplicon sequences from total RNA extraction over 24 to 96 hours. A) Biotic Control B) Biotic Zn 

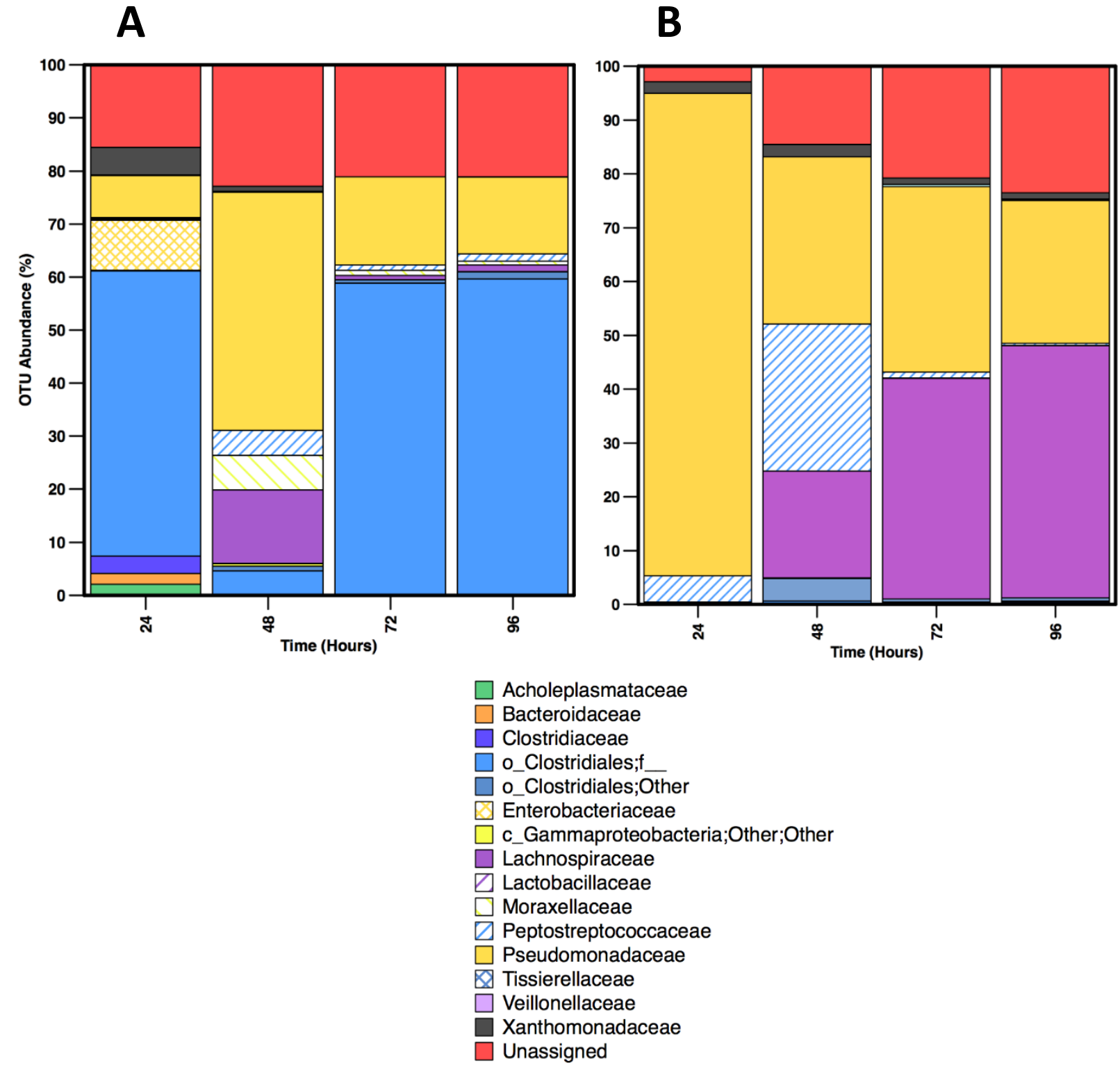

Figure 3.3: Filtered Operational Taxonomic Unit (OTU) relative abundance data at the family level. Values based off $16 \mathrm{~S}$ rRNA amplicon sequences from total RNA extraction over 24 to 96 hours. A) Biotic Control B) Biotic Zn 


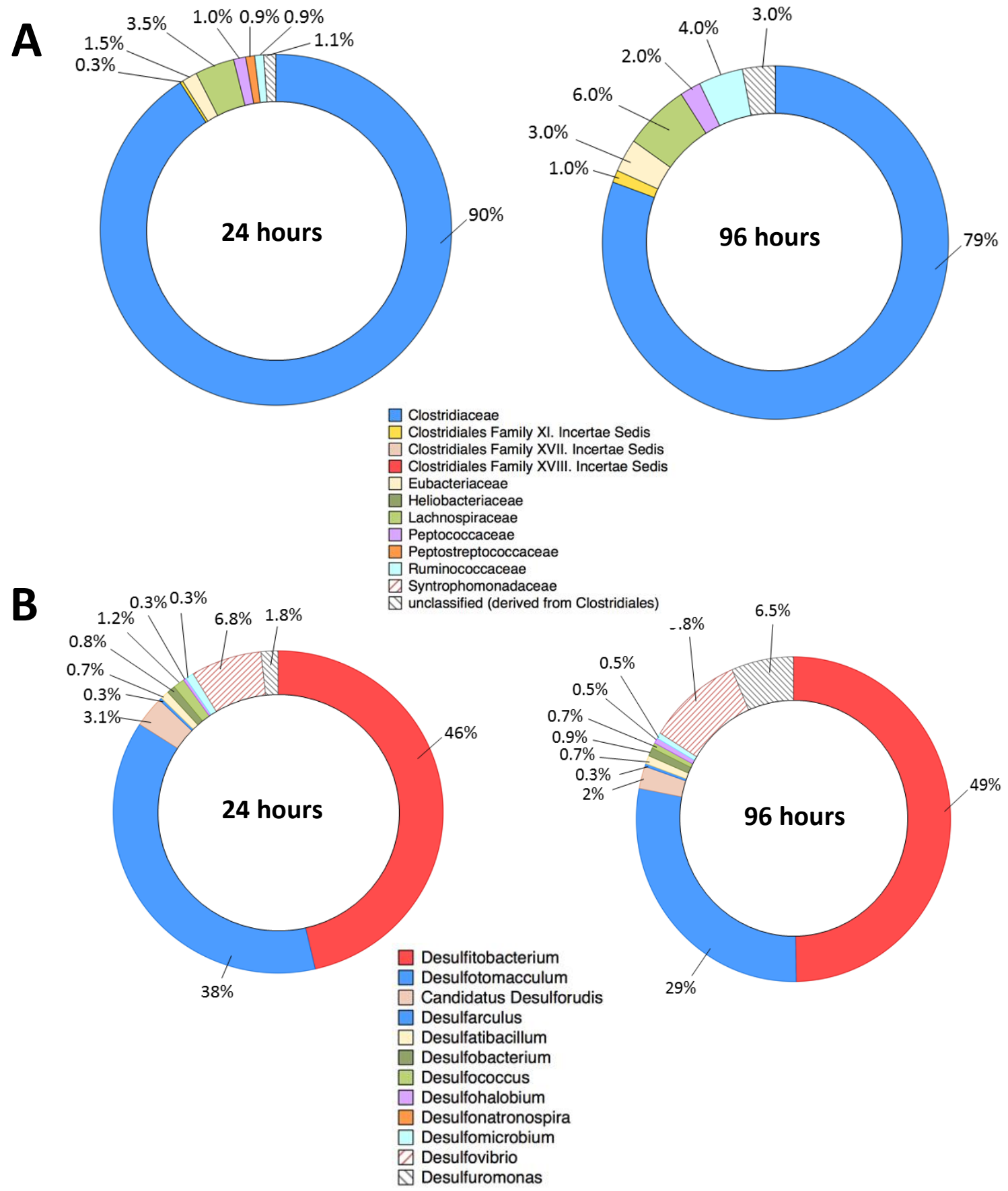

Figure 3.4: A) Relative abundance of families within the Clostridiales in the Biotic Control at 24 and 96 hours based on metatranscriptomic analysis from total RNA extraction. Clostridium species comprised $88 \%$ and $77 \%$ of the Clostridiaceae at 24 and 96 hours, respectively. Absent abundance labels at 24 hours include Clostridiales Family XVII. Incertae Sedis (0.03\%), Clostridiales Family XVIII. Incertae Sedis $(0.08 \%)$, Heliobacteriaceae $(0.14 \%)$, and Syntrophomonadaceae (0.13\%). B) Relative abundances between genera of sulfate reducing bacteria (SRB) in the Biotic Control at 24 and 96 hours. 


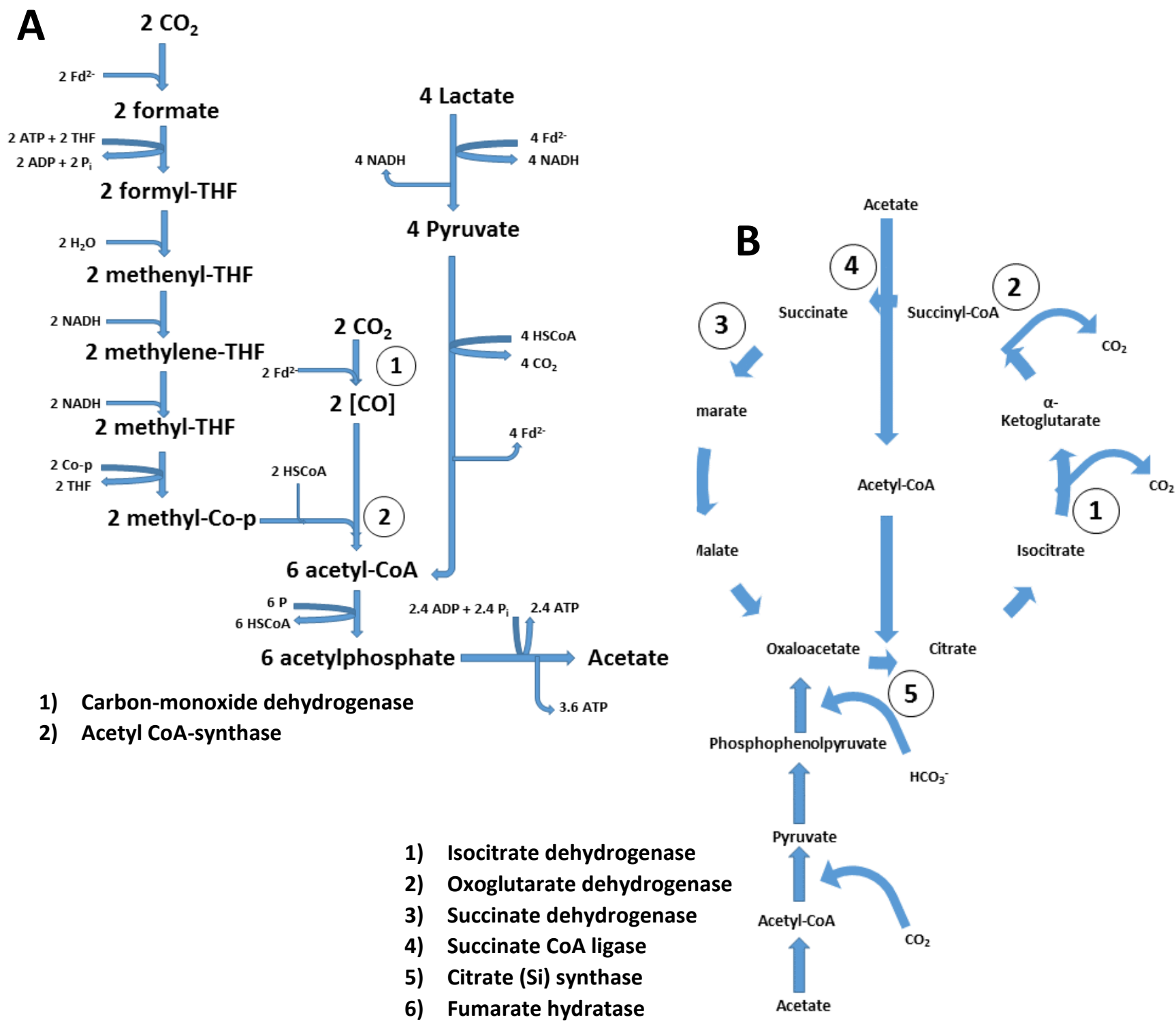

Figure 3.5: Key microbial lactate and acetate oxidation pathways. A) Lactate oxidation to acetate through the Wood-Ljungdahl pathway utilized by acetogenic bacteria. Lactate is converted to pyruvate via a lactate dehydrogenase, which is then converted to acetyl-CoA. Carbon-monoxide dehydrogenase (1) catalyzes the key reduction of $\mathrm{CO}_{2}$ to an enzyme-bound carbonyl group, with acetyl CoA-synthase (2) participating in the generation of acetyl-CoA, which in turn is converted to acetate. B) A modified Tricarboxylic Acid (TCA) cycle utilized by sulfate reducing bacteria to generate ATP via acetate oxidation. Key enzymes detected through metatranscriptomics analysis are numbered. 


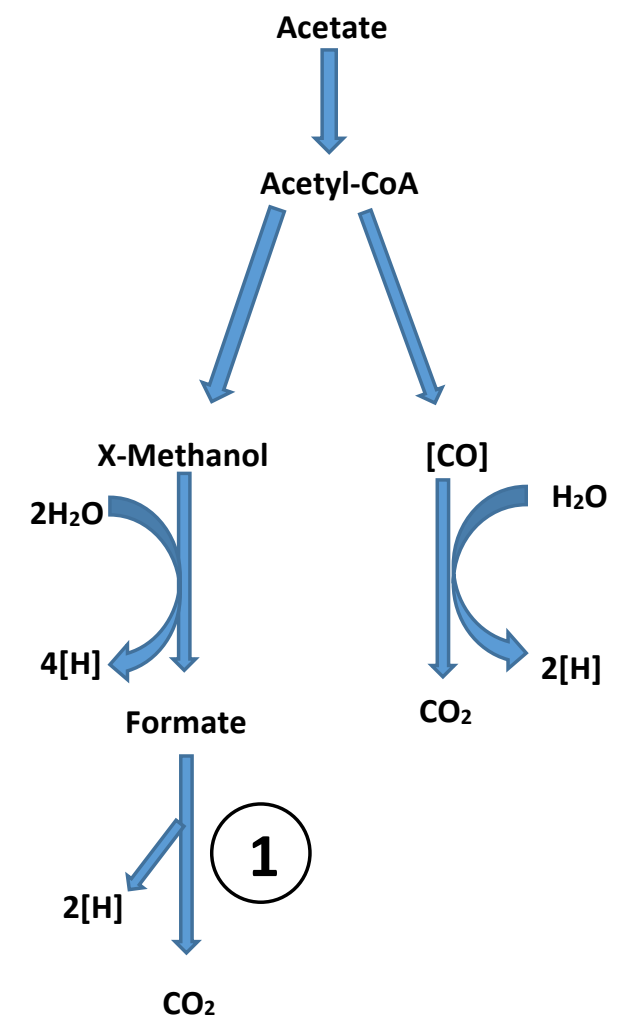

Figure 3.6: Acetyl-CoA pathway for acetate utilization by sulfate reducing bacteria. The reaction pathway is essentially the reverse of the acetogenic Wood-Ljungdahl pathway. Formate dehydrogenase (1) catalyzes the conversion of formate to $\mathrm{CO}_{2}$. 


\begin{tabular}{|c|c|c|c|c|}
\hline \multirow[b]{3}{*}{ Sulfur } & assimilatory sulfite reductase (ferredoxin) - & ○ & ○ & ○ \\
\hline & phosphoadenylylsulfate reductase (thioredoxin) - & O & 0 & O \\
\hline & adenylylsulfate reductase - & O & ○ & O \\
\hline \multirow{3}{*}{ Metabolism } & assimilatory sulfite reductase (NADPH) - & O & O & O \\
\hline & 3'-phosphoadenosine 5'-phosphosulfate synthase - & O & $\bigcirc$ & $\mathrm{O}$ \\
\hline & sulfate adenylyltransferase - & O & O & O \\
\hline \multirow{7}{*}{ TCA Cycle } & dihydrolipoyllysineresidue succinyltransferase - & & & \\
\hline & fumarate hydratase - & & & \\
\hline & citrate (Si)synthase - & & & \\
\hline & SuccinateCoA ligase (ADPforming) - & & & \\
\hline & succinate dehydrogenase - & & & \\
\hline & oxoglutarate dehydrogenase (succinyltransferring) - & & & \\
\hline & isocitrate dehydrogenase (NADP+) - & & & \\
\hline \multirow{3}{*}{ Acetogenesis } & (acetyl coA-synthase) - & & 0 & ○ \\
\hline & carbonmonoxide dehydrogenase (acceptor) - & O & 0 & 은 \\
\hline & & 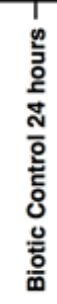 & 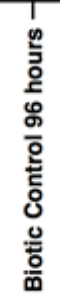 & 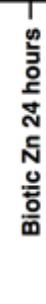 \\
\hline
\end{tabular}

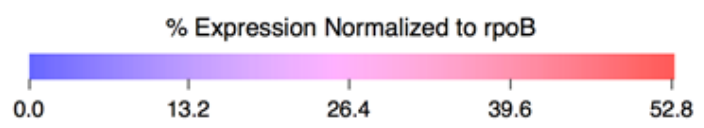

Figure 3.7: Key enzyme transcripts of energy metabolism pathways in the Biotic Control at 24 and 96 hours and Biotic $\mathrm{Zn}$ at 24 hours. The size and colour of the circles represents the normalized abundance of each transcript. 


\subsection{References}

Baker B. J. and Banfield J. F. (2003) Microbial communities in acid mine drainage. FEMS Microbiol. Ecol. 44, 139-52.

Baldwin S. A., Khoshnoodi M., Rezadehbashi M., Taupp M., Hallam S., Mattes A. and Sanei H. (2015) The microbial community of a passive biochemical reactor treating arsenic, zinc, and sulfate-rich seepage. Front. Bioeng. Biotechnol. 3, 27.

Bao, Z., Sato, Y., Kubota, M., \& Ohta, H. (2006) Isolation and characterization of thalliumtolerant bacteria from heavy metal-polluted river sediment and non-polluted soils. Microbes and Environments, 21(4), 251-260.

Bond P. L., Druschel G. K. and Banfield J. F. (2000) Comparison of Acid Mine Drainage Microbial Communities in Physically and Geochemically Distinct Ecosystems Comparison of Acid Mine Drainage Microbial Communities in Physically and Geochemically Distinct Ecosystems. Appl. Environ. Microbiol. 66, 4962-4971.

Brandis-heep A., Gebhardt N. A., Thauer R. K., Widdei F. and Pfennig N. (1983) Anaerobic acetate oxidation to COs by Desulfobacter postgatei. Microbiology, 222-229.

Christiansen, N., \& AHRING, B. K. (1996) Desulfitobacterium hafniense sp. nov., an anaerobic, reductively dechlorinating bacterium. International Journal of Systematic and Evolutionary Microbiology, 46(2), 442-448.

Dalla Vecchia, E., Suvorova, E. I., Maillard, J., \& Bernier-Latmani, R. (2014) Fe (III) reduction during pyruvate fermentation by Desulfotomaculum reducens strain MI-1. Geobiology, 12(1), 48-61.

Denef V. J., Mueller R. S. and Banfield J. F. (2010) AMD biofilms: using model communities to study microbial evolution and ecological complexity in nature. ISME J. 4, 599-610.

Deutscher M. P. (2003) Degradation of Stable RNA in Bacteria. J. Biol. Chem. 278, 45041-45044.

Deutscher M. P. (2006) Degradation of RNA in bacteria: Comparison of mRNA and stable RNA. Nucleic Acids Res. 34, 659-666.

Diaz-Ravina, M., \& Baath, E. (1996) Development of metal tolerance in soil bacterial communities exposed to experimentally increased metal levels. Applied and Environmental Microbiology, 62(8), 2970-2977.

DiLoreto Z. A., Weber P. A., Olds W., Pope J., Trumm D., Chaganti S. R., Heath D. D. and Weisener C. G. (2016) Novel cost effective full scale mussel shell bioreactors for metal removal and acid neutralization. J. Environ. Manage.

Drake, H. L., Gößner, A. S., \& Daniel, S. L. (2008). Old acetogens, new light. Annals of the New York Academy of Sciences, 1125(1), 100-128.

Druschel G. K. and Dick G. J. (2014) Advancing Geomicrobiology and Microbial Geochemistry. Eos, Trans. Am. Geophys. Union 95, 90. 
Ellis, R. J., Morgan, P., Weightman, A. J., \& Fry, J. C. (2003) Cultivation-dependent andindependent approaches for determining bacterial diversity in heavy-metal-contaminated soil. Applied and environmental microbiology, 69(6), 3223-3230.

Fortunato C. S. and Crump B. C. (2015) Microbial Gene Abundance and Expression Patterns across a River to Ocean Salinity Gradient. PLOS one, 1-22.

Gerritse, J., Renard, V., Gomes, T. P., Lawson, P. A., Collins, M. D., \& Gottschal, J. C. (1996) Desulfitobacterium sp. strain PCE1, an anaerobic bacterium that can grow by reductive dechlorination of tetrachloroethene or ortho-chlorinated phenols. Archives of microbiology, 165(2), 132-140.

Hiibel S. R., Pereyra L. P., Breazeal M. V. R., Reisman D. J., Reardon K. F. and Pruden A. (2011) Effect of Organic Substrate on the Microbial Community Structure in Pilot-Scale SulfateReducing Biochemical Reactors Treating Mine Drainage. Environ. Eng. Sci. 28, 563-572.

Hua Z.-S., Han Y.-J., Chen L.-X., Liu J., Hu M., Li S.-J., Kuang J.-L., Chain P. S., Huang L.-N. and Shu W.-S. (2014) Ecological roles of dominant and rare prokaryotes in acid mine drainage revealed by metagenomics and metatranscriptomics. ISME J. 9, 1280-1294.

Junier, P., Frutschi, M., Wigginton, N. S., Schofield, E. J., Bargar, J. R., \& Bernier-Latmani, R. (2009) Metal reduction by spores of Desulfotomaculum reducens. Environmental microbiology, 11(12), 3007-3017.

Kotsyurbenko, O. R., Glagolev, M. V., Nozhevnikova, A. N., \& Conrad, R. (2001) Competition between homoacetogenic bacteria and methanogenic archaea for hydrogen at low temperature. FEMS Microbiology Ecology, 38(2-3), 153-159

Labrenz M. and Banfield J. F. (2004) Sulfate-reducing bacteria-dominated biofilms that precipitate ZnS in a subsurface circumneutral-pH mine drainage system. Microb. Ecol. 47, 20517.

Monreal, J., \& Reese, E. T. (1969) The chitinase of Serratia marcescens. Canadian Journal of Microbiology, 15(7), 689-696.

Moran M. A., Satinsky B., Gifford S. M., Luo H., Rivers A., Chan L., Meng J., Durham B. P., Shen C., Varaljay V. a, Smith C. B., Yager P. L. and Hopkinson B. M. (2013) Sizing up metatranscriptomics. ISME J. 7, 237-43.

Müller, B., Sun, L., \& Schnürer, A. (2013) First insights into the syntrophic acetate-oxidizing bacteria-a genetic study. MicrobiologyOpen, 2(1), 35-53.

Murray, W. D. (1986) Symbiotic relationship of Bacteroides cellulosolvens and Clostridium saccharolyticum in cellulose fermentation. Applied and environmental microbiology, 51(4), 710714.

Muyzer G. and Stams A. J. M. (2008) The ecology and biotechnology of sulphate-reducing bacteria. Nat. Rev. Microbiol. 6, 441-54.

Norris, P., Man, W. K., Hughes, M. N., \& Kelly, D. P. (1976) Toxicity and accumulation of thallium in bacteria and yeast. Archives of microbiology, 110(2-3), 279-286. 
Ozuolmez D., Na H., Lever M. A., Kjeldsen K. U., Jørgensen B. B. and Plugge C. M. (2015) Methanogenic archaea and sulfate reducing bacteria co-cultured on acetate: teamwork or coexistence? Front. Microbiol. 6, 492.

Paulo L. M., Stams A. J. M. and Sousa D. Z. (2015) Methanogens, sulphate and heavy metals: a complex system. Rev. Environ. Sci. Biotechnol. 14, 537-553.

Piotrowska-Seget, Z., Cycoń, M., \& Kozdroj, J. (2005) Metal-tolerant bacteria occurring in heavily polluted soil and mine spoil. Applied Soil Ecology, 28(3), 237-246.

Sánchez-Andrea I., Sanz J. L., Bijmans M. F. M. and Stams A. J. M. (2014) Sulfate reduction at low pH to remediate acid mine drainage. J. Hazard. Mater. 269, 98-109.

Schauder, R., Eikmanns, B., Thauer, R. K., Widdel, F., \& Fuchs, G. (1986) Acetate oxidation to CO2 in anaerobic bacteria via a novel pathway not involving reactions of the citric acid cycle. Archives of microbiology, 145(2), 162-172.

Scheller, S., Goenrich, M., Boecher, R., Thauer, R. K., \& Jaun, B. (2010) The key nickel enzyme of methanogenesis catalyses the anaerobic oxidation of methane. Nature, 465(7298), 606-608.

Schippers, A., Breuker, A., Blazejak, A., Bosecker, K., Kock, D., \& Wright, T. L. (2010) The biogeochemistry and microbiology of sulfidic mine waste and bioleaching dumps and heaps, and novel Fe (II)-oxidizing bacteria. Hydrometallurgy, 104(3), 342-350.

Schmidtova J. and Baldwin S. A. (2011) Correlation of bacterial communities supported by different organic materials with sulfate reduction in metal-rich landfill leachate. Water Res. 45, 1115-1128.

Shukor, M. Y., Habib, S. H. M., Rahman, M. F. A., Jirangon, H., Abdullah, M. P. A., Shamaan, N. A., \& Syed, M. A. (2008) Hexavalent molybdenum reduction to molybdenum blue by S. marcescens strain Dr. Y6. Applied Biochemistry and Biotechnology, 149(1), 33-43.

Stams, A. J. M., Elferink, S. O., \& Westermann, P. (2003) Metabolic interactions between methanogenic consortia and anaerobic respiring bacteria. In Biomethanation I (pp. 31-56). Springer Berlin Heidelberg.

Tan G. L., Shu W. S., Hallberg K. B., Li F., Lan C. Y. and Huang L. N. (2007) Cultivation-dependent and cultivation-independent characterization of the microbial community in acid mine drainage associated with acidic Pb/Zn mine tailings at Lechang, Guangdong, China. FEMS Microbiol. Ecol. $59,118-126$.

Thauer RK (1990) Energy metabolism of methanogenic bacteria.Biochim Biophys Acta 1018:256259

Thauer R. K., Jungermann K. and Decker K. (1977) Energy conservation in chemotrophic anaerobic bacteria. Bacteriol. Rev. 41, 100-180.

Vaaje-Kolstad, G., Horn, S. J., van Aalten, D. M., Synstad, B., \& Eijsink, V. G. (2005) The noncatalytic chitin-binding protein CBP21 from Serratia marcescens is essential for chitin degradation. Journal of Biological Chemistry, 280(31), 28492-28497. 


\section{Chapter IV: Conclusions}

\subsection{Summary}

The primary goal of this Thesis work was to investigate the physico-chemical and microbial functional characteristics that influence remediation pathways in a passive treatment system for Acid Mine Drainage (AMD). Emphasis was on the influenced precipitation of zinc sulfide minerals by sulfate-reducing bacteria (SRB) as a Zn-removal pathway. In a successful passive treatment system, SRB will thrive in the anoxic regions of bioreactors, producing hydrogen sulfide as a by-product of their metabolism. This hydrogen sulfide reacts with divalent metals generating insoluble metal sulfides, effectively immobilizing these metals from solution; a state where they are less bio-available. This mechanism was studied in material from a passive mussel shell bioreactor (MSB) implemented at the Stockton Coal Mine of New Zealand using dedicated bacterial enrichments in controlled lab-experiments, with a set of defined hypotheses to be tested. In this approach, solution chemistry, mineral precipitation, and the functioning microbial community could be characterized to resolve the parameters that would allow for a successful decrease in metal concentrations.

Chapter 2 focused on physico-chemical analysis of bacterial enrichments during ZnS precipitation events, tracking cell activity, concentrations of metals ( $\mathrm{Zn}$ and $\mathrm{TI}$ ), sulfate, and hydrogen sulfide, and precipitation events through sacnning electron microscopy. Treatments are summarized in Table 2.1. Through experimentation and statistical analysis, it was determined that all biotic treatments amended with metals were able to decrease $\mathrm{Zn}$ concentrations and generate hydrogen sulfide significantly over control treatments (Table 2.2), thus the $1^{\text {st }}$ null hypothesis was rejected. Through mass balance calculations, the majority of $\mathrm{Zn}$ removal was postulated to be by adsorption to cell surfaces, and to a lesser extent by precipitation of $\mathrm{ZnS}$. Zn 
removal percentages by reaction with sulfide were estimated at $3.5 \%, 3.3 \%$, and $3.7 \%$ for the Biotic $\mathrm{Zn}$, Biotic $\mathrm{ZnTl}_{1}$, and Biotic $\mathrm{ZnTl}_{25}$ treatments, respectively. These values coincided with relatively low hydrogen sulfide production within the mixed bacterial community compared to other pure SRB culture studies. A disproportionately lower production of hydrogen sulfide was measured compared to the amount of sulfate removed from the system. This was explained by the identification of sulfate-transforming gene transcripts, yet the absence of downstream transcripts of hydrogen sulfide production. An assimilatory sulfate reduction pathway was believed to be driving early sulfate removal ( 0 to 96 hours) opposed to a dissimilatory pathway. The overall bacterial activity seemed to respond differently in treatments amended with metals compared to those without. The addition of $\mathrm{Zn}$ and $\mathrm{TI}$ decreased cell counts and imposed a lag on cell growth as observed by relative $16 \mathrm{~S}$ rRNA concentrations, thus the $2^{\text {nd }}$ null hypothesis was rejected. However, metals did not appear to affect final SRB contributions (i.e. sulfate removal), thus it was hypothesized that inhibitory metal impacts were fixated primarily on the early bacterial community. Scanning electron microscopy (SEM) and energy dispersive spectroscopy (EDS) investigations observed precipitates comprised of $\mathrm{Zn}$ and $\mathrm{S}$ in treatments amended with bacteria and $\mathrm{Zn}$ after 450 hours, but not in control treatments, thus were believed to be generated as a result of bacterial sulfate reduction. The precipitates exhibited a similar size range to biotically-influenced ZnS from other studies, as well as to ZnS examined from raw material from the anoxic layer of the MSB itself. However, lab generated ZnS differed considerably from naturalanalogues in abundance and formation habit, often observed as rare, single precipitates opposed to botryoidal aggregates (Figure 2.6, 2.7). The presence of organics and/or biofilms were predicted to have driven ZnS formations in the raw MSB material. Furthermore, though SRB were present in the mixed communities of the experimental treatments, their activity was likely hindered by 
more dominant species, resulting in less $\mathrm{ZnS}$ generation than expected. These observations resulted in a rejection of the $3^{\text {rd }}$ null hypothesis.

Chapter 3 focused on characterizing the relative abundance of active bacterial groups and dominant metabolic pathways in a Biotic Control and a $\mathrm{Zn}$-amended Biotic $\mathrm{Zn}$ treatment during early experimental time points ( 24 to 96 hours). This was performed through $16 \mathrm{~S}$ rRNA amplicon sequencing and metatranscriptomics, both based on total RNA extractions. It was observed that both treatments were dominated by the phyla Firmicutes and Proteobacteria, though the abundance and genera-constituents of these groups varied with time and with treatment. The Biotic Control exhibited an early abundance (24 hours) of families within the order Clostridiales, which were resolved to be mainly species of Clostridum. These species remained dominant throughout the Biotic Control, with the exception of the 48-hour time point, where Pseudomonas spp. showed higher relative abundance, along with bacteria of the, Lachnospiraceae and Moraxellaceae. At 24 hours, high relative transcripts for acetogenesis were identified through metatranscriptomic analysis, corresponding to lactate utilization by abundant acetogenic Clostridium species. This pathway was downregulated at 96 hours, indicating an exhaustion of lactate as a carbon substrate. Lactate-utilizing SRB were the most abundant sulfate reducers present throughout the Biotic Control, including Desulfitobacterium hafniense and Desulfotomaculum reducens, however acetate-utilizing species were also present and showed relative increases in abundance from 24 to 96 hours, including Desulfotomacculum acetoxidans and Desulfuromonas acetoxidans. The increased abundance of the acetate-metabolising variety over time was likely due to the corresponding availability of acetate, generated by Clostridium spp. Acetate oxidation was deemed to be occurring through a modified tricarboxylic acid (TCA) cycle, due to the increased abundance of transcripts from this pathway detected at 96 hours. 
Shannon $H$ and Chao1 diversity indices showed decreasing diversity values with time in the Biotic Control, driven by cell death in the closed system.

In the Bioitc Zn treatment, the genera Pseudomonas and Serratia expressed higher dominance at 24 hours with little influence by bacteria of the Clostridiales, including SRB. Pseudomonas spp. exhibited a higher resistance to metal loads, as observed in other research, and thus were able to persist through early experimental time points and outcompete other bacterial groups, while Serratia spp. likely thrived for similar reasons and performed in the bioreactor as key chitin degraders. TCA cycle transcripts were the highest of all samples at 24 hours in the Biotic $\mathrm{Zn}$ treatment, inferring this as the primary pathway for lactate oxidation by Pseudomonas spp. Low acetogenic pathway transcripts could explain a lag in SRB abundance, as acetate would be an easily-utilized carbon substrate for these bacteria. This would also explain a lag in hydrogen sulfide production in the Biotic Zn treatment compared to the Biotic Control. Despite this apparent lag, final SRB activity did not seem to be affected based on sulfate-removal rates that were consistent across metal and non-metal amended treatments. Dissimilatory sulfate reduction gene transcripts were either absent or in very low abundance during the time points investigated (24-96 hours), and thus sulfide generation was not accelerated until after 100 hours, as also indicated through chemical data. Rather, assimilatory sulfate reduction pathways were driving early sulfate removal.

The detection of SRB in the Biotic Control rejects the $1^{\text {st }}$ null hypothesis for this chapter, but low abundances in the Biotic $\mathrm{Zn}$ means that the same hypothesis cannot be rejected in the context of that treatment. As dissimilatory sulfite reduction genes were not detected during early experimental time points, the $2^{\text {nd }}$ null hypothesis set forth cannot be rejected. The major Clostridium and SRB identified in both treatments were endospore-forming varieties. This observation, along with the apparent metal-resistance of Pseudomonas and Serratia highlights 
the importance of resistance mechanisms in bacteria that are favourable in remediation technologies, including those applied to AMD treatment.

\subsection{Reflections and Future Work}

With improved sequencing platforms and bioinformatics pipeline software, it is becoming less rigorous and expensive to prepare and analyse large microbial datasets from environmental samples (Dick et al., 2015). This is allowing researchers to resolve, with more detail, the in-situ functioning of metabolic pathways driven by bacteria, such as in metatranscriptomic analysis. Of remediation relevance are those involved in the transformation/degradation of contaminants into more easily-degradable, less bio-available forms. The work in this Thesis has aided in the understanding of one of these positive fundamental pathways; the precipitation of potentially toxic metals from solution driven by sulfate-reducing bacteria. Although this process is well understood from a mechanistic point of view, there is much to be revealed of how SRB function as part of a grander microbial community, and how other species may facilitate or obstruct favourable chemical reactions. This research has shown that spore-forming SRB species have persisted in enrichments from a metal-laden treatment system. Thus, bacterial resistance to extreme conditions and the ability to adapt to fluctuating physical and chemical settings has relevance in remediation studies. Similar conclusions have been reached in degradation studies of petroleum hydrocarbons and biphenyls by Desulfotomacculum, showing that this genus is a vital component in a spectrum of contaminant degradation processes, and should be the focus of deeper investigation (Morasch et al., 2004; Selesi et al., 2009). This research has also observed the importance of substrate cycling in a microbial community, or simply put; one bacteria's trash is another one's treasure. SRB may not be able to thrive without easily degradable substrates provided by the breakdown of complex carbon (ex. cellulose, chitin, lignin) by other species. An example of this was characterized in this study, where lactate oxidation to acetate by fermentive 
Clostridium paved the way for sulfate reduction. This pathway could be better elucidated by applying genomic and transcriptomic techniques in parallel with flux balanced analysis (FBA) to quantify the fates of key carbon substrates (Edwards et al., 2002; Rao et al., 2011), and investigating a possible reversal of acetate metabolism that is relevant in anaerobic systems (Wolfe et al., 2005). The incorporation of stable isotope analysis could also be applied as indicators of biological sulfate reduction (Yoon et al., 2012).

This work has also demonstrated the advantages of an interdisciplinary approach to microbial systems, where both molecular and chemical methods can aid in unravelling in-situ functioning. For example, traditional assays have relied on the removal of sulfate as a proxy for sulfide generation rates, but this research has established that this link is not always clear cut. Assessment of gene pathways, including both dissimilatory and assimilatory sulfate reduction, can aid in tracking the cycling of sulfur in anaerobic environments and account for discrepancies observed from solution chemistry data. Such investigations may also be applied in resolving simultaneous sulfide-oxidation pathways that drive cryptic sulfur turnover in sediments, driven by mixed consortia of bacteria (Hausmann et al., 2016), or used in settings where SRB activity is undesirable, such as in the souring of hydrocarbons or in corrosion of infrastructure by hydrogen sulfide (Enning et al., 2014).

Though powerful, it should be noted that metatranscriptomic analysis is not without its limitations. While it is assumed that transcriptomic investigation reveals the actual active genes or gene pathways at a given time, it does not account for post-transcriptional modifications, and thus cannot be interpreted religiously as a direct indication of gene output, but rather a proxy for gene "potential" (i.e., just because an RNA molecule is synthesized, does not mean it will be translated into protein) (Abram et al., 2015., Bikel et al., 2015). The fields of proteomics and metabolomics that seek to resolve microbial functioning further down the translation path have 
potential in future microbial ecology studies, however bioinformatics software, pipelines, and libraries are still being developed to interpret accurately the data provided by such techniques, as well as overcoming hurdles related to large microbial genetic heterogeneity in environmental samples (Otto et al., 2014; Simon et al., 2011; Ulrich-Merzenich et al., 2007). Despite limitations, metatranscriptomics currently serves as a valuable and relevant technique, and can be utilized for prospecting of key genes or gene pathways, that can then be quantified by techniques such as targeted qPCR. Such as approach could add to the data collected for this thesis, if the experiment were to be repeated.

In conclusion, the data communicated in this dissertation has demonstrated the advantages of a multidisciplinary approach in environmental microbial ecology research, where chemical, microscopy, and molecular techniques have been combined in efforts to better understand fundamental mechanisms in bioremediation applications. These results can be applied in the improved implementation and monitoring of passive treatment technologies for metal-laden environments, where comprehension of favourable bacterial community functioning is required. 


\subsection{References}

Dick G. J. and Lam P. (2015) Omic Approaches to Microbial Geochemistry. Elements 11, 403408.

Edwards, J. S., Covert, M., \& Palsson, B. (2002). Metabolic modelling of microbes: the fluxbalance approach. Environmental microbiology, 4(3), 133-140.

Enning, D., \& Garrelfs, J. (2014) Corrosion of iron by sulfate-reducing bacteria: new views of an old problem. Applied and environmental microbiology, 80(4), 1226-1236.

Hausmann B., Knorr K.-H., Schreck K., Tringe S. G., Glavina del Rio T., Loy A. and Pester M. (2016) Consortia of low-abundance bacteria drive sulfate reduction-dependent degradation of fermentation products in peat soil microcosms. ISME J. 10, 1-11.

Morasch, B., Schink, B., Tebbe, C. C., \& Meckenstock, R. U. (2004) Degradation of o-xylene and $\mathrm{m}$-xylene by a novel sulfate-reducer belonging to the genus Desulfotomaculum. Archives of Microbiology, 181(6), 407-417.

Otto, A., Becher, D., \& Schmidt, F. (2014) Quantitative proteomics in the field of microbiology. Proteomics, 14(4-5), 547-565.

Rao S., Kim D. and Lalman J. A. (2011) Flux balance analysis of mixed anaerobic microbial communities: Effects of linoleic acid (LA) and pH on biohydrogen production. Int. J. Hydrogen Energy 36, 14141-14152.

Selesi, D., \& Meckenstock, R. U. (2009) Anaerobic degradation of the aromatic hydrocarbon biphenyl by a sulfate-reducing enrichment culture. FEMS microbiology ecology, 68(1), 86-93.

Simon C. and Daniel R. (2011) Metagenomic Analyses: Past and Future Trends. Appl. Environ. Microbiol. 77, 1153-1161.

Wolfe, A. J. (2005). The acetate switch. Microbiology and molecular biology reviews, 69(1), 1250 .

Ulrich-Merzenich G., Zeitler H., Jobst D., Panek D., Vetter H. and Wagner H. (2007) Application of the "-Omic-" technologies in phytomedicine. J. Nat. Remedies 7, 1-18.

Yoon S. J., Yáñez C., Bruns M. A., Martínez-Villegas N. and Martínez C. E. (2012) Natural zinc enrichment in peatlands: Biogeochemistry of ZnS formation. Geochim. Cosmochim. Acta 84, 165-176. 


\section{APPENDICES}

Appendix A

\begin{tabular}{lccccc} 
ANOVA \\
\hline $\begin{array}{c}\text { Test for equal } \\
\text { means }\end{array}$ \\
& Sum of sqrs & df & $\begin{array}{c}\text { Mean } \\
\text { square }\end{array}$ & F & p (same) \\
& & & & & \\
Between groups: & 1348.52 & 3 & 449.505 & 1108 & $9.90 \mathrm{E}-10$ \\
Within groups: & 2.83979 & 7 & 0.405685 & & \\
Total: & 1351.36 & 10 & & & \\
\hline
\end{tabular}

Tukey's pairwise comparisons

Abiotic Zn Biotic Zn BioZnTl 1 BioZnTI 25

\begin{tabular}{lr|r|r|} 
Abiotic Zn & 0.00025 & 0.0002519 & 0.000252 \\
Biotic Zn & 0.6098 & 0.08577 \\
BioZnTI $_{1}$ & 0.01734 \\
\hline
\end{tabular}

BioZnTI $_{25}$

Input Data (Zinc $\mathrm{mg} \mathrm{L}^{-1}$ )

$\begin{array}{llll}\text { Abiotic Zn } & \text { Biotic Zn } & \text { BioZnTI }_{1} & \text { BioZnTI }_{25}\end{array}$

$\begin{array}{llll}1.579646588 & 26.0607665 & 27.8481 & 24.61006527\end{array}$

$\begin{array}{llll}1.5 & 26.8454369 & 27.7504 & 25.13547997\end{array}$

$\begin{array}{lll}1.514339959 & 26.506257 \quad 25.9084\end{array}$

Figure S1: ANOVA Output, Tukey's Pairwise Comparisons, and Input data for zinc concentration change across $\mathrm{Zn}$-amended treatments. Square boxes represent statistically significant comparisons. 
ANOVA

Test for equal means

\begin{tabular}{llrrrrr} 
& \multicolumn{1}{l}{$\begin{array}{l}\text { Sum of } \\
\text { sqrs }\end{array}$} & \multicolumn{5}{c}{ Mean } \\
& df & square & $F$ & $p$ (same) \\
Between groups: & 594531 & & 5 & 118906 & 8.746 & 0.001076 \\
Within groups: & 163141 & 12 & 13595.1 & & \\
Total: & 757672 & 17 & & & \\
\hline
\end{tabular}

Tukey's pairwise comparisons

Abiotic Abiotic Biotic

Control $\mathrm{Zn} \quad$ Control Biotic Zn Biotic $\mathrm{ZnTl}_{1} \quad$ Biotic $\mathrm{ZnTl}_{25}$

Abiotic Control

1

\begin{tabular}{|l|l|}
\hline 0.02391 & 0.003345 \\
\hline 0.03186 & 0.004375 \\
\hline
\end{tabular}

Abiotic Zn

0.8296

\begin{tabular}{lr}
0.1995 & 0.0165 \\
\cline { 2 - 2 } 0.2557 & 0.02196 \\
0.7792 & 0.9999 \\
0.1986 & 0.9165 \\
& 0.6583
\end{tabular}

Biotic Control

Biotic Zn

0.6583

BioZnTI $_{25}$

Input Data (Sulfate diff $\mathrm{mg} \mathrm{L}^{-1}$ )

Abiotic Control

Abiotic Biotic Biotic

Zn Control Biotic Zn $\mathrm{ZnTI}_{\mathbf{1}}$

Biotic $\mathrm{ZnTI}_{25}$

$\begin{array}{rrrrrr}61.9 & 24.9 & 630.7 & 609.7 & 246.4 & 433.3 \\ 9.4 & 127.8 & 189.7 & 525.7 & 433.3 & 504.7 \\ 80.8 & 48 & 416.5 & 443.8 & 185.5 & 361.9\end{array}$

Figure S2: ANOVA Output, Tukey's Pairwise Comparisons, and Input data for Sulfate concentration change across all treatments. Square boxes represent statistically significant comparisons. 
ANOVA

Test for equal means

\begin{tabular}{lrcccc} 
& & \multicolumn{5}{c}{ Mean } \\
& Sum of sqrs & df & square & $F$ & p (same) \\
Between groups: & 2325.78 & 5 & 465.155 & 91.72 & $3.90 \mathrm{E}-09$ \\
Within groups: & 60.8603 & 12 & 5.0717 & & \\
Total: & 2386.64 & 17 & & & \\
\hline
\end{tabular}

Tukey's pairwise comparisons

Abiotic

Control

Abiotic Control

Abiotic Zn

Biotic Control

Biotic Zn

Abiotic Biotic

BioZnTI

Zn Control 0.8835

Control Biotic Zn $\quad$ BioZnTl $_{1} \quad$ BioZnTI $_{25}$

BioZnTI $_{25}$



\begin{tabular}{rlllll}
\multicolumn{1}{l}{ Abiotic Control } & Abiotic Zn & $\begin{array}{l}\text { Biotic } \\
\text { Control }\end{array}$ & Biotic Zn & \multicolumn{2}{l}{ Biotic } \\
ZnTI $_{\mathbf{1}}$ & Biotic ZnTI $_{25}$ \\
0 & 2.66380345 & 35.91535 & 9.794877875 & 13.30115 & 17.07018 \\
6.000711406 & -0.0146855 & 37.79986 & 12.64050273 & 12.54734 & 14.05495 \\
4.57789898 & 2.01727164 & 35.16154 & 11.2176903 & 18.57779 & 17.82399
\end{tabular}

Figure S3: ANOVA Output, Tukey's Pairwise Comparisons, and Input data for maximum hydrogen sulfide concentrations $\left(\mathrm{H}_{2} \mathrm{~S}\right.$ max $)$ across all treatments. Square boxes represent statistically significant comparisons. 
ANOVA

Test for equal

means

\begin{tabular}{lccccc} 
& Sum of & \multicolumn{5}{c}{ Mean } \\
& sqrs & df & square & $F$ & $p$ (same) \\
Between groups: & 561.674 & 5 & 112.335 & 9.937 & 0.000605 \\
Within groups: & 135.655 & 12 & 11.3046 & & \\
Total: & 697.329 & 17 & & & \\
\hline
\end{tabular}

Tukey's pairwise comparisons

Abiotic

Abiotic Biotic Biotic Biotic

Control

$\mathrm{Zn}$

1

Abiotic Control

Abiotic Zn

Biotic Control

Biotic Zn

年

\begin{tabular}{|c|c|c|c|}
\hline 0.001075 & 0.9904 & 0.969 & 0.9904 \\
\cline { 1 - 1 } 0.001014 & 0.9866 & 0.9607 & 0.9866 \\
\hline & 0.002476 & 0.003262 & 0.002476 \\
\cline { 2 - 3 } & &
\end{tabular}

Biotic ZnTI

1

1

1

Biotic $\mathrm{ZnTl}_{25}$

Input Data (Hydrogen Sulfide $\mu \mathrm{mol} \mathrm{L}^{-1}$ )

\begin{tabular}{cllrrl} 
& Abiotic & Biotic & \multicolumn{2}{l}{ Biotic } \\
Abiotic Control & Zn & Control & Biotic Zn & \multicolumn{1}{l}{$\mathrm{ZnTl}_{1}$} & Biotic ZnTI \\
1.832548259 & 2.663803 & 23.07574 & 4.788122 & 1.37074 & 2.756165 \\
2.294356701 & -0.01469 & 9.221483 & 0.447123 & 4.603399 & 2.571442 \\
0.908931375 & 2.017272 & 20.30489 & 4.603399 & 5.342292 & 4.511037
\end{tabular}

Figure S4: ANOVA Output, Tukey's Pairwise Comparisons, and Input data for final hydrogen sulfide concentrations $\left(\mathrm{H}_{2} \mathrm{~S}\right.$ final) across all treatments. Square boxes represent statistically significant comparisons. 
Table S1: Shannon $H$ and Chao1 Index values for Biotic Control and Biotic Zn treatments for 24, 48, 72, and 96 hours.

\begin{tabular}{|c|c|c|c|c|}
\hline & Shannon $H$ & & Chao1 & \\
\hline $\begin{array}{l}\text { Time } \\
\text { (hours) }\end{array}$ & Biotic & Biotic Zn & Biotic & Biotic Zn \\
\hline 24 & 5.05009544 & 2.20870695 & 260.894118 & 118.588235 \\
\hline 48 & 4.85994773 & 4.60641971 & 300.538462 & 248.5 \\
\hline 72 & 3.44097356 & 4.14465283 & 285.607143 & 287.204545 \\
\hline 96 & 3.49027076 & 4.19924901 & 250.0625 & 282.666667 \\
\hline
\end{tabular}

Table S2: Read numbers before and after filtering of $16 \mathrm{~S}$ rRNA amplicon sequenced samples for Biotic Control and Biotic Zn treatment.

\begin{tabular}{llllll} 
Sample Time Point (Hours) & & $\mathbf{2 4}$ & $\mathbf{4 8}$ & $\mathbf{7 2}$ & $\mathbf{9 6}$ \\
\hline Biotic Control & Unfiltered & 146684 & 36352 & 66078 & 53791 \\
& $\begin{array}{l}\text { Filtered } \\
\text { (minimum } \\
\text { cut-off 50) }\end{array}$ & 145926 & 24564 & 60456 & 45071 \\
& $\begin{array}{l}\text { Unfiltered } \\
\text { Biotic Zn }\end{array}$ & 86610 & 43774 & 91984 & 40527 \\
& $\begin{array}{l}\text { Filtered } \\
\text { (minimum } \\
\text { cut-off 50) }\end{array}$ & 74063 & 34582 & 75283 & 31644 \\
\hline
\end{tabular}


Table S3: Sequence data pre and post quality control for metatranscriptomic datasets analyzed through MG-RAST.

\begin{tabular}{|c|c|c|c|c|c|c|c|c|}
\hline & & & $\begin{array}{l}\text { Uploaded } \\
\text { Sequence } \\
\text { Count }\end{array}$ & $\begin{array}{l}\text { Post QC } \\
\text { Sequence } \\
\text { Count }\end{array}$ & $\begin{array}{l}\text { Post QC } \\
\text { Mean } \\
\text { Sequence } \\
\text { Length }\end{array}$ & $\begin{array}{l}\text { Identified } \\
\text { Protein } \\
\text { Features }\end{array}$ & $\begin{array}{l}\text { Identified rRNA } \\
\text { Features }\end{array}$ & $\begin{array}{l}\text { Annotated } \\
\text { Identified } \\
\text { Functional } \\
\text { Categories }\end{array}$ \\
\hline 24 & Biotic & & & & & & & \\
\hline \multirow[t]{6}{*}{ hours } & Control & Sample1 & $37,626,806$ & $7,788,749$ & $119 \pm 32 b p$ & 745,321 & 3,695 & 606,967 \\
\hline & & Sample2 & $36,927,006$ & $7,571,353$ & $119 \pm 32 b p$ & 736,930 & 3,518 & 599,209 \\
\hline & & Average & $37,276,906$ & $7,680,051$ & $119 \pm 32 b p$ & 741,126 & 3,607 & 603,088 \\
\hline & Biotic Zn & Sample1 & $53,380,957$ & $8,713,736$ & $122 \pm 33 b p$ & 653,339 & 5,815 & 590,283 \\
\hline & & Sample2 & & & & & & \\
\hline & & Average & $53,380,957$ & $8,713,736$ & & 653,339 & & 590,283 \\
\hline 96 & Biotic & & & & & & & \\
\hline \multirow[t]{3}{*}{ hours } & Control & Sample1 & $28,360,469$ & $5,858,009$ & $117 \pm 30 \mathrm{bp}$ & 645,646 & 4,010 & 495,485 \\
\hline & & Sample2 & $40,398,374$ & $7,594,944$ & $117 \pm 30 \mathrm{bp}$ & 790,453 & 4,523 & 606,426 \\
\hline & & Average & $34,379,422$ & $6,726,477$ & $117 \pm 30$ bp & 718,050 & 4,267 & 550,956 \\
\hline
\end{tabular}


Table S4: Normalized relative abundance values (\%) from duplicates for key transcripts across samples. Duplicates are shown from the Biotic Control at 24 and 96 hours and from the Biotic Zn treatment at 24 hours. Values are normalized to rpob, and displayed with Enzyme Commission numbers (E.C.)

\begin{tabular}{|c|c|c|c|c|c|c|c|}
\hline & E.C. number & $\begin{array}{l}\text { Bio Control } \\
24 \mathrm{~A}\end{array}$ & $\begin{array}{l}\text { Bio } \\
\text { Control } \\
24 \mathrm{~B}\end{array}$ & $\begin{array}{l}\text { Bio } \\
\text { Control } \\
96 \mathrm{~A}\end{array}$ & $\begin{array}{l}\text { Bio } \\
\text { Control } \\
96 \mathrm{~B}\end{array}$ & $\begin{array}{l}\text { Bio } Z n \\
24 A\end{array}$ & $\begin{array}{l}\text { Bio } Z n \\
24 B\end{array}$ \\
\hline \multirow[t]{2}{*}{ 3'-phosphoadenosine $5^{\prime}$-phosphosulfate synthase } & 2.7.7.4 2.7.1.25 & 1.70 & 1.53 & 3.06 & 3.13 & 1.75 & 1.68 \\
\hline & 1.2.7.4 1.2.99.2 & & & & & & \\
\hline Acetyl-CoA Synthase & 2.3.1.169 & 11.00 & 11.21 & 0.88 & 1.01 & 0.00 & 0.01 \\
\hline Aconitase & 4.2.1.3 4.2.1.99 & 11.59 & 11.11 & 18.91 & 18.49 & 33.20 & 33.48 \\
\hline adenylylsulfate reductase & 1.8.99.2 & 0.03 & 0.01 & 0.004 & 0.005 & 0.008 & 0.030 \\
\hline assimilatory sulfite reductase (ferredoxin) & 1.8.7.1 & 0.16 & 0.15 & 0.07 & 0.08 & 0.01 & 0.02 \\
\hline assimilatory sulfite reductase (NADPH) & 1.8.1.2 & 2.26 & 2.18 & 3.23 & 3.42 & 7.19 & 6.73 \\
\hline carbonmonoxide dehydrogenase (acceptor) & 1.2.99.2 & 12.50 & 12.89 & 2.08 & 2.20 & 0.07 & 0.06 \\
\hline citrate (Si)synthase & 2.3.3.1 & 5.84 & 5.71 & 10.46 & 10.21 & 15.21 & 15.02 \\
\hline cysteine synthase & 2.5.1.47 & 3.60 & 3.56 & 5.46 & 6.07 & 11.83 & 11.79 \\
\hline dihydrolipoyllysineresidue succinyltransferase & 2.3.1.61 & 5.14 & 4.95 & 8.92 & 8.33 & 15.24 & 15.32 \\
\hline formate dehydrogenase & 1.2.1.2 & 6.23 & 6.36 & 7.31 & 7.67 & 24.40 & 24.88 \\
\hline fumarate hydratase & 4.2.1.2 & 5.36 & 5.27 & 12.02 & 12.49 & 19.84 & 19.77 \\
\hline isocitrate dehydrogenase (NADP+) & 1.1.1.42 & 12.60 & 12.19 & 19.18 & 19.26 & 23.59 & 23.43 \\
\hline methyl coenzyme $M$ reductase & 2.8.4.1 & N/A & $\mathrm{N} / \mathrm{A}$ & $N / A$ & $\mathrm{~N} / \mathrm{A}$ & $\mathrm{N} / \mathrm{A}$ & $\mathrm{N} / \mathrm{A}$ \\
\hline oxoglutarate dehydrogenase (succinyltransferring)(sucA) & 1.2.4.2 & 11.62 & 11.50 & 19.69 & 19.31 & 38.59 & 39.54 \\
\hline phosphoadenylylsulfate reductase (thioredoxin) & 1.8.4.8 & 0.54 & 0.53 & 0.51 & 0.55 & 1.99 & 1.98 \\
\hline serine Oacetyltransferase & 2.3.1.30 & 1.57 & 1.45 & 2.04 & 2.27 & 3.93 & 3.88 \\
\hline succinate dehydrogenase sdh & 1.3.99.1 & 11.03 & 11.00 & 15.55 & 14.84 & 52.47 & 53.09 \\
\hline SuccinateCoA ligase (ADPforming) & 6.2.1.5 & 9.23 & 9.16 & 14.57 & 13.65 & 25.90 & 25.83 \\
\hline sulfate adenylyltransferase & 2.7.7.4 & 1.21 & 1.15 & 1.60 & 1.71 & 2.24 & 1.90 \\
\hline
\end{tabular}


Table S5: OTU assignments and relative abundance of dominant phyla in the Biotic Control and Biotic Zn treatments for 24, 48, 72, and 96 hours. Abundance values are averages of duplicate samples. Screw Flanders.

Biotic Control

Time

\begin{tabular}{lrrrr}
\hline Time & $\mathbf{2 4}$ & $\mathbf{4 8}$ & $\mathbf{7 2}$ & $\mathbf{9 6}$ \\
Unassigned & 0.1500 & 0.2294 & 0.2115 & 0.2144 \\
k_Bacteria;p_Firmicutes & 0.5900 & 0.2438 & 0.6107 & 0.6322 \\
k_Bacteria;p_Proteobacteria & 0.2200 & 0.5268 & 0.1778 & 0.1534 \\
\hline Biotic Zn & $\mathbf{2 4}$ & $\mathbf{4 8}$ & $\mathbf{7 2}$ & $\mathbf{9 6}$ \\
Unassigned & 0.0294 & 0.1459 & 0.2076 & 0.2351 \\
k_Bacteria;p_Firmicutes & 0.0519 & 0.5214 & 0.4347 & 0.4879 \\
k_Bacteria;p_Proteobacteria & 0.9187 & 0.3326 & 0.3578 & 0.2770 \\
\hline
\end{tabular}


Table S6: OTU assignments and relative abundance values of dominant families in the Biotic Control and Biotic Zn for 24, 48, 72, and 96 hours. Abundance values are averages of duplicate samples.

\begin{tabular}{|c|c|c|c|c|}
\hline Biotic Zn & Time & & & \\
\hline \#OTU ID & 24 & 48 & 72 & \\
\hline Unassigned & 0.0294 & 0.1459 & 0.2076 & 0.235 \\
\hline o__Clostridiales;Other & 0.0013 & 0.0425 & 0.0056 & 0.006 \\
\hline o__Clostridiales;f__ & 0.0006 & 0.0039 & 0.0006 & 0.001 \\
\hline f__Clostridiaceae & 0.0001 & 0.0022 & 0.0038 & 0.004 \\
\hline f_LLachnospiraceae & 0.0013 & 0.1985 & 0.4101 & 0.468 \\
\hline f__Peptostreptococcaceae & 0.0484 & 0.2737 & 0.0107 & 0.004 \\
\hline f__Veillonellaceae & 0.0000 & 0.0004 & 0.0035 & 0.002 \\
\hline$f \_[\text {Tissierellaceae }]$ & 0.0001 & 0.0001 & 0.0003 & 0.001 \\
\hline c__Gammaproteobacteria;Other;Other & 0.0000 & 0.0000 & 0.0001 & 0.000 \\
\hline f__Moraxellaceae & 0.0014 & 0.0005 & 0.0005 & 0.000 \\
\hline f__Pseudomonadaceae & 0.8960 & 0.3097 & 0.3445 & 0.264 \\
\hline f__Xanthomonadaceae & 0.0214 & 0.0225 & 0.0126 & 0.011 \\
\hline Biotic Control & Time & & & \\
\hline \#OTU ID & 24 & 48 & 72 & 96 \\
\hline Unassigned & 0.1500 & 0.2294 & 0.2115 & 0.2144 \\
\hline f_Acholeoplasmataceae & 0.0200 & 0.0000 & 0.0000 & 0.0000 \\
\hline f__Bacteroidaceae & 0.0200 & 0.0000 & 0.0000 & 0.0000 \\
\hline o__Clostridiales;Other & 0.0015 & 0.0094 & 0.0065 & 0.0129 \\
\hline o__Clostridiales;f__ & 0.5170 & 0.0458 & 0.5867 & 0.5934 \\
\hline f_Clostridiaceae & 0.0307 & 0.0005 & 0.0000 & 0.0000 \\
\hline f__Lachnospiraceae & 0.0013 & 0.1400 & 0.0073 & 0.0120 \\
\hline f__Peptostreptococcaceae & 0.0006 & 0.0473 & 0.0099 & 0.0135 \\
\hline f__Veillonellaceae & 0.0000 & 0.0006 & 0.0001 & 0.0002 \\
\hline$f \_[\text {Tissierellaceae }]$ & 0.0000 & 0.0003 & 0.0001 & 0.0001 \\
\hline c__Gammaproteobacteria;Other;Other & 0.0002 & 0.0042 & 0.0007 & 0.0008 \\
\hline f__Moraxellaceae & 0.0017 & 0.0652 & 0.0100 & 0.0069 \\
\hline f__Pseudomonadaceae & 0.0763 & 0.4514 & 0.1661 & 0.1443 \\
\hline f__Xanthomonadaceae & 0.0500 & 0.0060 & 0.0010 & 0.0015 \\
\hline
\end{tabular}




\title{
VITA AUCTORIS
}

\author{
AUTHOR \\ YEAR AND PLACE OF BIRTH \\ EDUCATION
}

\author{
Nicholas Falk \\ 1991 Windsor, Ontario, Canada \\ Riverside Secondary School, Windsor, \\ Ontario \\ 2004-2009 \\ University of Windsor, Windsor, Ontario \\ 2009-2014 B.Sc.
}

University of Windsor, Windsor, Ontario 2014-2017 M.Sc. 